\title{
Protecting hope: Situation analysis of vulnerable children in Uganda 2009
}

\author{
Sam Kalibala \\ Population Council \\ Lynne Elson
}

Follow this and additional works at: https://knowledgecommons.popcouncil.org/departments_sbsr-hiv

Part of the Demography, Population, and Ecology Commons, Health Services Research Commons, Immune System Diseases Commons, International Public Health Commons, Maternal and Child Health Commons, Quantitative, Qualitative, Comparative, and Historical Methodologies Commons, and the Virus Diseases Commons How does access to this work benefit you? Let us know!

\section{Recommended Citation}

Kalibala, Sam and Lynne Elson. 2010. "Protecting hope: Situation analysis of vulnerable children in Uganda 2009." New York: Population Council. 


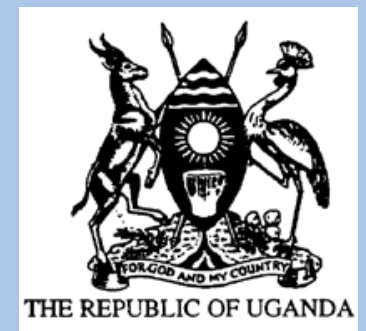

\section{Protecting Hope: Situation Analysis of Vulnerable Children in Uganda}

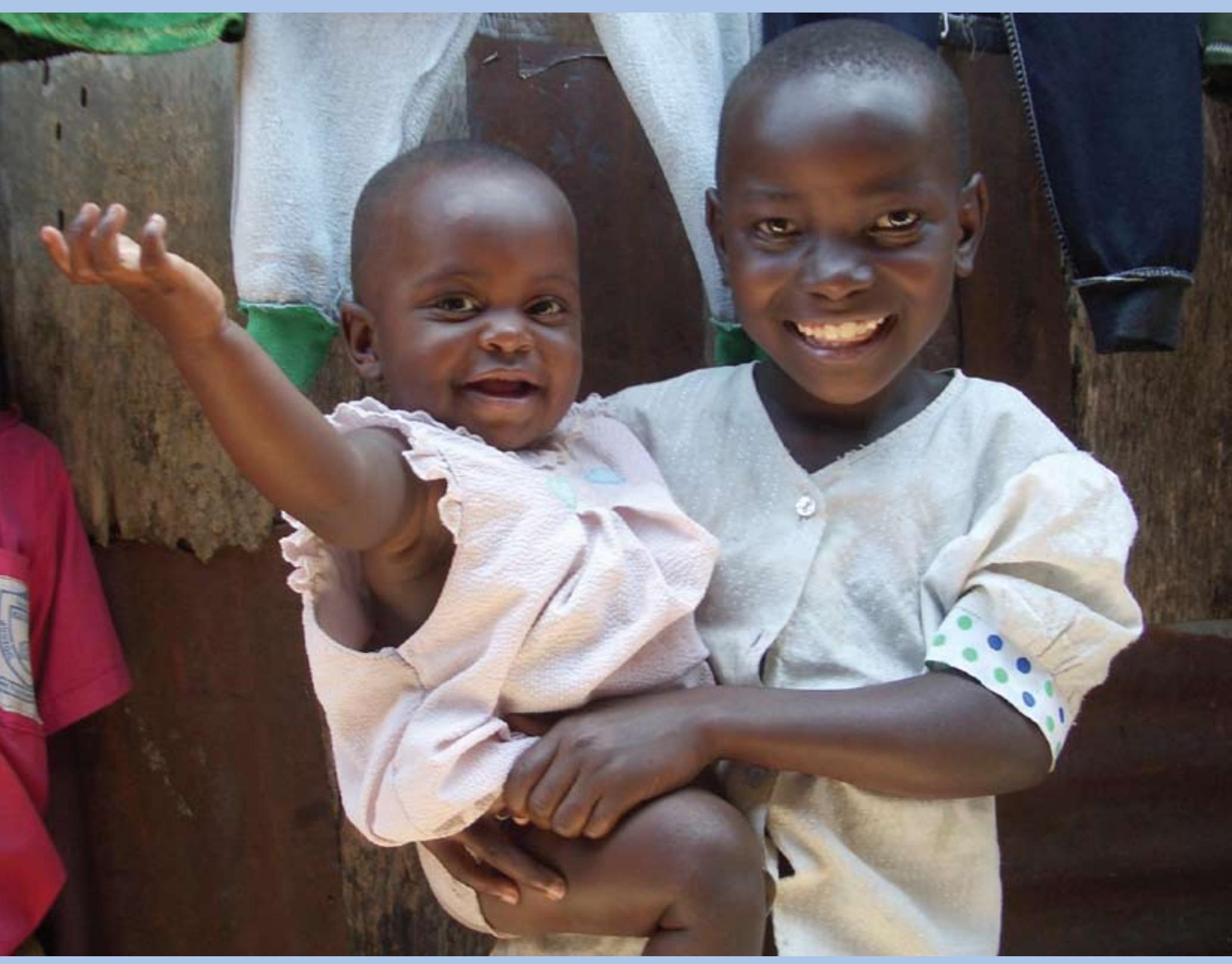




\section{Protecting Hope:}

\section{Situation Analysis of Vulnerable Children in Uganda \\ 2009}

Samuel Kalibala ${ }^{1}$ and Lynne Elson ${ }^{2}$ 


\section{Acknowledgements}

This Situation Analysis represents a joint effort of several organizations, working in close collaboration with key stakeholders from the government, non-governmental, and donor communities. The Population Council oversaw the Situation Analysis and expresses its appreciation to its partners, the Uganda Bureau of Statistics (UBOS) and Mathematica Policy Research (MPR), for their technical contributions. Specifically, UBOS conducted the household survey with expertise from James Muwonge, Andrew Mukulu, Helen Namirembe Nviiri, Vincent Sennono, Simon Kyewalyanga, and Hamidu Katikajjira, together with a large team of interviewers who went to the field. Minki Chatterji and Arif Mamun of MPR, working with consultant David Kaweesa Kisitu, conducted the costing analysis of services for vulnerable children.

Overall guidance for the Situation Analysis was provided by the Ministry of Gender, Labor and Social Development (MGLSD) through the National OVC Situation Analysis Steering Committee comprising Willie Otim (MGLSD), Chairperson, Dorothy Oulanyah (UNICEF), Herbert Mugumya (USAID), Franco Wandabwa (World Vision), Joyce Kadowe (Uganda AIDS Commission), Joyce Otim-Nape (NCC), Cornelius Williams (UNICEF), Stephen Kasaija (MGLSD), Grace Mayanja (CORE Initiative), and John Okiror (MGLSD), Secretary.

This report was authored by Samuel Kalibala and Lynne Elson on behalf of the Population Council. The authors would also like to thank several Population Council colleagues for their inputs at various stages of the process: Deborah Weiss for overall coordination of the project; Norah Omenda for administrative support; Katie Schenk for her review of this report; Hena Khan for editing; and Sherry Hutchinson for layout. We also appreciate Judith Bakirya's role in facilitating consensus around a definition of vulnerable children in Uganda and characterizing the response.

Finally, we thank the many participants in the Situation Analysis, including the individuals, families, and organizations that shared their experiences with and views of vulnerable children in Uganda.

This report was made possible through support provided by the United States Agency for International Development (USAID)/Uganda under the terms of Contract No. GHH-I-02-07-00034-00. The contents are the responsibility of the authors and do not necessarily reflect the views of USAID or the United States Government.

The Population Council conducts research worldwide to improve policies, programs, and products in three areas: HIV and AIDS; poverty, gender, and youth; and reproductive health. www.popcouncil.org

Published in January 2010.

Cover photo credit: (C2005 Heather A. Lawrence, Courtesy of Photoshare Copyright (c) 2010. United States Agency for International Development.

Suggested citation: Kalibala, Samuel, and Lynne Elson. 2010. "Protecting hope: Situation analysis of vulnerable children in Uganda 2009,” Final Report. New York: Population Council.

This document may be reproduced in whole or in part without permission of the Population Council provided full source citation is given and the reproduction is not for commercial purposes. 


\section{Table of Contents}

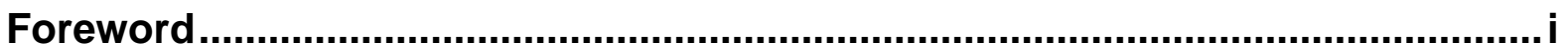

Abbreviations ................................................................................................. iii

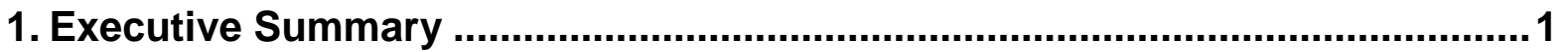

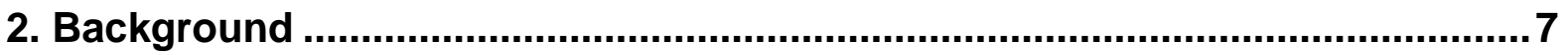

2.1 Overview —-The Situation of Vulnerable Children in Uganda ................................... 7

2.2 Responses to Vulnerable Children in Uganda ...................................................... 8

2.3 Situation Analysis Aim and Objectives ................................................................ 11

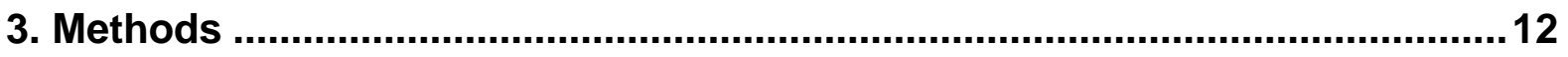

3.1 Literature Review of Secondary Data Sources .................................................. 12

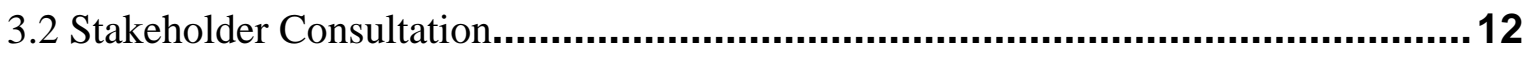

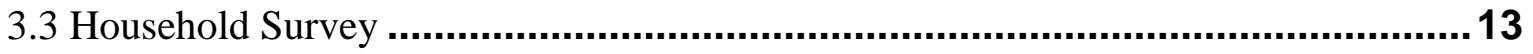

3.4 Qualitative Approaches ................................................................................ 15

3.5 Organizational Assessment and Case Studies ....................................................... 17

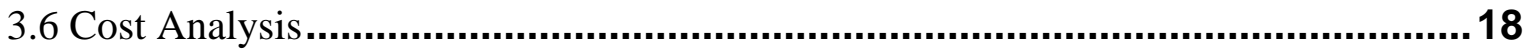

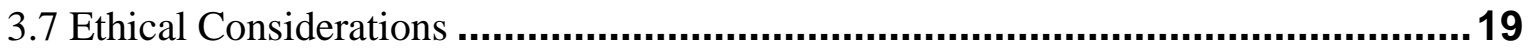

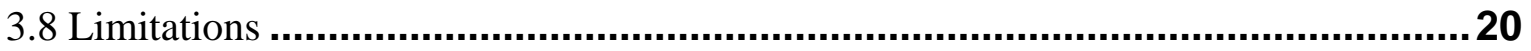

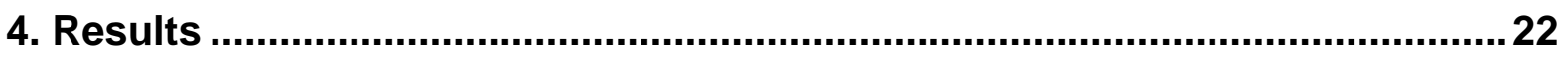

4.1 Describing the Problem: Circumstances of Orphaned and Vulnerable Children ......... 22

4.2 The Response: Approaches to Addressing Circumstances of Orphaned and

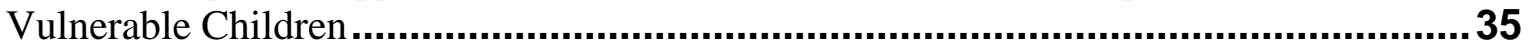

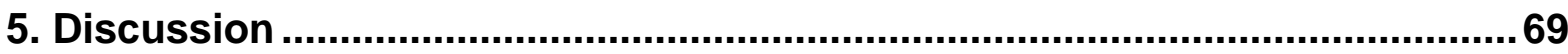

Objective 1: Definition of Vulnerable Children...........................................................69

Objective 2: Estimate of the Magnitude and Characteristics of Vulnerable Children ...... 70

Objective 3: Approaches Currently Used to Address the Needs of Vulnerable Children .71

Objective 4: Successful Strategies and Challenges, Focusing on the USG

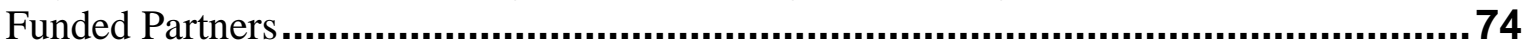

Objective 5: Determine the Costs of Delivering Support Services to

Vulnerable Children 


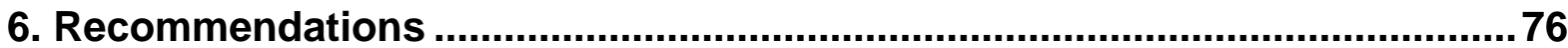

Strategy and Policy Makers .................................................................................. 76

Program Managers and Implementers .............................................................. 76

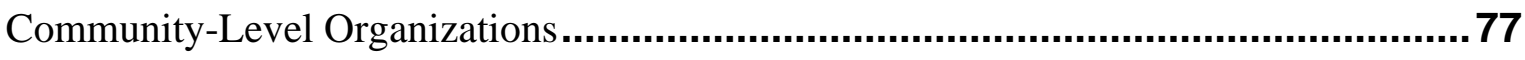

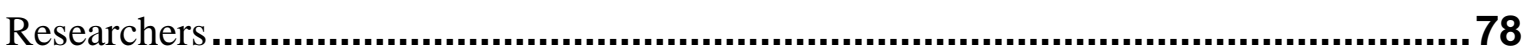

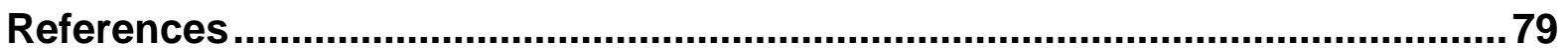




\section{Foreword}

Government of Uganda's commitment to the fulfillment of the rights of vulnerable children is manifested in the National Policy (NOP) and Strategic Programme Plan of Interventions (NSPPI). The NOP and the NSPPI have been under implementation since November 2004 and have guided actors in providing integrated and comprehensive services to vulnerable children.

While implementation of the policy and its corresponding plan has partially addressed the concerns of vulnerable children, there is limited information about the number of vulnerable children supported, their geographic distribution, characteristics and service gaps that remain to be addressed. In addition, data on existing programs addressing the rights of vulnerable children is also grossly inadequate. It is against this background that government of Uganda with support from the United States Agency for International Development (USAID) in Uganda contracted the Population Council and its partners; Uganda Bureau of Statistics (UBOS) and Mathematica Policy Research, to conduct a second Situation Analysis of vulnerable children in Uganda; the first Situation Analysis having been conducted in 2004 prior to the formulation of the NOP and the NSPPI. The major objective of the study was to establish the scope of the problem of vulnerable children and the current national response to it. Essentially, the analysis sought to contribute to building a knowledge and information base that would inform those working with vulnerable children and the development of the second National Strategic Programme Plan of Interventions.

The main findings of the study show that overall, progress towards the national OVC response remains on course, albeit un-evenly across some core service areas and subregions. Based on a simulation exercise, health core programme area was the best addressed with 15 percent of the vulnerable children reporting to have received medical assistance. In terms of services accessed by more than 6 percent of households, training in modern farming techniques, agricultural inputs and schooling stand out as most received. Specifically, 9.1 percent OVC households received modern farming techniques during the last 12 months; 7.7 percent received agricultural inputs while 6.9 percent received educational support for OVC. The least support received by households was recorded in start up capital at 1.8 percent and skills training at only 1.2 percent.

However, despite the general positive progress in realizing the rights of vulnerable children, the impact has been less marked in many other areas. Using indicators developed specifically for this study and definitions contextualized within the Uganda situation, up to 96 percent of children are considered to be vulnerable, 43 percent moderately while 8 percent are considered critically vulnerable. The study further indicates that out of an estimated 17.1 million children below the age of 18 years, 14 percent (approximately 2.43 million) have been orphaned.

High levels of prevailing poverty continue to impact negatively on OVC, heightening their vulnerability. Additionally, the demographic dynamics of Uganda show a rapid population growth especially among the vulnerable groups. This has several implications 
for resource allocation for the realization of the rights of vulnerable children. Consequently, enhanced funding for the OVC response remains essential if current achievements are to be safeguarded and future plans secured.

This Situation Analysis Study Report marks yet another milestone in the Uganda Government's commitment to improve the quality of life of vulnerable children. I wish therefore to express my appreciation to Population Council and its partners for the lead role they provided, USAID for the financial support and all those who worked tirelessly to produce this report. I hope that the findings and recommendations in the report shall be used by all stakeholders to enhance the OVC national response.

\footnotetext{
ppabries

Hon. Opio Gabriel

Minister for Gender, Labour and Social Development
} 


\section{Abbreviations}

\begin{tabular}{|c|c|}
\hline AIDS & Acquired Immune Deficiency Syndrome \\
\hline AVSI & Association of Volunteers in International Service \\
\hline CAWADISA & Children and Wives of Disabled Soldiers Association \\
\hline CRD & Community Resilience and Dialogue \\
\hline CBO & Community-Based Organization \\
\hline CBT & Community-Based Trainers \\
\hline CDC & Centers for Disease Control and Prevention \\
\hline CPA & Core Program Area \\
\hline CSO & Civil Society Organization \\
\hline CORE & Communities Responding to HIV/AIDS Epidemic \\
\hline FIDA & Federation of Women Lawyers \\
\hline FGD & Focus Group Discussion \\
\hline GOU & Government of Uganda \\
\hline HIV & Human Immunodeficiency Virus \\
\hline IGA & Income Generating Activity \\
\hline IRC & International Rescue Committee \\
\hline $\mathbf{L C}$ & Local Council \\
\hline MEEPP & Monitoring and Evaluation of the Emergency Plan Progress \\
\hline MGLSD & Ministry of Gender, Labor and Social Development \\
\hline NGO & Non-Governmental Organization \\
\hline NIU & National Implementation Unit \\
\hline NOP & National OVC Policy \\
\hline \multirow[t]{2}{*}{ NSPPI } & National Strategic Program Plan of Interventions for Orphaned and other \\
\hline & Vulnerable Children \\
\hline OVC & Orphaned and other Vulnerable Children \\
\hline PEPFAR & President’s Emergency Plan for AIDS Relief \\
\hline SIDA & Swedish International Development Agency \\
\hline TASO & The AIDS Support Organization \\
\hline TPO & Trans-cultural Psychosocial Organization \\
\hline
\end{tabular}


TSO Technical Services Organization

UBOS Uganda Bureau of Statistics

UDHS Uganda Demographic and Health Survey

UN United Nations

UNAIDS Joint United Nations AIDS Program

UNICEF United Nations Children’s Fund

UPE Universal Primary Education

USAID United States Agency for International Development

USG United States Government

USE Universal Secondary Education

UWESO Uganda Women's Effort to Save Orphaned Children

WFP World Food Program

WVU World Vision Uganda 


\section{Executive Summary}

The Government of Uganda (GOU) has focused attention on the problem of orphaned and other vulnerable children (OVC) through a number of policies, regulations, and initiatives. In 2004, the Ministry of Gender Labor and Social Development (MGLSD) developed the National OVC Policy (NOP), aimed at improving the quality of life for poor and vulnerable children, such as children who have been orphaned, children who are living on the streets, children who are at risk of abuse, and children exposed to situations of armed conflict.

However, despite the many efforts to improve the circumstances of vulnerable children in Uganda, policymakers, donors, and program managers still lack comprehensive and up-todate information about their numbers, geographic distribution, characteristics, and needs. Furthermore, documentation of existing programs addressing the circumstances of vulnerable children is limited. To address these needs, the United States Agency for International Development (USAID)/Uganda contracted the Population Council and its partners, Uganda Bureau of Statistics (UBOS) and Mathematica Policy Research, to conduct a Situation Analysis of vulnerable children in Uganda. The Situation Analysis aims to increase the understanding of the scope of the problem of vulnerable children and the response to it, including the full spectrum of core services, in order to facilitate country-wide planning and to inform current and future programming efforts.

\section{Methods}

Following a literature review and stakeholder consultation, the research team conducted a nationally representative household survey to estimate vulnerable children in Uganda. Two questionnaires, one general household questionnaire and a second exploring the welfare of children in the household, were administered to adult respondents in 2,551 households resulting in a total sample size of 7,946 children. Questions addressed household and children's circumstances, contact with external support programs, and the extent to which programs meet their needs.

Qualitative data collection activities conducted nationally included in-depth interviews ( $\mathrm{n}=$ 36), key informant interviews $(n=14)$, and focus group discussions $(n=18)$ with respondents in a variety of roles supporting children to further understand their situation. In addition, nine Child Forums were held to elicit the perspectives of children on the vulnerable children in their communities.

Other data collection methods included an assessment of organizations providing support for vulnerable children throughout Uganda, to explore the degree of comprehensiveness of service provision in terms of approaches employed and geographical coverage, and to seek information on costing. An in-depth cost analysis was conducted for selected organizations. 


\section{Results}

\section{Vulnerability scores}

Recognizing the need for a simple tool by which to rapidly assess children's vulnerability, the research team developed a vulnerability scoring system to apply to household survey data, in order to derive a single compound measure of vulnerability integrating a wide range of factors. This score can be used to assess and identify degrees of children's vulnerability from household survey data; differentiating between children who are critically, moderately or generally vulnerable, and those not to be considered vulnerable at all. This measure is intended for national strategic planning, targeting, and monitoring purposes.

\section{Estimates of orphaned and other vulnerable children}

Household survey data was used to estimate the number of vulnerable children in all four major regions of Uganda. Household survey data indicate that 14 percent of children in Uganda have been orphaned (i.e., experienced the loss of one or both parents), which is equivalent to a national total of 2.43 million out of 17.1 million children under age 18 . According to the Uganda-specific definition and indicators developed during this research, nationally, up to 96 percent of children have some level of vulnerability. Within this broad grouping of vulnerable children, degrees of vulnerability can be distinguished for the prioritization of support services: nationally, 51 percent of children in Uganda are considered moderately or critically vulnerable, equivalent to a national total of approximately 8 million vulnerable children in Uganda.

\section{Residential status of orphaned and other vulnerable children}

Survey data illustrate some differences in the distribution of orphanhood and vulnerability between children in urban and rural areas. Data suggest that orphanhood in urban areas is significantly higher than in rural areas (18 percent urban vs. 14 percent rural; $p=0.002$ ), but that degrees of vulnerability tend to be higher in the rural areas for moderately and critically vulnerable children combined (43 percent urban vs. 52 percent rural, $p=0.000$ ). Based on the vulnerability score, overall vulnerability tends to be highest in the conflictaffected Northern region, and lower in the more affluent Central region. Vulnerability tends to be higher in rural areas. The percentage of children defined as critically vulnerable remains fairly constant throughout the regions, at approximately 8-9 percent.

\section{Coverage of external support services}

The most common form of external support reported by household respondents was medical support, received for 15 percent of all children. Other common forms of support received by more than 6 percent of households were training in modern farming techniques, agricultural inputs and schooling. During qualitative research, adult and child respondents felt that few organizations are actually offering comprehensive care to vulnerable children. Most 
organizations tend to provide educational support and support in one or two other core program areas. However, the household survey indicated that only 11 percent of moderately vulnerable children and 8 percent of critically vulnerable children received schooling support.

The needs of the OVC are very wide and there is no particular organization that can meet comprehensively all the needs.

NGO staff, Northern region

\section{Government efforts to address the needs of vulnerable children}

The Situation Analysis examined the government's structures, tools and guidelines to enable implementers to provide services to vulnerable children in the country. In 2004, the Government of Uganda launched the National OVC Policy together with the National Strategic Program Plan of Interventions for Orphaned and other Vulnerable Children. However, levels of training and awareness of the National Strategic Plan among local leaders and service providers is limited. In addition to providing overall strategic, policy and technical guidance, the government through its various ministries is responsible for directly delivering services to vulnerable children in at least three areas: education, health care and child protection.

\section{Civil society organizations' efforts to address the circumstances of vulnerable children}

NGOs were reported to have a big impact on the few vulnerable children they reach, but many children are excluded as a result of the criteria used to define beneficiaries. The Situation Analysis includes details of funding sources, the services provided, and the coverage of the core program areas. Most organizations were found to select the children they serve based on vulnerability. The qualifying criteria differed from one organization to another, ranging from gender, level of vulnerability, age, physical state of the child, among others. Few organizations focused on street children and children from very poor families.

\section{Community efforts to address the circumstances of vulnerable children}

According to the National Strategic Plan, the nuclear and extended family should be the first line of response to the needs of vulnerable children followed by members of the community. Respondents cited numerous ways in which communities are supporting vulnerable children, especially helping external aid agencies to identify children needing help and participating in the monitoring of external aid to families with vulnerable children. At the same time, many respondents shared stories of abuse or neglect of children by caregivers, including taking property or selling goods intended for income generation. A common theme was the overwhelming impact of poverty and low resources on the community and families. 


\section{Promising practices in organizational approaches to providing services}

It was widely recognized that no single organization has the legislative authority, mandate, staff, or financial resources to meet all the needs of children and their families. For this reason partnership, networking, linkages and referrals comprise a strategy that was reported by many organizations. The Situation Analysis highlighted innovative examples of strategic partnerships. Although none of the organizations reviewed during this study could provide outcome data from their services, they did provide output data. The Situation Analysis includes promising practices in various areas such as collaboration, community involvement, capacity building and efforts at enhancing sustainability.

\section{Challenges to the efforts to provide support to vulnerable children in Uganda}

The underlying factor behind most challenges is the sheer inadequacy of resources. Throughout the interviews it was apparent that the household - the very entity that is supposed to protect vulnerable children - can become a serious source of abuse of children and misuse of donated resources or inherited properties of the children. These issues are supposed to be addressed by two core program areas, Child Protection and Legal Aid, yet these areas were receiving the least attention. Ensuring that high quality services are delivered in a coordinated manner that meets national standards remained a challenge. Another weakness was the lack of careful planning and good management skills for income generating activities.

\section{Cost of delivering comprehensive care and support for vulnerable children}

Based on the information gathered during the interviews with program staff as well as other documented information UWESO, TASO and World Vision Uganda were selected for a detailed cost analysis. This includes a breakdown of the services offered, total costs, costs per household, as well as the cost per child.

\section{Discussion}

This Situation Analysis brings together multiple data sources to explore the complex circumstances of children in Uganda who have been orphaned and rendered vulnerable through a variety of different factors. According to the analysis of survey data presented in this Situation Analysis, vulnerability is widespread among children in Uganda. The vulnerability score contributes to the overall goal of this Situation Analysis by providing an easily accessible tool to prioritize the circumstances of the most vulnerable children in the Ugandan context and to facilitate planning a response by policy makers and program implementers.

The widespread levels of children's vulnerability remain a cause of great concern, raising questions about the ability of existing services to address such high levels of need, and the efficiency of setting targeting criteria to guide service delivery. Stakeholders concur that they 
are overwhelmed by the task of providing services to such high levels of vulnerable children in increasingly dire circumstances. The assessment of external support received by children in the survey illustrated how few are actually being reached. The best case scenario was medical support reaching only 15 percent of the children in the households surveyed.

A major area that is deficient in the effort to help vulnerable children is coordination and networking. Some respondents reported a few examples of successful coordination at the district level and networking on a particular issue like child protection. However, most respondents were of the view that the organizations providing support to vulnerable children were largely uncoordinated and not networking.

Continuous monitoring of the situation of vulnerable children is another area of paramount importance that is not well done. To this end, process and output indicators need to be incorporated into regular household surveys. External support needs to be monitored at national, local and organizational levels to assess the coverage and effectiveness of support programs.

\section{Recommendations}

The following recommendations emerging from the data are suggested next steps for action by the different groups addressing the circumstances of vulnerable children in Uganda.

\section{Strategy and policy makers}

- Build district-level Government structures to ensure better coordination

- Increase funding and collaboration for child protection

- Review universal education systems to ensure that all children including vulnerable children realize their right to education

- Strengthen monitoring and evaluation

- Consider the role of institutional care and transition homes

- Address corruption at all levels

\section{Program managers and implementers}

- Review targeting criteria for interventions

- Conduct household assessments before delivering income generating activities

- Strengthen networking and coordination

- Increase community involvement in intervention design and delivery

- Address the concerns of older vulnerable children to ensure age appropriate interventions 


\section{Community-level organizations}

- Empower existing village level structures

- Build capacity of family to care for and protect vulnerable children

- Expand support networks for community-run programs

- Address the emerging culture of dependency

\section{Researchers}

- Provide more detailed mapping of OVC

- Measure outcomes over time

- Develop vulnerability scores

- Investigate street children further 


\section{Background}

\subsection{Overview-the Situation of Vulnerable Children in Uganda}

Uganda was one of the first countries in which the potential impact of the HIV and AIDS epidemic on children was documented and recognized (Hunter 1990, Müller and Abbas 1990, Dunn et al. 1992). According to Children on the Brink 2000 (Hunter and Williamson 2000), in 1990, 17 percent of Uganda's children below 15 years old were orphaned. The Uganda National Household Survey conducted by UBOS in 2005/6 identified that 15 percent of Ugandan children (below the age of 18 years old) were orphaned, suggesting that at that time there were approximately two million orphaned children in Uganda.

In Uganda, a child who has been orphaned is defined as a child below the age of 18 years old whose mother or father has died ${ }^{1}$ (MGLSD 2004b). According to this definition, orphaned children are just one category of vulnerable children in Uganda, since many more children live in situations that render them vulnerable. Rampant poverty and lack of access to basic services (such as appropriate housing, health care, education, water, and sanitation) have left many children vulnerable to high risks of exposure to harm. The criteria currently used in Uganda by the National OVC Policy (NOP) and National Strategic Program Plan of Interventions for Orphaned and Other Vulnerable Children (NSPPI) to identify vulnerable children (for purposes of enumeration and intervention allocation) are shown in Box 1.

\section{Box 1 Criteria currently used for identifying vulnerable children in Uganda}

1. Living on their own/institutionalized

2. Psychosocial status poor/potentially poor

3. Unstable environment (abusive, conflict, migratory)

4. In need, as determined by consensus but could include: inadequate food (one meal or less), inadequate clothing (fewer than three sets including uniform), poor shelter (grass thatch and mud walls), lack of/irregular education, regular cash income < US \$1 equivalent per day

5. Orphaned

6. Single/widowed caregiver or head of household

7. Chronically ill adult in household

8. Female caregiver or head of household

9. Elderly caregiver or head of household

10. Abandoned (parents known to be alive or assumed alive but cannot be located)

11. Parents or guardians cannot be located or are absent (are assumed dead or known to be missing and cannot be located)

12. Chronically ill child

13. Illiterate/not going to school

14. Disability

Source: NSPPI (MGLSG 2004b)

\footnotetext{
${ }^{1}$ A child who has lost a mother is a maternal orphan, while a child who has lost a father is a paternal orphan. A child who has lost both parents is a double orphan.
} 


\subsection{Responses to Vulnerable Children in Uganda}

\section{Government response}

The Government of Uganda (GOU) has focused attention on the problem of orphaned and other vulnerable children by enacting policies and regulations, attempting to register vulnerable children, and undertaking various efforts to promote community support and fostering and to re-unite children in orphanages with their extended families (MGLSD 2002).

In 1996 the GOU established the Children Statute (later renamed the Children Act), which provides a legal framework for the protection of children, stating that, "children have a right to education, immunisation, adequate diet, clothing, shelter, medical attention and not to be discriminated against, subjected to violence, abuse or neglect." The government also began encouraging communities to take orphaned children into their homes and to care for them. In 1997, the GOU introduced free Universal Primary Education (UPE).

In 2004, the Ministry of Gender Labor and Social Development (MGLSD) developed the NOP, aimed at improving the quality of life for poor and vulnerable children. In order to implement the NOP, the GOU and its partners developed a strategy document, the NSPPI (MGLSD 2004b) and the Quality Standards for the Protection, Care, and Support of Orphans and Other Vulnerable Children in Uganda (MGLSD 2007). These documents identified 10 core program areas (CPAs) essential to the wellbeing of vulnerable children under four main themes or building blocks (Table 1). 
Table 1 Core program areas for services for vulnerable children

\begin{tabular}{|c|c|c|}
\hline $\begin{array}{l}\text { Building } \\
\text { Blocks }\end{array}$ & $\begin{array}{l}\text { Core Program } \\
\text { Areas }\end{array}$ & Description \\
\hline \multirow[t]{4}{*}{$\begin{array}{l}\text { 1. Sustaining } \\
\text { Livelihoods }\end{array}$} & $\begin{array}{l}\text { CPA I: } \\
\text { Socioeconomic } \\
\text { Security }\end{array}$ & $\begin{array}{l}\text { The ability and capacity of orphaned and vulnerable children } \\
\text { and/or households with orphaned and other vulnerable } \\
\text { children to sustain their livelihood over the medium- and } \\
\text { long-term with or without short-term emergency assistance. }\end{array}$ \\
\hline & $\begin{array}{l}\text { CPA II: Food } \\
\text { Security and } \\
\text { Nutrition }\end{array}$ & $\begin{array}{l}\text { The process by which individuals and households ensure } \\
\text { that they are able to access through either primary } \\
\text { production or secondary acquisition, adequate and } \\
\text { appropriate foods that guarantee their short- and long-term } \\
\text { nutritional needs. }\end{array}$ \\
\hline & $\begin{array}{l}\text { CPA III: Care } \\
\text { and Support }\end{array}$ & $\begin{array}{l}\text { The provision of basic commodities, such as food, clothing, } \\
\text { bedding, and/or shelter to an orphan, other vulnerable child, } \\
\text { household, or institution taking care of orphaned and/or } \\
\text { other vulnerable children. }\end{array}$ \\
\hline & $\begin{array}{l}\text { CPA IV: } \\
\text { Mitigation of } \\
\text { the Impact of } \\
\text { Conflict }\end{array}$ & $\begin{array}{l}\text { The process by which individuals, households, and } \\
\text { communities-in collaboration with civil society, } \\
\text { government, and private sector-work to secure an } \\
\text { environment in which essential social services can reach } \\
\text { vulnerable populations affected by conflict. }\end{array}$ \\
\hline \multirow[t]{3}{*}{$\begin{array}{l}\text { 2. Linking } \\
\text { Essential } \\
\text { Social Sectors }\end{array}$} & $\begin{array}{l}\text { CPA V: } \\
\text { Education }\end{array}$ & $\begin{array}{l}\text { The formal and informal systems of information acquisition, } \\
\text { skill building, and technical experience that are made } \\
\text { available during childhood, but may involve adults who are } \\
\text { seeking to acquire new skills. }\end{array}$ \\
\hline & $\begin{array}{l}\text { CPA VI: } \\
\text { Psychosocial } \\
\text { Support }\end{array}$ & $\begin{array}{l}\text { Assistance to positively and meaningfully affect the } \\
\text { psychological and social situation that impacts on mental } \\
\text { function and social behavior in relation to family and society. }\end{array}$ \\
\hline & $\begin{array}{l}\text { CPA VII: } \\
\text { Health }\end{array}$ & $\begin{array}{l}\text { The state of physical, mental, and emotional well being that } \\
\text { provides an opportunity for individuals to be as productive } \\
\text { as possible and achieve their greatest potential. }\end{array}$ \\
\hline \multirow{2}{*}{$\begin{array}{l}3 . \\
\text { Strengthening } \\
\text { Policy and } \\
\text { Legal } \\
\text { Frameworks }\end{array}$} & $\begin{array}{l}\text { CPA VIII: Child } \\
\text { Protection }\end{array}$ & $\begin{array}{l}\text { The immediate response to circumstances and conditions } \\
\text { that create gross violation of the rights of children, } \\
\text { subjecting them to serious risks and hazards. }\end{array}$ \\
\hline & $\begin{array}{l}\text { CPA IX: Legal } \\
\text { Support }\end{array}$ & $\begin{array}{l}\text { OVC are protected from all forms of abuse and exploitation } \\
\text { and from hazards and harm. }\end{array}$ \\
\hline $\begin{array}{l}\text { 4. Enhancing } \\
\text { the Capacity } \\
\text { to Deliver } \\
\text { Services }\end{array}$ & $\begin{array}{l}\text { CPA X: } \\
\text { Strengthening } \\
\text { Capacity }\end{array}$ & $\begin{array}{l}\text { The process by which individual, household, community, } \\
\text { and national capacity are improved in order to deliver } \\
\text { adequate care, support and services to orphaned and other } \\
\text { vulnerable children. }\end{array}$ \\
\hline
\end{tabular}

Source: Quality Standards for the Protection, Care and Support of Orphans and Other Vulnerable Children in Uganda (MGLSD 2007)

The implementation of the NSPPI is managed by a NSPPI Implementation Unit (NIU), formerly the OVC Secretariat. The NIU is under the supervision of the Director of Social Protection and works closely with the Department of Youth and Children Affairs and with the Policy, Planning, and Accounting units of the MGLSD. 
In addition to the responsibilities of the NIU, there are also key areas of national law and policy affecting children, which are implemented through other government agencies and across all sectors, including education, health, and legal protection. Under the overall leadership of MGLSD, government agencies, including the Uganda AIDS Commission and the National Council for Children, work with other key players addressing issues affecting vulnerable children. Responsibilities include providing technical assistance and building capacity for implementation of interventions for vulnerable children and coordinating, monitoring, and evaluating interventions in government institutions, civil society organizations (CSOs), and the private sector. Through these agencies, interventions for vulnerable children are integrated into the respective aspects of the National Development Plan.

At the district level, support for vulnerable children involves the efforts of probation officers, the police, judges, and child welfare officers and Community Development Officers at the sub-county level. According to the NSPPI, local government plays an important coordinating and implementing role starting with the Ministry of Local Government through all levels of local councils - from the lowest, village level Local Council-1(LC-1) to the highest, district level Local Council-5 (LC-5). The representatives of the MGLSD in the districts are the District Probation and Social Welfare Officers, who work closely with the Secretary for Children's Affairs at the respective LC-5 offices. District AIDS Committees are also involved in the coordination of HIV-specific interventions targeting vulnerable children. In addition, OVC committees have been formed at district and sub-county levels, and child protection committees have been formed in some districts in the north and northeast regions.

The preferred practice in Uganda is that protection, care, and support services for vulnerable children are organized at the household level. In 1996, the MGLSD enacted a policy that favored family- and community-based care, with institutional care a last resort (MGLSD 2002). In the absence of immediate family, vulnerable children should be cared for by the extended family and community members to keep the children in a familiar and stable environment.

\section{Donor, non-governmental organization, and civil society response}

The major development partners funding the provision of services for vulnerable children include the United States Government (USG), UNICEF, and the Civil Society Fund-a basket funding mechanism of the GOU (through Uganda AIDS Commission and MGLSD) which currently received funds from the USG, the United Kingdom Department for International Development, Irish Aid, the Danish International Development Agency, the Italian Development Cooperation, and the Global Fund to Fight AIDS, Tuberculosis, and Malaria. Funding from these partners sometimes flows through government entities, but a significant proportion is channeled through CSOs.

The GOU recognizes the crucial role of and works closely with non-governmental organizations (NGOs), community-based organizations (CBOs), CSOs, and faith-based organizations to provide care, support, and protection for vulnerable children. A National Steering Committee on Vulnerable Children comprising representatives of implementing 
organizations was set up to promote partner coordination and to provide guidance and support for the implementation of the NSPPI. There are thousands of NGOs and CSOs involved in the response.

\subsection{Situation Analysis Aim and Objectives}

Despite the many efforts to improve the circumstances of vulnerable children in Uganda, policymakers, donors, and program managers still lack comprehensive and up-to-date information about their numbers, geographic distribution, characteristics, and needs. Furthermore, documentation of existing programs addressing the circumstances of vulnerable children is limited. To address these needs, the United States Agency for International Development (USAID)/Uganda contracted the Population Council and its partners, Uganda Bureau of Statistics (UBOS) and Mathematica Policy Research, to conduct a Situation Analysis of vulnerable children in Uganda. The Situation Analysis aims to increase the understanding of the scope of the problem of vulnerable children and the response to it, including the full spectrum of core services, in order to facilitate country-wide planning and to inform current and future programming efforts. Specific objectives are to:

1. Develop a Uganda-specific definition of vulnerable children;

2. Apply this definition to estimate the magnitude and characteristics of vulnerable children;

3. Identify approaches currently used to address the needs of vulnerable children;

4. Document successful strategies and challenges, focusing on the USG-funded partners; and

5. Determine the costs of delivering support services to vulnerable children. 


\section{Methods}

The Situation Analysis was guided by the framework established in Conducting a Participatory Situation Analysis of Orphans and Vulnerable Children Affected by HIV/AIDS (Family Health International 2005) and includes the following methods:

1. Literature review of secondary data sources,

2. Stakeholder consultation,

3. Household survey,

4. Qualitative research,

5. Organizational assessments and case studies, and

6. Cost analysis.

\subsection{Literature Review of Secondary Data Sources}

The team began by conducting a desk review of resources addressing vulnerable children in Uganda. These include a variety of MGLSD documents covering policy, strategic plans, data, services, and quality standards for vulnerable children, as well as MGLSD guidelines and tools for service providers and caregivers, addressing training, best practices, needs/program assessment, quality standards, management information systems, and resource tracking. Other sources of information included assessments of socioeconomic interventions and psychosocial support programs by the Makerere Institute of Social Research and the Makerere Institute of Psychology, respectively, and the Monitoring and Evaluation of the Emergency Plan Progress (MEEPP) database, which is used to record information about organizations providing support for vulnerable children under the United States President's Emergency Plan for AIDS Relief (PEPFAR).

The literature review helped the team to characterize the current response to vulnerable children in Uganda and the response of the recent past. The MGLSD documents were vital in providing information about the evolution of the governmental response since the mid-1980s. The two studies conducted by Makerere University provided a systematic analysis of the response in the specific areas of psychosocial support and socioeconomic strengthening. Data from the MEEPP data base helped in quantifying the response using good quality service delivery data. (Please see References section for a complete list of documents consulted for this Situation Analysis.)

\subsection{Stakeholder Consultation}

The team also consulted with stakeholders to elicit their views on the key issues affecting vulnerable children in Uganda and to seek their support and guidance in the development of the Situation Analysis. A stakeholder meeting was held on December 17, 2008 at the CORE Initiative offices in order to review the proposed methodology of the Situation Analysis. Participants represented MGLSD, CORE Initiative, UNICEF, USAID, and measurement experts from UBOS. Topics included: identifying key criteria and quantitative indicators as 
well as methodology for the identification of vulnerable children; identifying criteria and methodology for selection of organizations for the cost study and for the organizational assessments; and agreeing on the best ways to elicit views of children.

In March 2009 the MGLSD appointed a Steering Committee comprising key stakeholders who had been involved in the implementation of OVC interventions, including representatives from government, United Nations (UN) and bilateral agencies, CSOs, and faith based organizations. Their key assignments were to:

1. Review the proposed survey tools and recommend adoption and usage; and

2. Provide recommendations and guidance to MGLSD and development partners on findings of the formative assessment.

Finally, team members attended external meetings to consult with key experts on vulnerable children in Uganda. These included the MGLSD Brainstorming Workshop to prepare for NSPPI revision (Entebbe, 6 August 2009) and the MGLSD/CORE Initiative Workshop to share lessons learned in programming for support of vulnerable children in Uganda (Kampala, 26-28 August 2009).

\subsection{Household Survey}

\section{Survey design and sampling}

The household survey sample was designed to allow for estimates of vulnerable children at the national level, for urban and rural areas, and for the four statistical regions of Central, Eastern, Northern, and Western (Table 2).

Table 2 Summary of household survey coverage

\begin{tabular}{lc}
\hline Region & Number of districts surveyed \\
\hline Central & 15 \\
Eastern & 23 \\
Northern & 16 \\
Western & 19 \\
\hline
\end{tabular}

The sample was selected using a two-stage sampling design. In the first stage, 263 clusters were selected from a list sampled in the 2008 National Service Delivery Survey. ${ }^{2}$ In the second stage, 10 households were selected from each cluster (enumeration area) using simple random sampling, based on a complete listing of the households in the cluster. The sample size goal was 2,630 households. Denominators given in the tables refer to the appropriate

\footnotetext{
${ }^{2}$ The 2008 National Service Delivery Survey sample was based on the 2002 Population and Housing Census sampling frame.
} 
household survey sample, and sampling weights ${ }^{3}$ were used to derive weighted estimates of national equivalents based upon survey data.

\section{Instrument development}

Instruments were developed using existing tools from the Uganda Demographic and Health Survey (UBOS and Macro International 2007) and Conducting a Participatory Situation Analysis of Orphans and Vulnerable Children Affected by HIV/AIDS (Family Health International 2005).

Two survey instruments were developed for use at each household:

1. A general household questionnaire

2. A questionnaire exploring the welfare of all child residents in the household.

Questions relating to children's vulnerability were asked for each child under 18 years old residing in the households surveyed, resulting in a total sample size of 7,946 children in 2,551 households. Questions addressed household and children's circumstances, contact with external support programs, and the extent to which programs met their needs. It should be noted that all questions, including those about children, were answered by an adult respondent.

\section{Survey organization and field work}

Training of data collectors took a total of eight days and included lectures and field work practice, as well as translation of the questionnaires into the six major local languages. The questionnaires were pretested during the field work practice exercise. Nine data collection teams, each comprising a supervisor, three interviewers, and a driver, were deployed to the field over a one-month period between May and June 2009. The teams were guided by a LC1 official who helped identify the houses listed in the sample.

\section{Data management and processing}

Processing of the household data commenced immediately after the fieldwork was completed. To ensure high data quality, a system of double entry was used. Data processing personnel included a supervisor, data entry operators, and office editors to further assess the

\footnotetext{
${ }^{3}$ Weighting methodology: Sampling weights are adjustment factors applied to each case in tabulations to adjust for differences in probability of selection and interview between cases in a sample, either due to design or happenstance. Many times the sample is selected with unequal probability to expand the number of cases available (and hence reduce sample variability) for certain areas or subgroups for which statistics are needed. In this case, weights need to be applied when tabulations are made of statistics to produce the proper representation. When weights are calculated because of sample design, corrections for differential response rates are also made. There were two main sampling weights in the Situation Analysis: household weights and individual weights. The household weight for a particular household is the inverse of the selection of the cluster (enumeration area) multiplied by the inverse of its household selection probability from the cluster.
} 
consistency of the data collected before being captured. The data was captured using CS Pro. A computer program for verification and validation was developed and operated during data processing. Range and consistency checks were included in the data entry program. More intensive and thorough batch edits were carried out using MS-Access by the processing team. After data cleaning, the data sets were converted to STATA/IC 10 to enable generation of analytical tables and graphs. Where cross-tabulations revealed differences in key indicators, tests of statistical significance were conducted using Epi Info STATCALC.

\subsection{Qualitative Approaches}

Qualitative data collection activities were conducted in English in May 2009 in 13 districts representing the four regions of Uganda (Table 3), using a convenience sample based upon interviewer travel routes and approved by the Steering Committee.

\section{In-depth interviews}

In-depth interviews ( $\mathrm{n}=36$ ) were conducted with teachers and head teachers, local political leaders, NGO representatives, police officers, and probation officers. These participants were chosen for their roles in supporting vulnerable children in their community and because their opinions, information, and experience are crucial to understanding the situation of vulnerable children. Interviews addressed: participant roles with regard to vulnerable children, definitions of vulnerable children, the needs of vulnerable children, and the current response to these needs, the NSPPI, and participant experiences with situations where children are abused, neglected, or denied rights.

\section{Key informant interviews}

Interviews ( $\mathrm{n}=14$ ) were conducted with national-level officials from MGLSD, UNICEF, USAID, Uganda AIDS Commission, The AIDS Support Organization (TASO), CORE, the Ministry of Health, and World Vision. Key informants were selected to include a crosssection of participants from the government, donors, and major national NGOs providing support to vulnerable children. Interviews addressed similar topic as the in-depth interviews, as well as participants' assessment of funding for the support, care, and protection of vulnerable children.

\section{Focus group discussions}

Focus group discussions (FGDs) $(\mathrm{n}=18)$ were held with community-level participants including LC leaders and chiefs, field staff of support organizations for vulnerable children, relevant field government staff, and teachers. FGDs ranged from 8 to 12 participants and were not separated by sex, expertise, or seniority. At least one FGD was conducted in each district; in districts where no Child Forums (see below) were conducted, two FGDs were conducted. 


\section{Child Forums}

This Situation Analysis sought to explore the views of children in a sensitive, age-appropriate way. In consultation with key stakeholders, the team determined that an appropriate vehicle for exploring the views of children would be to conduct discussions within the setting of their own schools. These discussions became known as "Child Forums."

In eight of the 13 districts, a Child Forum was conducted in a primary school (for children aged 6 to 12 years old) and a secondary school (for children aged 13 to 17 years old).

Districts were conveniently selected based on the travel schedule of the interviewers.

Moderators were local school teachers who had been specially trained by the team on issues of children's vulnerability. The children were selected by the teacher and only those children whose parents agreed and brought them on the required day participated. Each Child Forum was attended by between 20 to 40 students, mixed in sex but separated by age.

Moderators were instructed not to ask or let children narrate personal stories, but rather to talk about their awareness of orphaned and other vulnerable children in their community, their needs, who helps them, and what they felt should be done to help them. Older children (aged 13 to 17 years old) were asked about their awareness of children taking risks such as having sex or using drugs and alcohol, children in conflict with the law, children's participation in decision-making about their own lives, and how the community responds to children infected and affected by HIV and AIDS.

Table 3 Summary of qualitative methods

\begin{tabular}{|c|c|c|c|c|c|c|c|c|c|}
\hline \multirow[t]{2}{*}{ Region } & \multirow[t]{2}{*}{ District } & \multicolumn{5}{|c|}{ IDIs } & \multirow[t]{2}{*}{ FGDs } & \multicolumn{2}{|c|}{$\begin{array}{l}\text { Child } \\
\text { Forums }\end{array}$} \\
\hline & & $\begin{array}{c}\text { Teacherl } \\
\text { Head teacher }\end{array}$ & $\begin{array}{l}\text { Political } \\
\text { leader }\end{array}$ & $\begin{array}{l}\text { NGO } \\
\text { staff }\end{array}$ & Police & $\begin{array}{c}\text { Probation } \\
\text { officer }\end{array}$ & & $\begin{array}{l}\text { Ages } \\
6-12\end{array}$ & $\begin{array}{l}\text { Ages } \\
13-17\end{array}$ \\
\hline \multirow[t]{4}{*}{ Central } & Kampala & 1 & 1 & 2 & 1 & & 3 & 2 & 1 \\
\hline & Luwero & & & 1 & & & 1 & & \\
\hline & Mubende & & & 1 & 1 & & 1 & 1 & 1 \\
\hline & Masaka & & & & 1 & 1 & 1 & 1 & 1 \\
\hline \multirow[t]{3}{*}{ Eastern } & Jinja & 1 & & 1 & 1 & & 1 & 1 & 1 \\
\hline & Mbale & & 1 & 1 & 1 & & 2 & 1 & 1 \\
\hline & Soroti & & 1 & 1 & & & & & \\
\hline \multirow[t]{3}{*}{ North } & Lira & & 1 & 1 & & & 1 & 1 & 1 \\
\hline & Gulu & & 1 & & 1 & 1 & 2 & & \\
\hline & Arua & 1 & & 1 & 1 & & 1 & 1 & 1 \\
\hline \multirow[t]{3}{*}{ West } & Masindi & & 1 & & 1 & & 1 & 1 & 1 \\
\hline & Fort Portal & & & 2 & 1 & & 1 & & \\
\hline & Mbarara & & 2 & & & 1 & 2 & & \\
\hline Total & & 4 & 8 & 11 & 10 & 3 & 18 & 9 & 8 \\
\hline
\end{tabular}




\section{Instrument development}

All instruments used to guide qualitative interactions were developed in collaboration with the members of the Steering Committee during a two-day workshop in March 2009. The evaluation team used these tools to train the interviewers, pilot test them, and collect data. Members of the Steering Committee participated in the training of interviewers and in the review of outcomes of the pilot testing.

\section{Data management and analysis}

A moderator and a note-taker were present for every qualitative interaction. Data were collected using hand-written notes plus audio taping. Transcripts were typed in Microsoft Word from audio tapes and notes, and checked by supervisors to verify accuracy. The team developed a coding tree, verified it against a sample of 10 transcripts, and applied it to manually categorize the transcripts. Emerging themes were extracted from the categorized data and written up by theme, including verbatim quotes.

\subsection{Organizational Assessment and Case Studies}

The final data collection method used was an assessment of organizations providing support for vulnerable children throughout Uganda, to explore the degree of comprehensiveness of service provision in terms of approaches employed and geographical coverage, and to seek information on costing.

Organizations were identified for inclusion in the scanning process if they met the following inclusion criteria:

- intervention was implemented for at least two years;

- area of coverage was at least at the level of the sub-county; and

- intervention reached at least 300 direct beneficiaries.

Analysis focused mainly on USG-supported programs for vulnerable children in Uganda, but some non-USG-funded organizations were deliberately included in order to provide a broader perspective of programs for vulnerable children. The team ensured that there was fair geographical distribution across the four major regions of the country (Moroto and Arua in the North; Masindi, Fort Portal, and Mbarara in the West; Mubende, Masaka, Kampiringisa, and Kampala in Central; and Bugiri, Tororo, and Soroti in the East). Further, at least one organization serving children on the streets and one serving children in conflict with the law were included. Screening questionnaires included indicators regarding numbers of vulnerable children reached; geographic coverage; type, characteristics, comprehensiveness of support; and monitoring and evaluation of programs.

Ten organizations were selected for individual case studies. A self-administered questionnaire was developed for this purpose and covered the following topics: level of intensity of services, comprehensiveness, integration, use of national standards, referrals and linkages, monitoring and evaluation, challenges, strengths, and weaknesses. 


\subsection{Cost Analysis}

A separate screening process was conducted for organizations to be included in the cost analysis. A preliminary list of 20 organizations providing services for vulnerable children on a national scale was prepared in consultation with USAID/Uganda, and visits were made to those that were currently active (Plan International, Save the Children International, the Christian Children's Fund, TASO, Uganda Women's Effort to Save Orphaned Children [UWESO], Uganda Society for Disabled Children, and World Vision Uganda).

Based on information provided during meetings with management and programmatic staff, inclusion criteria for the cost analysis were:

- Served approximately 2,000 or more children

- CPAs covered (as defined in the NSPPI—see Table 1 above)

- Diversity of service delivery approach

- Wide geographic coverage

- Different types of organization (e.g., local vs. international NGO)

- Diverse donor funding

- Availability of financial and programmatic data.

The CPAs formed the foundation for the cost analysis. They were used to classify services provided by the selected organizations and to estimate costs of various activities/interventions (i.e., package of services) under each.

The analysis utilized the activity-based costing approach to calculate costs of services for vulnerable children. Under this approach, a defined set of services delivered to a specific group of beneficiaries was considered an activity, and costs were estimated for each activity. For example, under the food security and nutrition CPA, an organization may have provided training on agricultural production to farmers, nutrition education for mothers and nutrition supplements to children. For the cost analysis, each of these services was considered a separate activity, and costs were estimated for each.

The costs of services to vulnerable children were analyzed from the provider's perspective. As a result, the cost analysis includes costs that were directly incurred by the provider under consideration, and excludes costs covered by the children or households. The estimated costs do not include cost of resources that were not purchased by the provider (e.g., donated goods, in-kind services, materials and services provided by another organization). Further, the unit cost per agency was not estimated because not every beneficiary received every service delivered by an organization. Thus unit cost per agency would not be useful, and could possibly be misleading.

As data for the financial year 2008 were available at all three organizations, the cost analysis presents estimated costs for 2008 in constant 2008 Uganda shillings and US dollars, where 1 US\$ $=1720.4$ USh (Bank of Uganda 2009). The organizations delivering services to vulnerable children incur costs in maintaining and expanding assets, including office space, service facilities, furniture, equipments, and machinery. Expenses on assets differ from current operating expenses as the market value of an asset lasts more than one year. Hence, the costs of assets cannot be directly applied to the annual costs of delivering services to 
vulnerable children. This cost analysis instead applied the cost of using an asset in each year of its life.

The primary source of data for the cost analysis was the organization's financial records. In addition, data on the number of beneficiaries for each intervention was used as provided by the organization. The data on number of beneficiaries enables estimates of the unit costs for each intervention to be made. Information regarding the organization's approach to service delivery, and the description of the interventions, was gathered from periodic reports (e.g., annual report, strategic plan) and through interviews with program staff.

\subsection{Ethical Considerations}

This Situation Analysis was exempt from full review under the ethical review process of the Population Council, on grounds that data collection did not expose participants to aboveminimal risk. Nevertheless, every effort was made to anticipate and safeguard against ethical concerns, especially those associated with data collection among vulnerable children (Schenk and Williamson 2005).

Prior to the arrival of the data collectors in the district, the team worked with local probation officers who sought permission to collect data from LC members. LC members granted permission and provided guidance throughout the process of data collection activities.

All tools were locally reviewed and pre-tested in the field. Informed consent processes and data collection instruments were developed in close consultation with service providers currently delivering services to vulnerable children.

\section{Household survey}

Data collectors were trained to administer an informed consent procedure for both adults and children explaining the purpose of the activity, that participation was voluntary, and that questions could be refused at any time. Survey respondents indicated their consent verbally, and the interviewer then signed the consent form as a witness.

Survey interviewers were instructed to seek informed consent only from an adult selfidentifying as the household head. However, there were two exceptions. In a situation where a child was the head of the household, the child was given information about the survey and if they assented to the interview, the LC-1 official consented for the child head to be interviewed. The same thing was done for a situation where a head of the household was absent but the spouse was present and aged less than eighteen years old.

To provide anonymity, the name of the household head was not recorded. While in the field, completed paper and/or electronic questionnaires were kept securely by supervisors. Paper questionnaires were then transferred to a locked data room at UBOS. Electronic records were stored on a password-protected server on a secure network. Presentation of quantitative 
results groups households together in large subsets, preventing identification of households or individuals.

\section{Qualitative research}

Consent procedures were followed as above. All identifying details were removed from reported quotes. Participants of the qualitative research did not receive any payment. FGD participants were provided with refreshments during the research activities.

\subsection{Limitations}

\section{Household survey}

Conducting a population-based household survey focuses attention on the circumstances of children currently living in those households. Therefore by definition, children living on the streets and in institutions (i.e., orphanages) are excluded. The only way to explore the issues affecting street children is through a lengthy process of trust-building, which was not possible within the context of this Situation Analysis. However, the qualitative methods indirectly explored the situation of street children by seeking the views of those who might come into contact with them.

Furthermore, findings of low and variable levels of child-headed households reported from other enumeration exercises in the region (e.g., Urassa et al. 1997; Ministry of Sport Youth and Child Development [Zambia] 2004) suggest that household survey methods such as those employed in this Situation Analysis may consistently underestimate the magnitude of childheaded households, and that youth-focused participatory qualitative approaches are more appropriate for gathering information about such households.

The household survey was also limited in its capacity to evaluate issues of child abuse, especially in cases where the household head was the perpetrator. Also beyond the scope of this Situation Analysis was exploration of child soldier activity, children in conflict with the law, caregiver substance abuse, and sex work.

A known limitation of the household sampling approach employed for this exercise is that sampling every child in the household results in a dataset in which children from large households are over-represented. Such a household-level focus overlooks the heterogeneity of children within households, and is likely to result in underestimates of vulnerability if vulnerable children are clustered in households with many children.

\section{Child participation}

Despite all the efforts made to train and support moderators, data emerging from the Child Forums were often of limited depth. One possible explanation is that moderators were teachers. The relationship between a pupil and teacher could have resulted in a typical 
structured question and response format more like a group interview or classroom format than a FGD.

\section{Organizational assessments and case studies}

The team was unable to obtain a master list of organizations delivering services to vulnerable children to be used for the case studies. The list used was based upon a convenience sample identified through previous assessments conducted by the MGLSD and a listing of organizations receiving support from the Civil Society Fund. Although team members made every effort to ensure fair geographical coverage, the data cannot be assumed to be representative. Nevertheless, the data still shed light on programming issues for vulnerable children across the country.

The organizational assessment exercise relied upon the use of self-administered questionnaires, both in the initial screening of organizations and in the more detailed case studies. Although the overall response rate in this assessment was very high (124 out of 129 questionnaires were returned), not all organizations were equally responsive, and many organizations returned incomplete questionnaires. Thus, descriptive data frequently show a denominator that is lower than the total number of organizations assessed. Further, information on outcomes of interventions was scant, making it impossible for this Situation Analysis to examine the effectiveness of interventions.

\section{Cost analysis}

Since the cost analysis presents only the estimated costs and does not connect this information to outcomes, it is not possible to judge the relative cost-effectiveness of one intervention over another. An intervention might be more costly than another, but it may also be more effective in improving beneficiary wellbeing outcomes. Determining the impact and cost-effectiveness of the interventions is a complex process that would require collecting data on outcome measures from a group of beneficiaries and an appropriate comparison group of households and children before and after the beneficiaries received services. That is an important exercise that is beyond the scope of this Situation Analysis. 


\section{Results}

In this section, integrated results from all data sources are presented addressing all the objectives of the Situation Analysis. The first section describes the nature of the problem: the circumstances of children who have been orphaned and rendered vulnerable. The second section describes approaches to addressing this problem.

\subsection{Describing the Problem: Circumstances of Orphaned and Vulnerable Children}

\subsubsection{Process for developing vulnerability scores}

Participants of the key informant interviews, in-depth interviews, and FGDs expressed a need for a nationally accepted, standardized system for assessing children's vulnerability. To date, there is no national estimate of the number of vulnerable children in the country, nor any accepted definition of what constitutes vulnerability. While a measurable definition of orphaned children is straightforward, defining and estimating the number of other vulnerable children remains difficult. Respondents indicated that while program implementers were using various criteria, there was no consensus.

I think there has been a big problem that we have looked at a vulnerable child as a child who has lost parents, a child who may be working, or a child who is out of school or a child who has been sick for the past month. That has been the definition. The others will look at a child who is disabled. But our understanding is that not every orphan is vulnerable. He could be an orphan but in school, family is well resourced, has a caregiver and is not necessarily vulnerable. So I think we need a definition, we have not seen a clear definition and I think there is no consensus yet on the definition of OVC.

Donor agency staff, Kampala

The challenge remains in defining vulnerable children differently. It is important that the Ministry harmonizes... My recommendation is that we should have a standardized criterion.

NGO staff, Eastern region

Recognizing a perceived need for a simple tool by which to rapidly assess children's vulnerability, the research team developed a vulnerability scoring system to apply to household survey data, in order to derive a single compound measure of vulnerability integrating a wide range of factors. This measure is intended to be useful for national strategic planning, targeting, and monitoring purposes.

Participants in the stakeholder consultation developed a consensus on key indicators of children's vulnerability, based on the 10 CPAs. A total of 42 indicators covering eight categories were selected (Table 4), including the 14 listed in the NSSPI. Members of the Steering Committee assessed these indicators and assigned a score between 0 and 3 , 
according to the severity of the vulnerability each was deemed to cause. Scores were assigned for each indicator for every child under the age of 18 years old covered in the household survey, and the sum was calculated to determine a vulnerability score for each child, ranging from 0 to 21. No further weighting by category was conducted. In order to prioritize the most vulnerable children, cut-off thresholds for categorizing vulnerability scores (critically, moderately, generally, or not vulnerable) were determined. 
Table 4 Categories and indicators of children's vulnerability

\begin{tabular}{|c|c|c|}
\hline Category & Indicator & Score \\
\hline $\begin{array}{l}\text { 1. Household } \\
\text { relationships } \\
\text { and situation }\end{array}$ & $\begin{array}{l}\text { - } \text { Child head of household } \\
\text { - } \text { Elderly head of household } \\
\text { - Child }<17 \text { yrs but married } \\
\text { - } \text { Child } 17 \text { to } 18 \text { yrs but married } \\
\text { - household } \\
\text { - Number of people in household is }>6 \\
\text { - Child rarely or never saw guardian before } \\
\text { - Negative changes in child's life since joining HH (e.g., food, school grades etc) } \\
- \text { Does not visit with absent siblings } \\
\text { - Child has no one to talk to in case of problems }\end{array}$ & $\begin{array}{l}2 \\
1 \\
2 \\
1 \\
1 \\
1 \\
1 \\
1 \\
1 \\
1 \\
1 \\
1\end{array}$ \\
\hline 2. Parental status & $\begin{array}{l}\text { - Death of mother } \\
\text { - } \text { Death of father } \\
\text { - Serious 'impairment' of mother } \\
\text { - } \text { Serious 'impairment' of father } \\
\text { - } \text { Father illness of at least } 3 \text { months in last } 1 \text { year } \\
\text { - Child never visits mother } \\
\text { - Child never visits father }\end{array}$ & $\begin{array}{l}3 \\
2 \\
1 \\
1 \\
1 \\
1 \\
2 \\
2\end{array}$ \\
\hline $\begin{array}{l}\text { 3. Household } \\
\text { characteristics }\end{array}$ & $\begin{array}{l}\text { - Main source of drinking water (surface water) } \\
\text { - Ho sustainable source of food } \\
\text { - } \text { If no one in HH aged } 18 \text { yrs or more reported main activity in last } 7 \text { days as } \\
\text { paid work }\end{array}$ & $\begin{array}{l}1 \\
2 \\
1\end{array}$ \\
\hline $\begin{array}{l}\text { 4. Child's school } \\
\text { attendance }\end{array}$ & $\begin{array}{l}\text { - If child aged } 12 \text { to } 17 \text { yrs and has never attended school } \\
\text { - If child aged < } 12 \text { yrs and has never attended school } \\
\text { - If child aged } 12 \text { to } 17 \text { yrs and did not attend school during } 2009 \\
\text { - If child aged }<12 \text { yrs and did not attend school during } 2009 \\
\text { - If reason for absence from school is paid work } \\
\text { - If reason for absence from school is unpaid work for family or any other work } \\
\text { - If reason for absence from school is: not want to go, periods, ceremonies, } \\
\text { illness, lack of uniform or stationary, mistreated at school }\end{array}$ & $\begin{array}{l}2 \\
1 \\
1 \\
2 \\
3 \\
2 \\
1\end{array}$ \\
\hline $\begin{array}{l}\text { 5. Child's health } \\
\text { and nutrition }\end{array}$ & $\begin{array}{l}\text { - If when sick place of medical consultation is not health facility } \\
\text { - If usual number of meals per day } \\
\text { - If child did not eat anything yesterday } \\
\text { - If family had more meals than child yesterday }\end{array}$ & $\begin{array}{l}1 \\
1 \\
3 \\
1\end{array}$ \\
\hline $\begin{array}{l}\text { 6. Child's } \\
\text { disabilities }\end{array}$ & $\begin{array}{l}\text { - If child has complete difficulty in seeing } \\
\text { - If child has complete difficulty in hearing } \\
\text { - If child has complete difficulty in walking or climbing steps } \\
\text { - If child has complete difficulty in communicating }\end{array}$ & $\begin{array}{l}3 \\
3 \\
3 \\
3\end{array}$ \\
\hline $\begin{array}{l}\text { 7. Child's basic } \\
\text { material needs }\end{array}$ & $\begin{array}{l}\text { - If child does not possess a blanket } \\
\text { - If child does not possess a pair of shoes } \\
\text { - If child does not possess } 2 \text { sets of clothes }\end{array}$ & $\begin{array}{l}1 \\
1 \\
1\end{array}$ \\
\hline $\begin{array}{l}\text { 8. Child's risk } \\
\text { taking }\end{array}$ & $\begin{array}{l}\text { - If child aged }<17 \text { yrs is sexually active } \\
\text { - If child aged } 17 \text { to } 18 \text { yrs is sexually active } \\
\text { - If child is }<17 y \text { rs and has ever been pregnant } \\
\text { - If child is } 17 \text { to } 18 \text { yrs and has ever been pregnant } \\
\text { - If child has own child and there is someone else }>18 \mathrm{yrs} \text { in } \mathrm{HH} \\
\text { - If child has own child and there is no one else }>18 \mathrm{yrs} \text { in } \mathrm{HH} \\
\text { - If child often takes alcohol everyday or every week } \\
\text { - If child uses drugs (marijuana, petrol etc) }\end{array}$ & $\begin{array}{l}2 \\
1 \\
2 \\
1 \\
1 \\
2 \\
2 \\
3\end{array}$ \\
\hline
\end{tabular}


The team then applied these indicators to the household survey data, described below, to measure and characterize the population of vulnerable children in Uganda, providing a tool for establishing priorities among this large group of children.

\subsubsection{Estimates of orphaned and vulnerable children}

\section{Description of the household survey sample}

The household survey reached a total of 2,551 households located in all four major regions of Uganda (Table 5). Data from the child-specific questions of the household questionnaire covered 7,946 children resident in these households.

Table 5 Distribution of household survey responses

\begin{tabular}{lcc|cc}
\hline Region & \multicolumn{2}{c|}{ Household survey } & \multicolumn{2}{c}{ Child survey } \\
& $\mathbf{N}$ & $\mathbf{\%}$ & $\mathbf{N}$ & \% \\
\hline Central & 764 & 30.0 & 1,959 & 24.7 \\
Eastern & 656 & 25.7 & 2,370 & 29.8 \\
Northern & 477 & 18.7 & 1,548 & 19.5 \\
Western & 654 & 25.6 & 2,069 & 26.0 \\
Total & 2,551 & 100.0 & 7,946 & 100.0 \\
\hline
\end{tabular}

The household survey was designed to be nationally representative, and descriptive indicators of the households show that this was in fact the case, with indicators comparable to those reported in the 2006 Uganda Demographic and Health Survey (UDHS) (UBOS and Macro International 2007).

The survey also included data on the prevalence of households headed by young and elderly people, who are identified in the NSPPI as sources of child vulnerability (Box 1). As expected from a household survey, very few child-headed households were identified. Only 0.4 percent of the 2,551 sampled households were headed by a child under the age of 19 years old, and 5 percent by a youth aged 19 to 24 years old. A total of 23 percent of households were headed by a woman.

Very few disabled children were identified during the household survey, ranging from 1 percent reported by the household head as having some degree of communication difficulty to 3 percent with hearing difficulties. Since disabilities are stigmatized in many communities, it is possible that these characteristics were under-reported.

\section{National estimates}

The data from the household survey was weighted as explained in the methodology section to ensure that it was statistically representative. The percentages derived from the household data were based on the weighted data and not on the number of respondents from the household survey and hence are labeled as weighted percentages. In order to show the national implications of the data, estimates of actual numbers of children affected can be calculated as weighted population estimates. 
Household survey data indicate that 14 percent of children in Uganda have been orphaned, which is equivalent to a national total of 2.43 million out of 17.1 million children under age 18 (Table 6). This level is close to data reported in the UDHS, where it was reported that 15 percent of children younger than 18 years old were orphaned (UBOS and Macro International 2007).

The vulnerability score methodology provides a tool for establishing priorities among this large group of vulnerable children. Following the vulnerability categorization scheme described above, survey data indicate that more than 96 percent of children in Uganda can be considered vulnerable, with 8 percent (1.4 million) critically vulnerable, 43 percent $(7.4$ million) moderately vulnerable, and 45 percent generally vulnerable (7.7 million) (Table 6).

Table 6 National estimates of orphans and vulnerable children

\begin{tabular}{lccc}
\hline & $\begin{array}{c}\text { Number of } \\
\text { children in survey }\end{array}$ & $\begin{array}{c}\text { Weighted } \\
\text { percentage }\end{array}$ & $\begin{array}{c}\text { Weighted population } \\
\text { estimate }\end{array}$ \\
\hline Orphaned & 1,175 & 14.2 & $2,430,147$ \\
Not orphaned & 6,573 & 83.3 & $14,289,531$ \\
Not stated & 198 & 2.5 & 431,403 \\
Total & 7,946 & 100.0 & $17,140,366$ \\
\hline Critically vulnerable & 746 & 8.1 & $1,388,521$ \\
Moderately vulnerable & 3,535 & 43.0 & $7,360,421$ \\
Generally vulnerable & 3,401 & 45.0 & $7,721,294$ \\
Not vulnerable & 264 & 3.9 & 670,128 \\
Total & 7,946 & 100.0 & $17,140,366$ \\
\hline
\end{tabular}

Table 6 shows that for 2.5 percent of the children, parental status was not stated. For purposes of comparison between orphaned and non-orphaned children, these children were excluded from the analysis. Thus the denominator for orphaned children in subsequent tables and figures excludes the children for whom the parental status is missing in the data. When calculated without the children whose parental status data is missing the data shows that 15 percent of the children in Uganda are orphaned and 85 percent are not orphaned.

During FGDs and interviews, many participants expressed being overwhelmed by the numbers of vulnerable children in need of support in their communities.

Vulnerable children are cropping up every day, they are increasing each and every day and the funds received by the NGO are not sufficient to solve all the needs the children might have.

NGO staff, Central region

\subsubsection{Regional estimates of orphaned and vulnerable children}

Data from the household survey illustrate regional differences in the distribution of vulnerable children. Children's vulnerability is widespread in all regions of Uganda: between 
94 percent (Central region) and 99 percent (Northern region) of children could be defined as vulnerable. Regional data (Figure 1 and Table 7) illustrate greater variability in the degrees of vulnerability represented by the vulnerability score, but the percentage of those who are critically vulnerable remains fairly constant, between 8 percent (Eastern region) and 9 percent (Northern region).

Overall levels of vulnerability appear to be highest in the Northern region, perhaps reflecting the long period of conflict, combined with the violent cattle-rustling culture of Karamoja. There is some suggestion that regional variation in vulnerability may correlate with wealth distribution (based on data from UDHS) and reflecting higher levels of poverty in the conflict-affected North, and relatively more affluence in the Central region.

Figure 1 Regional distribution of vulnerable children

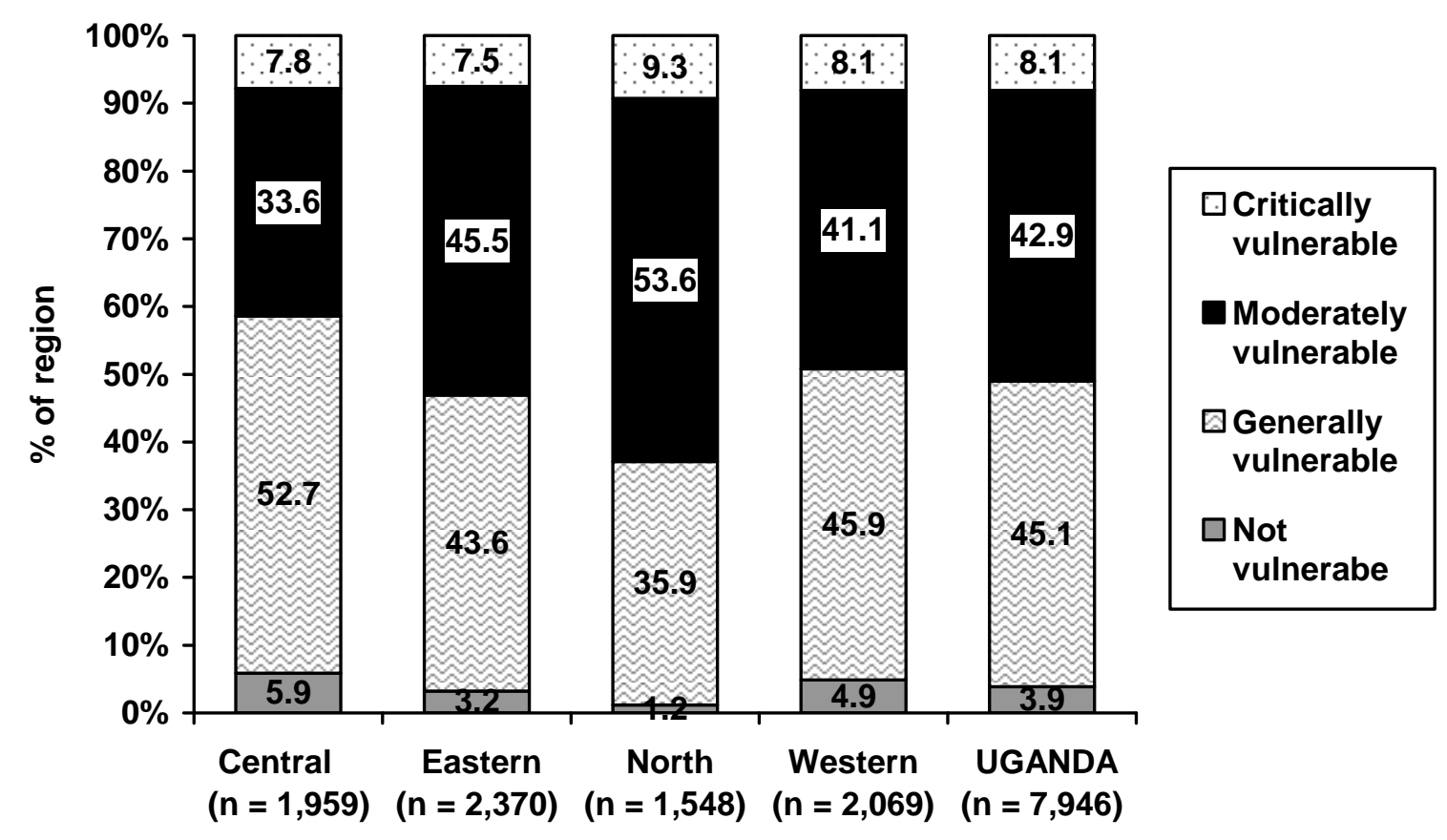

Table 7 illustrates regional variation in rates of orphanhood and vulnerability. It shows that rates of orphanhood range between 11 percent of children in the Eastern region and 17 percent of children in the Central region-possibly mirroring the national patterns of HIV prevalence, which are higher in the Central (9 percent) than the Eastern (5 percent) region (Uganda HIV/AIDS Sero-behavioral Survey of 2004/2005). Meanwhile, the percentage of children categorized as "moderately" vulnerable ranges between 34 percent in the Central region and 54 percent in the North. 
Table 7 Regional distribution of orphaned children and vulnerable children, percent

\begin{tabular}{|c|c|c|c|c|c|}
\hline & \multicolumn{2}{|c|}{ Orphaned } & Not orphaned & \multicolumn{2}{|c|}{ Total } \\
\hline Central $(n=1,959)$ & \multicolumn{2}{|c|}{16.6} & 83.4 & \multicolumn{2}{|l|}{100} \\
\hline Eastern $(n=2,370)$ & \multicolumn{2}{|c|}{11.4} & 88.6 & \multicolumn{2}{|l|}{100} \\
\hline North $(n=1,548)$ & \multicolumn{2}{|c|}{15.0} & 84.9 & \multicolumn{2}{|l|}{100} \\
\hline Western $(n=2,069)$ & \multicolumn{2}{|c|}{15.5} & 84.5 & \multicolumn{2}{|l|}{100} \\
\hline Total $(n=7,946)$ & \multicolumn{2}{|c|}{14.5} & 85.5 & \multicolumn{2}{|l|}{100} \\
\hline & $\begin{array}{c}\text { Critically } \\
\text { vulnerable }\end{array}$ & $\begin{array}{l}\text { Moderately } \\
\text { vulnerable }\end{array}$ & $\begin{array}{c}\text { Generally } \\
\text { vulnerable }\end{array}$ & $\begin{array}{c}\text { Not } \\
\text { vulnerable }\end{array}$ & Total \\
\hline Central $(n=1,959)$ & 7.8 & 33.6 & 52.7 & 5.9 & 100 \\
\hline Eastern $(n=2,370)$ & 7.5 & 45.5 & 43.8 & 3.2 & 100 \\
\hline North $(n=1,548)$ & 9.3 & 53.6 & 35.9 & 1.2 & 100 \\
\hline Western $(n=2,069)$ & 8.1 & 41.1 & 45.9 & 4.9 & 100 \\
\hline Total $(\mathrm{n}=7,946)$ & 8.1 & 42.9 & 45.1 & 3.9 & 100 \\
\hline
\end{tabular}

\section{Residential status of orphaned and vulnerable children}

Survey data shown in Table 8 and Figure 2 illustrate some differences in the distribution of orphanhood and vulnerability between children in urban and rural areas. Data suggest that orphanhood in urban areas is significantly higher than in rural areas (18 percent vs. 14 percent; $p=0.002$ ), but that degrees of vulnerability tend to be higher in the rural areas (43 percent moderately vs. 52 percent critically vulnerable, $p=0.000$ ). It is likely that these patterns reflect the differential patterns of HIV prevalence, which tends to be higher in urban areas than rural areas (10 percent vs. 6 percent) (Uganda HIV/AIDS Sero-behavioral survey of 2004/2005). Data could reflect the patterns of migration and fostering associated with parental illness and household dissolution. However, these data record the child's current living status and not their original home prior to any migration. This data implies a need to shift the focus of support from targeting orphans towards targeting children with high vulnerability regardless of whether or not they are orphaned.

Table 8 Orphanhood and vulnerability status by residency

\begin{tabular}{lcc}
\hline & \multicolumn{2}{c}{ Weighted percentage } \\
& Urban & $\begin{array}{c}\text { Rural } \\
\mathbf{n}=\mathbf{6 , 9 3 2}\end{array}$ \\
\hline Orphaned & $\mathbf{n = 8 0 8}$ & 14.0 \\
Not orphaned & 18.2 & 86.0 \\
Total & 81.8 & 100.0 \\
\hline & 100.0 & $\mathbf{n = 7 , 1 2 0}$ \\
\hline Critically vulnerable & $\mathbf{n = 8 2 6}$ & 8.3 \\
Moderately vulnerable & 6.8 & 43.9 \\
Generally vulnerable & 36.1 & 44.3 \\
Not vulnerable & 49.9 & 3.4 \\
Total & 7.3 & 100.0 \\
\hline
\end{tabular}




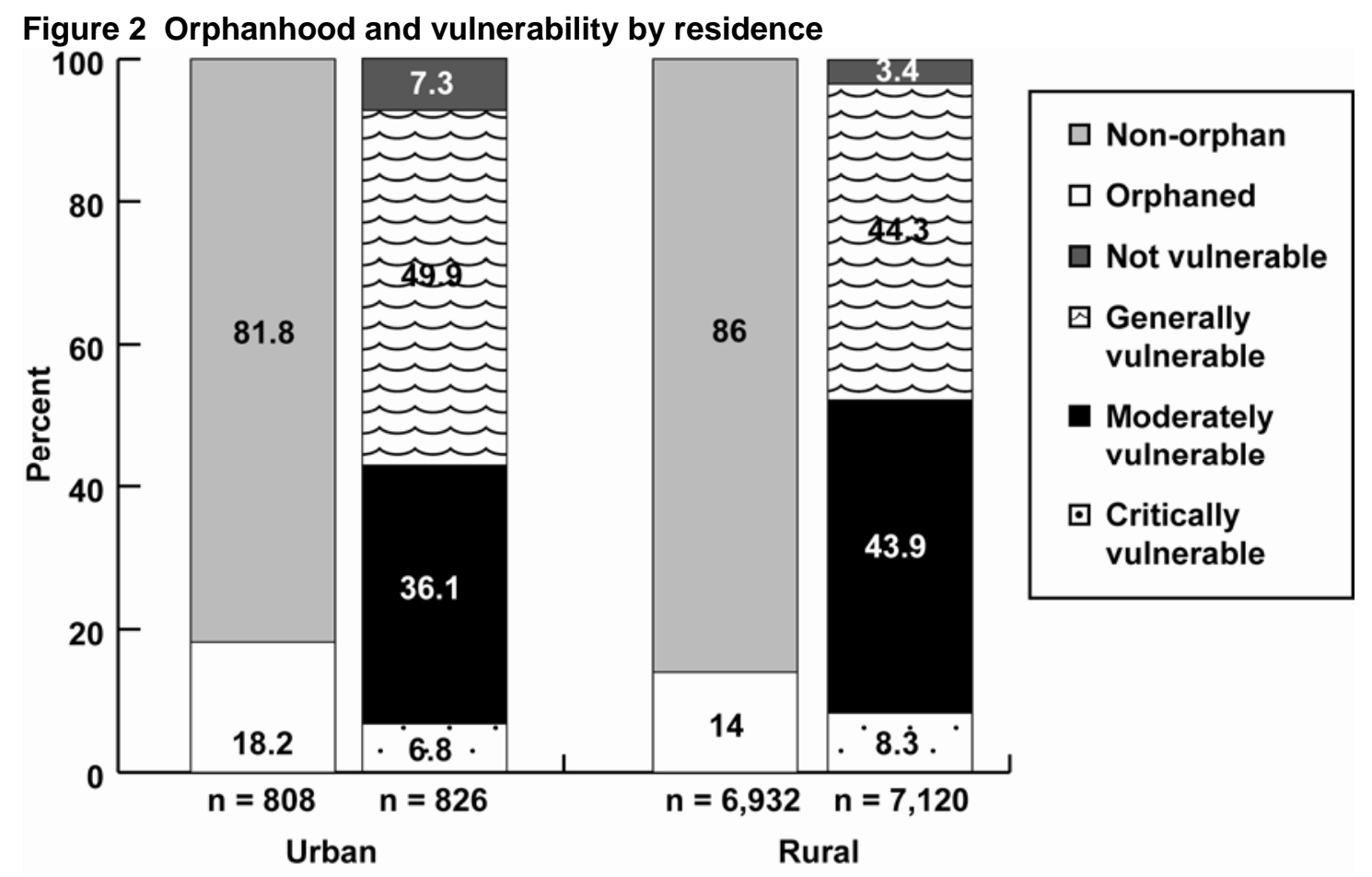

\subsubsection{Descriptive characteristics of children covered in the household survey}

In this section, descriptive features of the children covered in the household survey are presented. Preliminary analysis indicated no statistically significant differences between male and female children in the distribution of orphanhood or vulnerability, so results are combined for boys and girls.

\section{Age distribution}

Analysis of children's vulnerability must take their age into account, since this variable is correlated with many factors assessed in the vulnerability score (e.g., school attendance, sexual activity).

Table 9 shows that children who have been orphaned have an older age distribution than children who have not. These trends are consistent with those published in the UDHS, and are not surprising since the older a child, the older the parent, and the greater chance the parent will have died. This age distribution of orphaned children may also reflect the reduction in HIV incidence seen in the country in the past 15 years and a reduced death rate of parents given the use of antiretroviral therapy. Table 9 also shows the distribution of moderate vulnerability (selected because of the size of this category) by age group with a peak in younger age group of 5-9 years old compared to orphanhood. Thus if it is true that the orphans have a tendency to be older because of reduced AIDS death then vulnerability is not being equally affected by this factor. 
Table 9 Age distribution of orphaned children and moderately vulnerable children, percent

\begin{tabular}{lccc}
\hline & $\begin{array}{c}\text { Moderately vulnerable } \\
(\mathbf{n}=\mathbf{3}, \mathbf{5 4 5})\end{array}$ & $\begin{array}{c}\text { Weighted percentages } \\
\text { Orphaned } \\
(\mathbf{n = 1 , 1 7 5})\end{array}$ & $\begin{array}{c}\text { Not orphaned } \\
(\mathbf{n}=\mathbf{6 , 5 7 3})\end{array}$ \\
\hline $0-4$ yrs & 14.4 & 9.5 & 34.5 \\
$5-9$ yrs & 37.4 & 22.8 & 30.1 \\
$10-14$ yrs & 33.8 & 43.4 & 25.0 \\
$15-17$ yrs & 14.5 & 24.3 & 10.4 \\
Total & 100.0 & 100.0 & 100.0 \\
\hline
\end{tabular}

\section{Parental death}

When discussing children in the household who had lost a parent, respondents were asked to report on the cause of death. In interpreting this data, it is important to bear in mind that data reflect respondents' knowledge and perceptions, moderated through a lens of stigma and other community beliefs. Findings therefore may not be the actual cause of death.

Table 10 shows that the leading cause of parental death reported was AIDS, responsible for 43 percent of all maternal deaths and 33 percent of all paternal deaths. Another common cause of death of mother and father was "long illness" (a common euphemism for AIDSrelated illness) (10 percent and 14 percent, respectively). Accidents were responsible for less than 1 percent of mothers' deaths compared to 12 percent of fathers' deaths, reflecting the greater mobility of men and higher prevalence of accidents. Children participating in the Child Forums provided their perceptions of causes of death of parents in their community, mentioning more indirect causes such as poverty, land conflicts, wars, and poor nutrition, as well as specific illnesses such as sickle cell anemia and malaria.

Table 10 Cause of parental death among orphaned children resident in the household

\begin{tabular}{lcc}
\hline & Father & Mother \\
& $\mathbf{n = 8 4 1}$ & $\mathbf{n = 4 6 3}$ \\
\hline AIDS & 32.6 & 42.7 \\
Long illness & 14.4 & 10.5 \\
Accident & 12.0 & 0.7 \\
Bewitched & 6.0 & 5.1 \\
Malaria & 9.6 & 10.0 \\
Other & 18.3 & 22.9 \\
Not known & 7.0 & 8.0 \\
No response & 0.2 & 0.0 \\
Total & 100.0 & 100.0 \\
\hline
\end{tabular}

\section{School attendance}

Survey data revealed no significant differences in school attendance between male and female children. The following analysis therefore presents school attendance for all children by age and orphanhood status. (Since school attendance is included as one of the factors contributing to the vulnerability score, analysis by vulnerability status is inappropriate.) 
When orphaned children are compared to non-orphaned children by age (Table 11) it is notable that orphaned children aged 6 to12 years old were significantly more likely (93 percent) to be currently going to school compared to their non-orphaned counterparts (90 percent, $\mathrm{p}=0.000)$. However, in the age group 13 to 17 years old, orphaned children were less likely to be attending school (78 percent ) compared to non-orphaned children (87 percent, $\mathrm{p}=0.000$ ).

Table 11 also shows that, in general, younger children were more likely to be currently attending school than the older ones. This difference is more pronounced for orphaned children-93 percent of those aged 6 to 12 years old were currently in school compared to 78 percent of the orphaned children aged 13 to 17 years old $(p=0.000)$. Similarly, older children were more likely to have previously attended school and left than the younger ones, with a more pronounced difference among orphaned children-18 percent of those aged 13 to 17 years old had left school compared to 2 percent of those aged 6 to 12 years old ( $\mathrm{p}=$ $0.000)$.

These patterns may reflect a combination of several different trends in the community. The policy of UPE supports the school attendance of younger children, whereas support for secondary education (including the additional costs of school materials such as books or other fees) is less readily available. Furthermore, support for younger children to remain in school in the immediate aftermath of parental death may be followed by subsequent difficulties as the child grows up and the family faces up to household financial realities, or the fostering family shows preference to keeping their own biological children in school while fostered children are kept out of school to perform chores or earn an income.

Figure 3 School attendance by age and orphanhood status

92.8

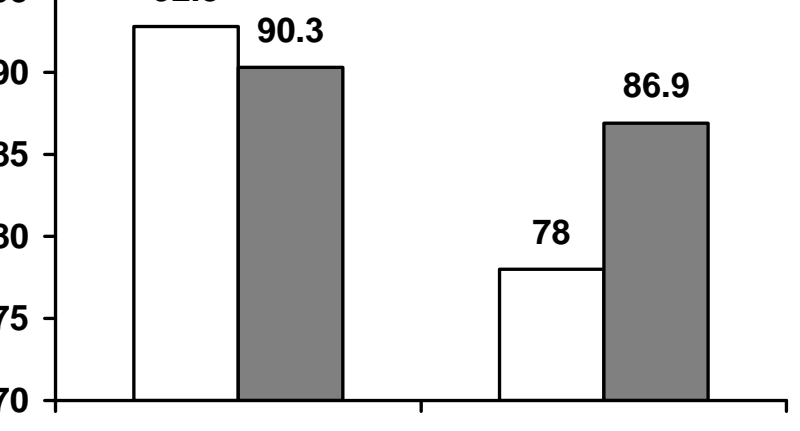

$\square$ Orphaned

$\square$ Non-orphaned

Age 6-12

Age 13-17 
Table 11 Schooling status of orphaned and vulnerable children by age

\begin{tabular}{lccccc}
\hline & $\begin{array}{c}\text { Age group in } \\
\text { years }\end{array}$ & $\begin{array}{c}\text { Currently } \\
\text { attending } \\
\text { school }\end{array}$ & $\begin{array}{c}\text { Previously attended } \\
\text { but did not attend } \\
\text { in 2009 }\end{array}$ & $\begin{array}{c}\text { Never } \\
\text { attended }\end{array}$ & Total \\
\hline Orphaned $(\mathrm{n}=1,040)$ & $6-12$ & 92.8 & 1.5 & 5.6 & 100 \\
Not orphaned $(\mathrm{n}=4,322)$ & $13-17$ & 78.0 & 17.6 & 4.4 & 100 \\
& $6-12$ & 90.3 & 0.9 & 8.8 & 100 \\
& $13-17$ & 86.9 & 7.3 & 5.8 & 100 \\
\hline
\end{tabular}

For those children who were reported being absent from school in the last week ( $n=608)$, reasons for not attending school included illness (21 percent), not having any school stationery (14 percent), not having paid their school fees (10 percent), and because they were doing domestic work (6 percent) or working for their families (5 percent).

\section{Basic material needs}

In the qualitative approaches respondents were asked their opinions on the most important needs of vulnerable children. Responses included basic material needs (e.g., food and clean water), shelter, education (e.g., access to scholastic materials and uniforms), and health care services and supplies (e.g., access to facilities that are not too far away, medicines for themselves and their parents, and for those with HIV, CD4 counts), and sanitation supplies (e.g., toiletries and sanitary towels for girls). Other needs included psychosocial support (counseling), love, parental guidance, security, and income generating activities (IGAs) or job opportunities for parents. Children in a forum in the Western region mentioned equipment for disabled children such as wheelchairs, better access to classrooms and toilets for the physically disabled and special schools for the deaf and blind. One child in the Western region mentioned the need for protection for girls from their own guardians.

The government should construct more medical centers so that the OVCs can access medical care.

Child Forum participant, male aged 13 to 17 years old, Central region

The UDHS considers possession of the basic material goods of a blanket or bed cover, shoes of any type, and two sets of clothing as indicators of children's vulnerability. This household survey (Table 12) revealed that children who had been orphaned were statistically less likely than children who were not orphaned to have these goods in their possession, including shoes (29 percent vs. 34 percent, $\mathrm{p}=0.001$ ) and two sets of clothes $(53$ percent vs. 59 percent, $\mathrm{p}=$ 0.001). A similar trend was observed for possession of a blanket but the difference was not found to be statistically significant. 
Table 12 Possession of basic items of clothing by orphaned and vulnerable children

\begin{tabular}{|c|c|c|c|c|c|c|}
\hline & \multirow[b]{2}{*}{$\begin{array}{c}\text { Orphaned } \\
(n=1,026)\end{array}$} & \multicolumn{5}{|c|}{ Weighted percentages } \\
\hline & & $\begin{array}{c}\text { Not } \\
\text { orphaned } \\
(n=4,354)\end{array}$ & $\begin{array}{c}\text { Critically } \\
\text { vulnerable } \\
(n=647)\end{array}$ & $\begin{array}{l}\text { Moderately } \\
\text { vulnerable } \\
(n=2,748)\end{array}$ & $\begin{array}{c}\text { Generally } \\
\text { vulnerable } \\
(n=1,561)\end{array}$ & $\begin{array}{c}\text { Not } \\
\text { vulnerable } \\
(n=46)\end{array}$ \\
\hline Has a blanket & 30.4 & 32.5 & 10.4 & 16.1 & 62.3 & 100.0 \\
\hline $\begin{array}{l}\text { Has a pair of } \\
\text { shoes }\end{array}$ & 29.1 & 34.4 & 15.5 & 16.9 & 63.2 & 100.0 \\
\hline $\begin{array}{l}\text { Has two sets of } \\
\text { clothes }\end{array}$ & 53.3 & 58.7 & 42.6 & 47.1 & 77.3 & 97.3 \\
\hline
\end{tabular}

\section{Other characteristics of vulnerable children}

In the Child Forums, children were asked if they were aware of vulnerable children in their community and further asked to describe which children they considered to be vulnerable. The child participants described vulnerable children as those who are orphaned, disabled, babies, sick, mistreated, poor, living with or affected by HIV/AIDS, and "mad." Children participating in the Child Forums indicated that they thought that sexual activity, drugs and alcohol use were common, and that such risk-taking was most prevalent among street children, disabled children and "mad children." Use of the word "mad" occurred in three of the 16 Child Forums. While no further explanation is available from the transcripts of the Child Forums it can be speculated that by "mad child" the Child Forum participants were referring to children living outside of family care who are unkempt and not living an orderly life.

The street children are stressed, so they take alcohol or cigarettes to kill stress. Child Forum participant, female aged 13 to 17 years old, Central region

In the Child Forums for the older age group of 13 to 17 a question was added about awareness of children in conflict with the law. Participants indicated that the main ways in which children came into conflict with the law were through theft, gambling, "fornication," rape, defilement, drug abuse, sex work, use of vulgar language, fighting, and homosexuality (which is a crime in Uganda). Poverty, peer pressure, poor home atmosphere, and lack of guidance were also cited as situations that cause children to come into conflict with the law.

Throughout the country children reported not being involved in decision-making about their lives, for example regarding the choice of schools. Children reported that parents were too busy to talk to them, that children cannot sit and discuss with parents, that parents dictate what children must do, and that parents think children are too young to be consulted.

They don't consult me about the subjects I should take at school.

Child Forum participant aged 13 to 17 years old, Central region

While lack of consultation about their education choices was a prominent example, some children cited instances where they felt they were consulted. Indeed one cited school choice as the only time he was consulted. 
They only consult you when they want to change you from that school.

Child Forum participant aged 13 to 17 years old, Central region

In the Child Forums children were asked how supportive their community was towards children affected by HIV/AIDS. Within each Child Forum there was a mixture of responses regarding stigmatization of children who have parents infected with HIV, parents who have died from AIDS, and children who are infected themselves. Some children stated they were still largely stigmatized, isolated, feared and neglected, while others stated that they are loved, cared for and given counseling by the community.

They [children living with HIV] are neglected because they will die soon.

Child Forum participant, female aged 13 to 17 years old, Central region

Others [community members] contribute to the child or family and others backbite and rumormonger.

Child Forum participant, female aged 13 to 17 years old, Western region

In a country like Uganda where there has been much awareness and sensitization about HIV, it is not surprising that the children reported positive attitudes toward people living with HIV. However, stigma and discrimination remain persistent issues that may not easily be eliminated from a society.

\subsubsection{Street children}

While it was beyond the scope of this study to quantify the numbers of street children, information regarding this important group of vulnerable children emerged from FGDs, interviews and Child Forums. Respondents reported that they perceived an ever-increasing number of children living on the street, not exclusively because they have lost their parents, but also because households are too poor to feed and care properly for children, and because children are escaping abuse at home from parents or guardians. During FGDs, some participants working for NGOs and the government mentioned the difficulties of taking the children off the streets and rehabilitating them. During the Child Forums, children reported that street children were frequently involved in risk-taking activities such as taking drugs and alcohol, gambling, sex work and theft.

Most of the children on streets, their homes are well but because there is no love, and they are abused in their own homes, so they end up running away.

NGO staff, Eastern region

It is very hard to remove children from the street, they run away from you, they don't want to listen.

Police officer, Northern region

A special group of street children that was reported by FGD and IDI participants especially from Eastern Uganda are children from Karamoja (Box 2) who have moved into towns of Eastern Uganda and in Kampala. 
And now here in Mbale, you know it is a major transit route for the Karamojongs moving from Moroto to Mbale, Iganga, Jinja, Kampala and then Kiryandongo. So we can also look at children in transit, they are also vulnerable children.

FGD participant, social worker, female, Eastern region

\section{Box 2 Causes of child migration from Karamoja to streets of Kampala}

The north-east of Uganda is inhabited by the Karamajong who are a nomadic, pastoralist tribe among whom frequent insecurity is common as they raid cattle from each other and their neighbors in part due to a traditional rite of passage for young men. Since the widespread acquisition of automatic weapons this tradition of cattle rustling has made the entire area dangerous. Children from Karamoja who are on the streets of Kampala, Jinja, Iganga, Mbale and other towns, move on foot from town to town doing odd jobs and proceeding to the next town until they reach Kampala. Kangore Church of Uganda, in Karamoja, operates a centre which receives some of these children when they return from Kampala and elsewhere. According to one of the staff from this centre there are three main reasons for children moving from Karamoja to these cities. One is to escape famine and hunger. The second reason is that some children live in the cattle rustling corridor and their parents advise them to leave the danger zone and go to the cities for safety. The third reason is peer influence by children who return from the cities to visit relatives. They come with "goodies" and convince other children to return to the city with them.

Information provided by Social Worker, St Mark Church of Uganda, Kangore

\subsection{The Response: Approaches to Addressing Circumstances of Orphaned and Vulnerable Children}

In this section, results are presented describing responses to the circumstances described above, including responses to children from various sources of support.

\subsubsection{Coverage of external support services}

During the household survey, caregivers were asked whether they had received any free external organized support for children living in the household during the last 12 months (including government, private, religious, charity or community-based programs). Separate questions were asked for each CPA, taking into account whether services were targeted at each child or household. Results for services targeted by child are shown in Figure 4, and results for services targeted by household are shown in Figure 5.

The most common form of external support reported by household respondents was medical support (medical care, supplies or medicine), reported received by 15 percent of all children. Other common forms of support reported received by more than 6 percent of children living in surveyed households were training in modern farming techniques, agricultural inputs and schooling (Figure 4). 
Figure 4 Coverage of external support services, among all children living in surveyed

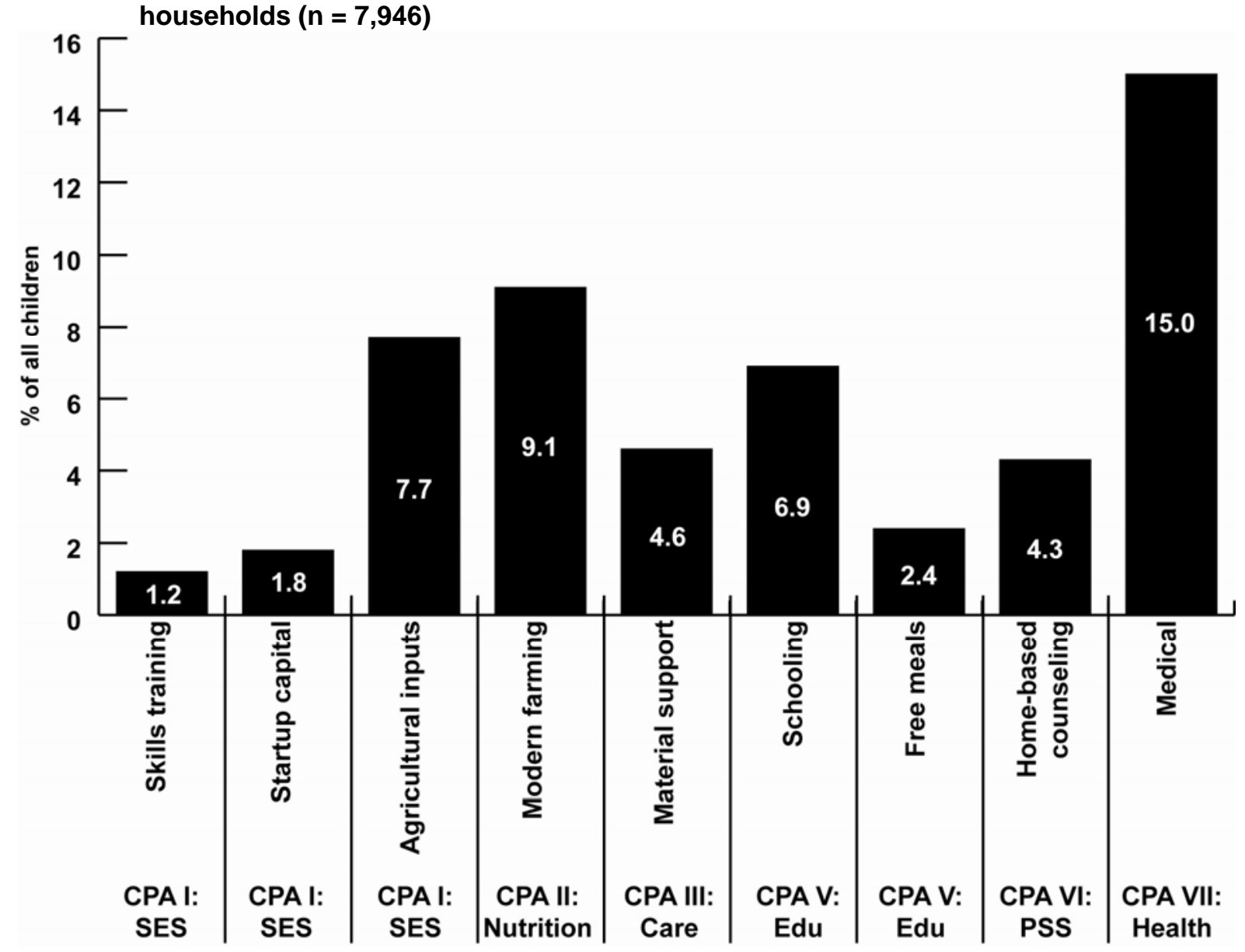

Figure 5 shows that for most CPAs (such as CPA-I:Socio-Economic Support, CPA-II:

Nutrition and CPA-III: Care and Support), the majority of children reporting receiving these services were in the generally vulnerable group as opposed to moderately and critically vulnerable. Only CPA V (Education and in-school free meals) were received by a higher proportion of the more vulnerable children (71 percent of moderately and critically vulnerable children combined). CPA-I: Socio-Economic Support: skills training was actually received by more children of low levels of vulnerability, 67 percent were generally or not vulnerable. In some instances this is probably due to the fact that in many parts of the country, entire communities are extremely poor and the CSOs choose to deliver services at a community level rather than at a household level. 
Figure 5 Distribution of vulnerability among children in households who received particular types of support

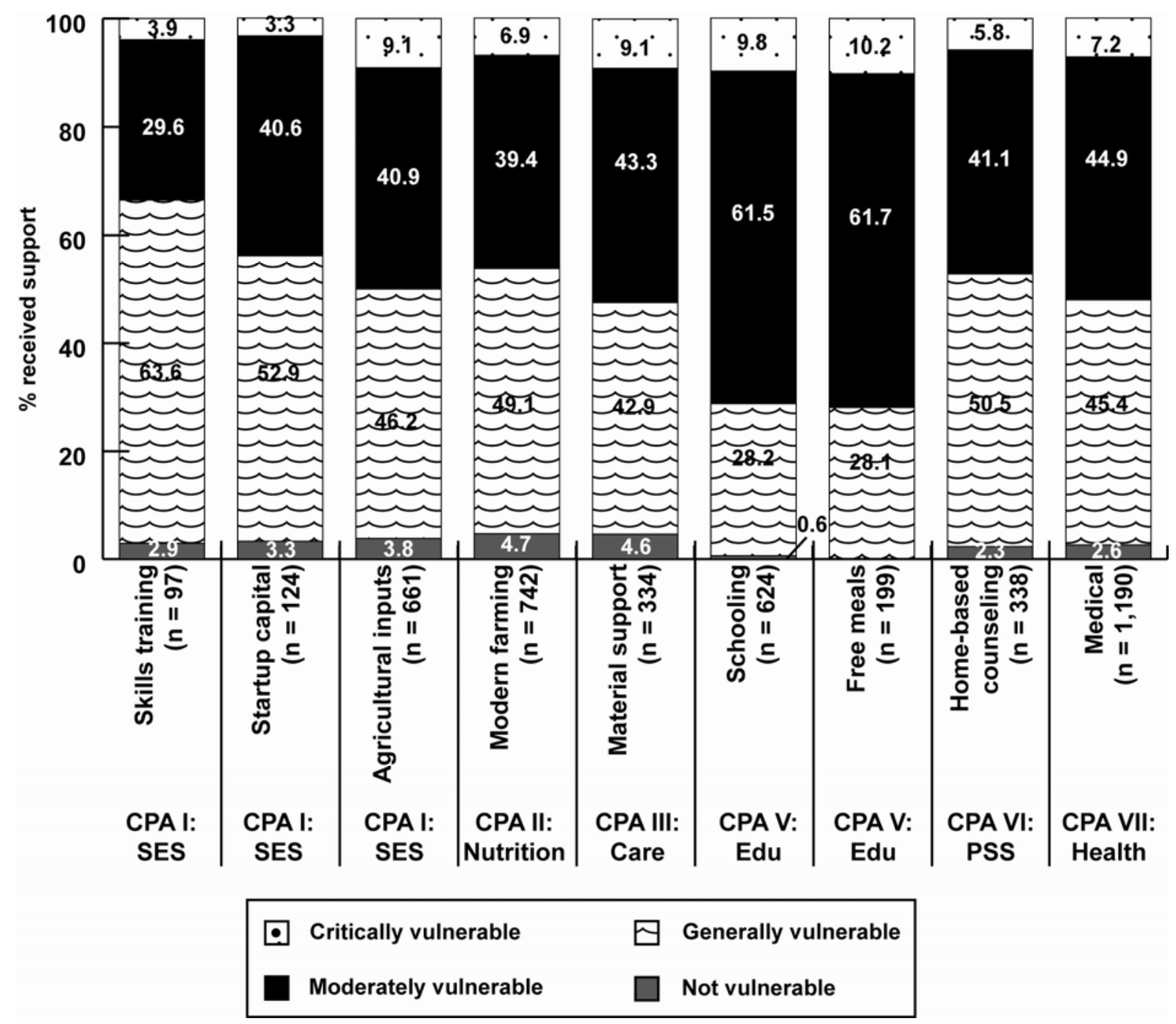

In order to assess whether external support was successfully being targeted at orphaned children the data on external support received by households was analyzed by orphanhood. Since 15 percent of children in Uganda are orphaned one can use this as a crude measure to gauge whether external support is targeting orphaned children. Figure 6 illustrates that for the following forms of external support, orphaned children or their households represented less than 15 percent of the recipients: skills training, material support and psychosocial support. On the other hand, for the rest of the CPAs shown it appears the proportion of recipients that are orphaned children exceeds 15 percent. This is especially the case for school support, free meals and agricultural inputs. This data compared to data in Figure 5 suggests that while the provision of external support targets orphaned children to a reasonable extent, it is not adequately targeting other vulnerable children. 
Figure 6 Orphanhood status among children in households receiving external support

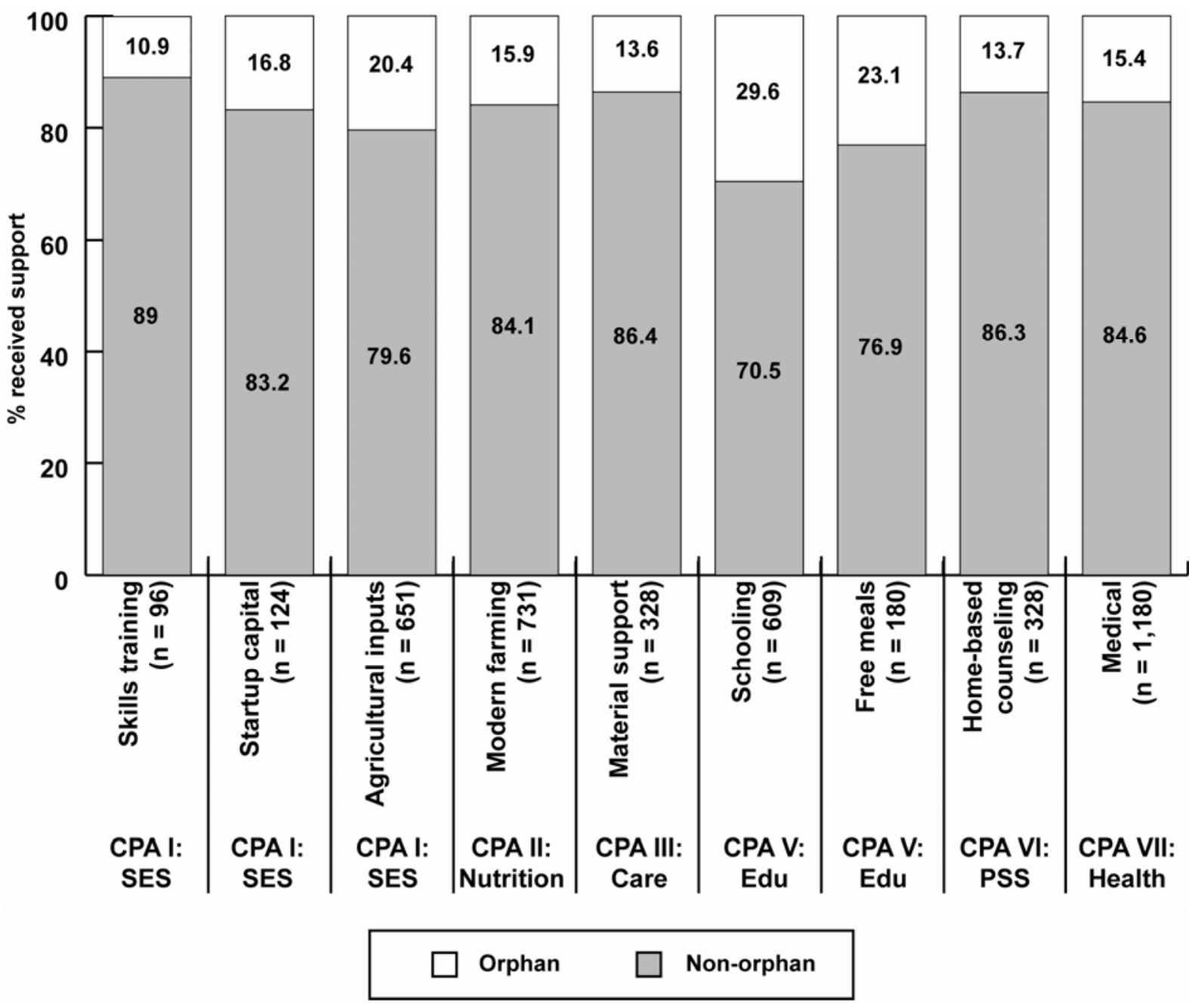

\section{Adequacy of external support}

Adult and child respondents felt that few organizations are actually offering comprehensive care to vulnerable children. Most organizations tend to provide educational support and support for one or two other CPAs.

The needs of the OVC are very wide and there is no particular organization that can meet comprehensively all the needs.

NGO staff, Northern region

The children in the Forums reported that vulnerable children in their communities are assisted by the government, NGOs, churches, the United Nations, relatives, schools, commercial businesses like "Coca Cola," and rich individuals who sponsor children. However, this support was not considered sufficient or comprehensive by most respondents.

If they were getting enough help, they would not be called vulnerable.

Child Forum participant, female aged 13 to 17 years old Eastern region 


\subsubsection{Government efforts to address the needs of vulnerable children}

At the national level, MGLSD with technical assistance from partners (especially the CORE Initiative and UNICEF) has developed structures, tools and guidelines to enable implementers to effectively provide services to vulnerable children in the country. The structures consist of the following committees, listed in ranking order:

- National OVC Steering Committee;

- National Implementation Unit;

- Technical Resource Committee;

- Technical Working Group;

- District OVC Coordination Committee; and

- Sub-county OVC Coordination Committee.

In addition, the MGLSD has designated eight key organizations as Zonal Technical Service Organizations to provide technical support at the service delivery level. Each Technical Service Organization covers 10 districts.

Guidelines include the National OVC Policy and the NSPPI, both of which were launched in 2004. Other technical materials include guidelines, tool kits and training manuals for service providers, quality standards tools, mapping guides, and the Management Information System (MIS) tool and a resource tracking tool (listed in Section 3/Lit Review Methods).

To support these activities, the government provides personnel in form of Probation and Welfare Officers in all districts, although there are still a number of key positions that remain unfilled. Government has provided offices for these personnel, but there are still gaps in the level of budgetary support for the running costs of these offices and for supervisory and monitoring visits in the field.

\section{The National Strategic Plan}

The general view of both government and NGO respondents to qualitative interviews was that the implementation of the NSPPI has been varied with some geographic areas lagging behind others, particularly in the war zones of the North. Only national and district-level officials, including district level political leaders, larger NGOs, probation officers, Community Development Officers, and police are aware of the NSPPI and its content and were involved in its development. The majority of local leaders and local service providers reported not to have been trained in the content and use of the NSPPI.

I think this National Strategic Plan-we have here a technical organization called Africare. These people, they have conducted trainings. I happen to be among the participants. We were trained on the National Quality Standards. Among the ten CPAs, we as the police relate to the program area of legal support-that one is based with police, because when children's rights are violated and children [are] in conflict with the law, that issue goes directly to the area of legal protection. 
The process of implementing it [the NSPPI] is very slow. At the district level we may know much about it, but down there, it is not yet fully articulated down in the communities. So many organizations don't know about its contents, [but] they might have heard about it [in general].

NGO official, Northern region

According to both the NGO and government respondents, the government structures described in the NSPPI, such as the District OVC Coordination Committee and Sub-county OVC Coordination Committee, are now in place, and personnel have received training in topics such as child protection. However, many offices lack the resources, training, funds and staffing levels to travel and conduct activities such as case investigation and family tracing.

The systems are inefficient and the capacity of it to do work is not sufficient. The funding of the district community department is low, it is not talked about. Sometimes you find the person is alone, the probation officer is alone, the linkage between him/her and the sub-county is very minimal.

NGO staff, Eastern region

The current response is not good because as the police we are under-staffed with no transport-in case of an emergency and no phone-so this is a big problem.

Police officer, Eastern region

\section{Coordination and collaboration}

Coordination of support activities for vulnerable children and ensuring collaboration among implementers is a key role of government. According to respondents the national and districtlevel coordination of service provision for vulnerable children is functioning in some districts. In other districts there still are gaps in coordination due to lack of transport for probation officers and a lack of communication. For example, in some situations staff of organizations did not know where to refer vulnerable children for particular services.

There is also limited coordination between the central government and local elected leaders. However, there are some exceptions. In the North, coordination seems to be stronger as a result of structures built by the UN in response to the war. In a few districts it is clear some organizations are collaborating with each other and coordinating their response to ensure vulnerable children receive comprehensive services.

First of all, coordination of the various players in caring or providing services for these vulnerable children is lacking. Who is there to police these various service providers?

NGO staff, Central region

[In] the north, that is mainly Lango and Acholi area, the UN brought together different agencies so you had the coordination mechanisms.... They have for example joint planning, joint strategies, joint community structures.

Donor agency staff, Central region 
This district here is working jointly to protect the vulnerable children. Working jointly as a team-that is the probation officer, police, the community development officer, up to the sub-county level. And the volunteers, the NGOs all are working as a team, so which means that when an NGO has mobilized a group or community, they give the topics there, the probation officer gives topics. Then the communities, they see it from there.

Police officer, Western region

\section{Government's role in direct implementation of activities for vulnerable children}

In addition to providing overall strategic, policy and technical guidance, the government through its various ministries is responsible for directly delivering services to vulnerable children in at least three areas: education, health care and child protection.

Education. The government of Uganda provides free primary school education through UPE, which is available in all parts of the country. Under the same ministry the government has initiated the Universal Secondary Education (USE) to provide free secondary school education; however USE is still in its infancy and has not reached all parts of the country. Although the UPE system was put in place to ensure education for all it still seems to be excluding vulnerable children due to resources needed for uniforms, stationary and exam fees. At the same time, the quality of education that is received is thought to be poor. According to teachers during the FGDs and interviews, many schools in the UPE system are not given sufficient budgets from the government to cover all of their costs and payments are often received very late. This leads them to turn to parents to pay for some materials which many cannot afford. None of these schools seem to have a routine free lunch program but sporadic programs that are dependent on outside donors.

Despite the fact that UPE and USE [are] free of charge, some head teachers ask items from these children which they cannot afford-like ream papers, registration fee-which makes it hard for those who can't afford, and they end up not going to school.... Education is not well addressed. Most schools don't have the required equipment, text books and enough qualified teachers and permanent structures.

Head teacher, Central region

Healthcare. The government also provides free health care through its Ministry of Health facilities which exist in all parts of the country. As is common in sub-Saharan Africa, respondents reported that government medical facilities are often under-staffed and rural facilities often experience delayed deliveries of drugs. This is likely to impact vulnerable children disproportionately, since they are unable to afford to pay any medical fees or for medications at the health facility or from private clinics and pharmacies where they are often referred.

The government dispensary nearby, when you visit there, you may find that the medical personnel are not there, so people end up going to (private) clinics. And if at all they are there, they say they don't have drugs, and they always refer you to Nakaseke or Kiwoko hospital, which are very far from [here]. If they tell you that we 
don't have drugs around or medical kits, they refer you to a nearby drug store to buy, and the people don't have the money, so they resort to local herbs.

Head teacher, Central region

Child protection. It was the prevailing view of respondents that the infrastructure for child protection has been established, that staff have been trained, and that they are committed to supporting vulnerable children. However, it was felt that most offices are struggling to do their job properly due to a lack of funds, under-staffing and the large geographic area each office is responsible for.

The systems that are supposed to help are not functioning well from district to the lower structure. This is because [of] lack of facilitation.

NGO staff, Western region

[Child] Protection units are doing a good job when they are approached but only you find that some areas the police stations are far from the people.

Teacher, Central region

In some cases, respondents reported that officials were reported to be corrupt and that the procedures to file a report and obtain justice were said to be lengthy and costly. In cases of incest, if child abusers are charged, often family members request a withdrawal or will bribe police to release the offender.

I would say that one of the factors hindering the services rendered to these OVCs is the corruption and bribery where you would like to assist, for example a defiled child-you get the suspect and take that person to [the] police, but because of bribery that person is imprisoned and all of a sudden you find that [he] is released without even knowing how he was released, and the case ends.

FGD participant, Central region

Another challenge to protecting children was the widespread lack of awareness amongst children, caregivers and communities of what constitutes abuse and a criminal offense, so that much abuse goes unreported.

Other OVCs are not even aware of their rights-that is why there is violation of rights.

NGO staff, Western region

\subsubsection{Civil society organization efforts to address the circumstances of orphaned and vulnerable children}

\section{Capacity of civil society organizations}

Local NGOs were generally thought by respondents to have limited capacity while international NGOs have a higher capacity to address the needs of vulnerable children. 
There are different levels, most national NGOs don't have adequate capacity, many international NGOs have this capacity.

Donor agency staff, Central region

The CSOs are very disorganized. They do not have the capacity to handle this issue. We [CSOs] are not even working at 5 percent, we just are giving the government a hand in tackling the issue of vulnerable children in Uganda.

NGO staff, Central region

Most of those engaged in OVCs don't have the capacity. They have not undergone training on OVCs handling. ... They are not even aware of the national strategic policy.

NGO staff, Western region

NGOs were reported to have a big impact on the few vulnerable children they reach, but many needy children are excluded as a result of the criteria used to define beneficiaries. The use of age as a criterion is penalizing teenagers who started school late, excluding them from continued school support once they turn 18 years old. Stakeholders felt some NGOs set their agendas and targets without involving the community and end up giving inappropriate support.

[A certain organization] donates wheelchairs, but now we know how to make our own that are friendly to our terrain.

NGO staff, Central region

The service providers are still very few on the ground. The service providers don't give the real support to facilitate these OVCs to cope up with the situation.

Government official, Western region

The fund providers need children below 18 years, so when someone reaches 18 years when is in Senior 3 or 4, you can't push or educate them further. They end up dropping out of school....

NGO staff, Central region

Respondents reported that many international NGOs who were previously supporting vulnerable children in their areas have left and moved to conflict zones, leaving other areas unsupported.

There were two NGOs I knew. Those people used to help, they used to build houses for the needy and orphans. They used to pay fees and meeting their medical bills but now these NGOs we only see their offices, see the cars labeled. When you ask them they are telling us that their program in Luwero ended some time back that now they are committed in other areas like northern Uganda.

Head teacher, Central region 


\section{Funding sources}

Organizations serving vulnerable children receive funds from different sources, both local and international, as well as from the income they generate from their activities. Others still, like SOS, World Vision and Plan International receive funding from their parent organizations. While some organizations like Joint Clinical Research Centre, Tigers Club, Trans-cultural Psychosocial Organization and TASO, have more than one source of funding, others like Kampiringisa, Good Care and Family Support, have single sources of funding.

Since 2005, 125 implementing partners (mainly CSOs) received funding from PEPFAR through the MGLSD and Civil Society Fund to implement projects for HIV and vulnerable children in 64 districts of Uganda. The CSOs that benefited from this fund include national and international NGOs, CBOs, faith based organizations, and private sector organizations. Under the CORE Initiative project, a total of 48 CSOs received funding through the MGLSD to implement activities for vulnerable children and HIV prevention. Since 2007, the granting process has been harmonized under the Civil Society Fund.

According to the MGLSD, currently the USG, UK Department for International Development (DFID), Irish AID, Danish International Development Agency, and Italian Corporation are putting funds in the Civil Society Fund which is being used to support activities for vulnerable children and HIV/AIDS in the country. Through the Civil Society Fund, 28 CSOs were awarded grants to deliver services to vulnerable children in a number of CPAs. Additionally, 94 CSOs and 3 CSOs were awarded grants to deliver HIV/AIDS and Pediatric AIDS services, respectively. Furthermore, the Civil Society Fund was also in the final stages of issuing conditional grants to 80 local governments and another round of grants to CSOs to deliver services to vulnerable children in 17 targeted districts of Uganda.

\section{Nature of service provision}

Data in this section is derived from the organizational assessment questionnaires. Of the 138 screening questionnaires dispatched, completed tools were returned by 124 organizations. These 124 organizations categorized themselves as non-governmental, faith-based or community-based and a few considered themselves to be all three. While some specifically focus on orphaned children (UWESO and Uganda Orphans and Rural Development Program) or all vulnerable children (Toro Babies, Children and Wives of Disabled Soldiers Association (CAWADISA), others integrate services for vulnerable children along with their other main areas of activities such as HIV (TASO) or general community development (Caritas).

While the majority of organizations have a defined geographical area of coverage, TASO, Uganda Red Cross and Kampiringisa do not confine their coverage to specific regions of the country and as such consider themselves to have a nationwide constituency. Other organizations are very restricted in the coverage. Eleven out of eighteen organizations included in the in-depth analysis work in peri-urban and rural areas.

Of the 78 organizations who reported their geographic area of coverage, 48 (62 percent) provide services in more than three sub-counties (Table 13). The number of sub-counties in a district can range from as few as three to as many as fifteen. Hence, this coverage data shows that even when organizations are providing services for vulnerable children in a district they cover only a small proportion of the district. 
Table 13 Number of sub-counties served

\begin{tabular}{|c|c|c|}
\hline Name of town base & $\begin{array}{c}\text { No. of organizations serving } 3 \text { or LESS } \\
\text { sub-counties }(n=30)\end{array}$ & $\begin{array}{l}\text { No. of organizations serving MORE } \\
\text { than } 3 \text { sub-counties }(n=48)\end{array}$ \\
\hline Kampala & 5 & 13 \\
\hline Moroto & 6 & 2 \\
\hline Tororo & 4 & 5 \\
\hline Soroti & 0 & 1 \\
\hline Kabarole (Fort Portal) & 1 & 5 \\
\hline Wakiso & 1 & 3 \\
\hline Masindi & 4 & 1 \\
\hline Arua & 4 & 6 \\
\hline Mubende & 2 & 5 \\
\hline Gulu & 0 & 4 \\
\hline Masaka & 2 & 1 \\
\hline Mbarara & 1 & 2 \\
\hline PERCENT of total & $38.5 \%$ & $61.5 \%$ \\
\hline
\end{tabular}

The average number of beneficiaries reached by the organizations in 2008 was 6,217 ranging from 12 vulnerable children by the Rural Initiative for Community Empowerment to 54,650 by CAWADISA. An equal number of male and female children were provided with services.

However, a further look at the numbers served (Table 14) shows that just over half (51 percent) of the 95 organizations that answered this questions served 300 or less vulnerable children in 2008. And 41 percent served 500 or more vulnerable children, with only a few (8 percent) falling between 300 and 500 vulnerable children. The organizations clustered in the lower range of clients are most likely the community level organizations while the organizations clustered in the upper range (500 or more) are the bigger national or international organizations.

Table 14 Number of vulnerable children served in 2008

\begin{tabular}{lcc}
\hline $\begin{array}{l}\text { Number of vulnerable children } \\
\text { served in } \mathbf{2 0 0 8}\end{array}$ & $\begin{array}{c}\text { Number of } \\
\text { organizations }\end{array}$ & $\begin{array}{c}\text { Percentage of total } \\
\mathbf{n}=\mathbf{9 5}\end{array}$ \\
\hline Between 0 and 100 & 22 & 23.2 \\
Between 101 and 300 & 26 & 27.4 \\
Between 301 and 500 & 8 & 8.4 \\
Above 500 & 39 & 41.1 \\
\hline
\end{tabular}

Due to limited resources most of the organizations tend to use the approach of giving a little to many children to attain a certain level of satisfaction. All but one organization (Tigers Club) target the children together with the household that supports them, and some target the surrounding community. All organizations have the same definition of vulnerable children that was developed previously by MGLSD in collaboration with stakeholders: "children whose parents are either dead or whose parents cannot meet their basic needs." Most of the organizations select the children they serve on the basis of vulnerability. In most cases, there are specific criteria that must be met for one to benefit from services offered. 
These criteria differ from one organization to another, ranging from gender, level of vulnerability based on the NSPPI criteria, age, and physical state of the child, among others. However, the organizations, regardless of their selection criteria, are mostly focusing on children who are either orphaned, have parents living with HIV, have HIV themselves, are disabled, or are displaced by conflicts. Few organizations focus on street children and children from very poor families. Almost all of the organizations rely on the community and local councils to select the beneficiaries and will have a management committee to review these. Kampiringisa, Rugaba Youth and SOS use only the government and courts to select their beneficiaries. Some organizations also involve the community in the implementation and monitoring of the vulnerable children program such as Uganda Orphans and Rural Development Program and Good Care and Family Support.

When the children outgrow the age of focus some organizations discontinue support. However, for some organizations these children are exited from the program and integrated into the community. Some organizations such as UWESO provide vocational training and start-up support to assist them to get employment or initiate a small business. The exited children are also given moral/social support to assist them in the communities:

We keep follow up on them because some of them head families. We provide start up kits (e.g. start up hair creams for a hairdressing business). Some of them are still on training or studying. We keep on surrounding them (give them support and keep in touch with them) until they finish.

NGO staff, Central region

\section{Coverage of the CPAs}

This section discusses coverage of CPAs based on data obtained from the organizational assessment. As mentioned before, these organizations included USG and non-USG funded support for services for vulnerable children. In section 4.2.5 coverage is again discussed but with a specific focus on USG-funded implementers and the data used there was obtained from the MEEPP data base.

Between all of the 124 organizations reviewed, all of the Core Program Areas are covered. Education is the most commonly supported, by 70 percent of the organizations (Table 15), followed by health (57 percent) while "mitigation of the impact of conflict" is addressed by the least number of organizations (19 percent). The approaches used to deliver each of the CPAs, together with case studies to illustrate some "promising practices". 
Table 15 Frequency of CPAs covered

\begin{tabular}{lcc}
\hline CPA & $\begin{array}{c}\text { Number of } \\
\text { organizations } \\
\text { providing CPA } \\
\text { (n= 124) }\end{array}$ & $\begin{array}{c}\text { Percent of } \\
\text { respondent } \\
\text { organizations }\end{array}$ \\
\hline CPA-V: Education & 87 & 70.2 \\
CPA-VII: Health care & 71 & 57.2 \\
CPA-II: Food and nutrition & 68 & 54.8 \\
CPA-VIII: Child protection & 65 & 52.4 \\
CPA-VI: Psychosocial support & 62 & 50.0 \\
CPA-I: Socio-economic security & 57 & 46.0 \\
CPA-III: Care and support & 56 & 45.2 \\
Part of CPA-III: Clothing & 50 & 40.3 \\
Part of CPA-III: Shelter & 42 & 33.9 \\
CPA-IX: Legal support & 36 & 28.2 \\
CPA-X: Capacity building of others in support of vulnerable children & 35 & 28.2 \\
CPA-IV: Mitigation of impact of conflict & 23 & 18.5 \\
\hline
\end{tabular}

\subsubsection{Community efforts to address the circumstances of orphaned and vulnerable children}

\section{Family level}

According to the NSPPI, the nuclear and extended family should be the first line of response to the needs of vulnerable children, followed by members of the community. Respondents to interviews and FGDs had a number of expectations for the family.

There are also parents and guardians; they also have a role to play. They support in providing children's education, the scholastic materials and also they have to provide love, care and protection which is okay in ensuring that the child is stable in a home.

NGO staff, Eastern region

Many respondents were of the view that some households are abusive or negligent of vulnerable children. The NSPPI states that, "government officials and other actors with child protection responsibilities recognize that immediate threats to children's safety and wellbeing may also come from their families and communities.” For example, it was reported that the support provided to vulnerable children at the household level is not always given to them by the caregiver or is only partially given. Further, the support provided to households in terms of IGAs is often sold off by caregivers. It was also reported that many of the cases of physical and sexual abuse to the children are perpetrated by family members and rarely reported unless by the child itself. Some caregivers neglect to seek health care for vulnerable children or to access UPE.

One of the reasons cited for neglect in child forums and qualitative interviews is the fatalistic attitude that vulnerable children orphaned by AIDS must be infected with HIV and are going to die, so there is no reason to waste resources on them. Another reason is that some caregivers are elderly grandparents who neither have the energy nor the know-how to effectively access services. The third reason offered was that many caregivers and 
community members have developed a dependency syndrome which views vulnerable children as "belonging" to the NGO providing support.

The extended family is expected to send a helping hand to the household where the vulnerable child is hosted. Respondents reported that some relatives living and working in the cities and abroad do send remittances to the caregivers. For some households, respondents felt the remittances made a difference in that they improved the care provided to the vulnerable children as well as in the success of the IGAs given to the family. This point corroborates the view expressed by the socioeconomic study (Makerere Institute of Social Research 2008) that households that have successful IGAs are those with some level of other income that supports them while the IGA matures. The money sent is, however, often not adequate as it is sometimes intended to cover only education and not the other needs of the vulnerable children. Another reason the money is insufficient is that many times the people handling it take some for themselves. This includes people outside the recipient household who are sent as messengers to deliver the money as well as caregivers.

The extended family has been reported to also grab the property of deceased relatives thus leaving the orphaned children destitute. This is an abuse of a long running cultural practice in Africa where the siblings of the deceased are supposed to take over the property as well as care for the children of the deceased.

We hear from these women's groups that so-and-so has left a coffee plantation, but the relatives are the ones benefiting from it when children are suffering.

Head teacher, Central region

\section{Community level}

Regarding members of the community, according to respondents in the FGDs and interviews, many communities are involved in providing services to vulnerable children in different ways. In some instances the community is consulted in the design of programs for vulnerable children. Often they are involved in the initial identification of vulnerable children in need or in confirming their vulnerable status through committees for NGOs. In other places, the community assists the police with transport for community education about child protection and rights. It is still the community which is the first and main source of support for vulnerable children as the children remain with relatives or foster families.

Usually, it's the community which tells us of the children who should be helped; then after that we make our baseline survey....

$$
\text { NGO staff, Central region }
$$

[First, we] identify the problems and identify the children who need that kind of support. Then we also involve them [community members] in meeting on a monthly basis to give them reports of what has happened. We also have the local community persons who help us in monthly monitoring of activities and give us reports. And then we recognize those people in groups those who are caring for the children so all of them come in and have a say.

NGO staff, Northern region 
Community members are also actively involved in monitoring households receiving external support for vulnerable children to ensure that the support is used properly. Indeed, some communities are organized in groups that are linked to the programs of organizations providing external support and this enables these organizations to provide capacity building to the community to provide support to vulnerable children.

But for them [community] in their groups they meet weekly so some body in that group will stand up and try to talk on behalf of all of them. So as I talk now we have those groups, the care givers they care for the children so you find that they are actively involved, when they come together they understand as a group.

NGO staff Northern region

A number of respondents to IDIs and FGD referred to efforts by NGOs to ensure child participation in identification of beneficiaries, designing of interventions and monitoring service delivery.

Then there is also the child participation, the children participate themselves, they are involved in identification of needs, they also participate in planning and recruiting and also, monitoring so it's also one way we have innovated.

NGO staff, Eastern region

The interviews did not yield stories or experiences of community leaders providing their own direct support to particular households with vulnerable children. Further, respondents were in general disappointed that community members and community leaders are not usually able to identify and help vulnerable children in the community who may either not have a home or are in a home where they are being neglected or abused. Where such cases have been identified it has always been when the situation was desperate and the vulnerable children were taken to an NGO rather than helped by the community.

\section{The role of poverty}

A theme running across these deficiencies in the family and community support system for vulnerable children is poverty. Due to poverty caregivers, community members and community leaders fail to provide care to vulnerable children unless they receive external support and where external support is provided some of it is used by the caregivers to meet their own needs.

The community at times sells off what has been given to them. They don't also maintain the projects given to them. The challenge is poverty, when services are being offered to these OVCs, the LC-1 look at it as an opportunity for them to gain.

NGO staff, Western region

Throughout the country, poverty was reported to be a major challenge. Communities and extended families are often too poor to be able to help; everyone expects government and NGOs to look after vulnerable children and misappropriation of orphan property and misuse of external support is common. 
Communities have neglected these children so to make matters worse that is why you see most children on the streets. The households have limited capacity due to low levels of income because the majority is unemployed.

NGO staff, Central region

The stakeholders felt a culture of dependency has been created. They reported that many children are being "dumped" by struggling families and the traditional social network has been broken by HIV/AIDS which has killed many of the "bread-winners."

A culture of dependency has been created, so relatives stop visiting, taking responsibility or providing anything for OVC.

NGO staff, Eastern region

The community at times sells off what has been given to them. They also don't maintain the projects given to them.

NGO staff, Western region

In summary, the community in Uganda is reported to be playing a facilitator's role to ensure external support to households with vulnerable children but is neither playing a leadership role nor using its own resources to support its vulnerable children. And the main cause of this inability is widespread poverty.

\subsubsection{Successes and challenges (focusing on the USG funded partners)}

\section{Program outputs of USG funded partners supporting vulnerable children}

The purpose of this section is to show the contribution of USG funding toward care and support of vulnerable children in Uganda. The data shown in Table 16 was generated from PEPFAR output data for the six months in the semi-annual report of 2008. Table 16 shows 22 Prime Partners that received grants from PEPFAR to implement support activities for vulnerable children. Most of these Prime Partners in turn gave sub-awards to Implementing Partners that operated the service outlets. For example, Christian Aid has sub-granted three local NGOs to deliver its PEPFAR-supported vulnerable children program: AIDS Care, Education, and Training, Concerned Parents Association, and Youth With A Mission.

Table 16 shows that there were a total of 862 service outlets or implementing partners which delivered services to a total of 150,500 vulnerable children in the six month reporting period of this semi-annual report of 2008. It is clear that USG supported organizations are having a high output through many service outlets. However, it is notable that the current USG effort is reaching 150,500 vulnerable children which represent 11 percent of the estimated 1.4 million critically vulnerable children. Regarding comprehensiveness of services about 16 out of 22 Prime Partners (73 percent) support service delivery at their outlets for at least 5 CPAs. However, it should be noted that none of the Prime Partners is supporting services in all CPAs. Regarding geographical coverage the table shows that none of the organizations covers the entire 80 districts of Uganda, the largest number of districts covered by an organization is 33 by Joint Clinical Research Center. Also half of the prime partners support services for vulnerable children in at least four regions of the country (data not shown). 
Table 16 Summary of PEPFAR funded organizations providing support to vulnerable children

\begin{tabular}{|c|c|c|c|c|}
\hline $\begin{array}{l}\text { Name of PEPFAR } \\
\text { Prime Partner }\end{array}$ & $\begin{array}{l}\text { Number of } \\
\text { districts } \\
\text { served }\end{array}$ & $\begin{array}{l}\text { Number of } \\
\text { service } \\
\text { outlets }\end{array}$ & $\begin{array}{l}\text { Number of vulnerable } \\
\text { children in first } 6 \\
\text { months of } 2008\end{array}$ & $\begin{array}{l}\text { Number of } \\
\text { CPAs } \\
\text { provided }\end{array}$ \\
\hline AFRICARE & 1 & 93 & 10,534 & 7 \\
\hline AIDS Relief & 11 & 20 & 3,815 & 3 \\
\hline AVSI & 14 & 41 & 7,664 & 6 \\
\hline CHRISTIAN AID & 4 & 15 & 8,456 & 7 \\
\hline CORE & 4 & 91 & 6,783 & 9 \\
\hline Deloitte and Touche & 14 & 22 & 12,974 & 7 \\
\hline DoD-UPDF & 10 & 10 & 890 & 4 \\
\hline Inter-Religious Council of Uganda & 20 & 41 & 11,752 & 8 \\
\hline Joint Clinical Research Center & 33 & 51 & 7,616 & 3 \\
\hline Mildmay & 6 & 9 & 3,222 & 5 \\
\hline MJAP & 2 & 2 & 1,531 & 5 \\
\hline $\begin{array}{l}\text { Opportunity International } \\
\text { Uganda Agency for Economic } \\
\text { Development }\end{array}$ & 10 & 10 & 1,121 & 4 \\
\hline PEACE CORPS & 7 & 18 & 1,527 & 5 \\
\hline PIDC & 4 & 12 & 16,298 & 5 \\
\hline Plan International & 7 & 294 & 22,526 & 4 \\
\hline REACHOUT & 1 & 3 & 962 & 4 \\
\hline Salvation Army & 11 & 94 & 19,531 & 7 \\
\hline STATE-IMC & 1 & 15 & 798 & 2 \\
\hline STATE-IRC & 2 & 2 & 339 & 4 \\
\hline STATE-Small grants & 3 & 5 & 29 & 7 \\
\hline TASO & 11 & 11 & 11,794 & 9 \\
\hline Walter Reed Kayunga & 1 & 3 & 338 & 8 \\
\hline Total & & 862 & 150,500 & \\
\hline
\end{tabular}

Source: MEEPP Database

\section{Promising practices}

Selection of beneficiaries. Reaching the largest number of vulnerable children requires setting up a selection mechanism that is both objective and subjective. Caritas, Tigers Club, Uganda Youth Development Link, Uganda Red Cross, TASO and UWESO all said they were using the definition contained in the National OVC policy (MGLSD 2004a). However, a major challenge observed was that while it was simple to identify an orphan, it was difficult to identify who was vulnerable enough to deserve assistance with the limited available resources. Thus it is important to include a subjective element based on the realities of the given community as defined by the local stakeholders.

During the CORE Initiative workshop of August 2009, stakeholders stressed that for determining vulnerability, the best approaches are those that involve the community. A good example is Community Resilience and Dialogue (CRD), working through International Rescue Committee (IRC) in Karamoja which has established committees at the sub-county level and at schools to help identify children needing services. Plan International also uses 
school teachers and community leaders who, through observation and community visits, are able to identify children who are in real need of scholastic materials.

Community involvement and participation. The community was involved in the identification of beneficiaries especially through selection committees. The community was sometimes involved in the follow up of vulnerable children as well as monitoring the resources provided to households for the support of these children. Community involvement at these levels is thus an emerging promising practice. For example CRD/IRC not only established selection committees to identify and refer vulnerable children for services provided by IRC but also engaged the communities to follow-up with the children during the holiday periods. A further promising practice of involving the community is at the implementation of services.

Organizations are training family and community members to participate in service delivery. Mildmay reported training and involving family members especially on child adherence to antiretroviral treatment. However, as mentioned elsewhere in this report the degree to which communities are using their own resources to support vulnerable children is very low and in many cases non-existent. Thus the thinking around community involvement should aim further than its current success and work towards helping the community to identify its own resources and build capacity to provide support to vulnerable children.

Capacity building. Training community level actors such as CSO staff, community leaders, family and community members and other cadres such as teachers is important in building the capacity of communities to effectively respond to the needs of vulnerable children. It is a promising practice that contributes to sustainability by ensuring that something remains behind after PEPFAR funding ceases. The vast majority of PEPFAR funded organizations reported providing some kind of training to implementers of support services for vulnerable children. The topics covered varied. Africare/COPE reported training CSO staffs in care and support, programming, managerial and reporting skills as well as monitoring and evaluation. Association of Volunteers in International Service (AVSI) provided training on business management to community members and provided them with capital funding to start businesses. Other organizations reported training household members in psychosocial care and child rights while others reported training community leaders and staffs of CSOs on psychosocial support, child protection, supporting IGAs, facilitation of savings and loans projects and life skills facilitation.

CORE initiative reported providing capacity building through CBO networks and TSOs and in order to evaluate the impact of these capacity building efforts the CORE Initiative carries out baseline and post-intervention assessments of capacity of CSO receiving this capacity building. Indeed some organizations were able to report some outcomes from their capacity building interventions. Plan International trained teachers and religious leaders in care and support of OVC and reported that, as a result, these trained personnel were visiting homes that have vulnerable children and providing this support and are also helping to fight HIVrelated stigma in the community. TASO carried out child/guardian workshops and reported that they were useful in enabling the guardian and the vulnerable child to sort out issues between them and live in harmony. TASO has also trained teachers in child counseling and this has resulted in improved communication between teachers and vulnerable children. Further, TASO carried out workshops on will-writing and memory book writing which enabled parents living with HIV to discuss with their children plans for after the parent dies. 
TASO and the State Department through the International Medical Corps both reported that the training they provided to family members of vulnerable children on farming techniques and livelihoods combined with agricultural inputs resulted in increased food and income for the households. This evidence suggests that capacity building is effective and it can contribute to sustainability at least by empowering the community with skills to respond to the needs of vulnerable children.

Sustainability efforts. Sustainability refers to the extent to which organizations are making attempts to ensure care for vulnerable children beyond the life of the current projects. Since these organizations are funded by PEPFAR, for a limited time, it is prudent that efforts are being undertaken at sustainability. As mentioned above, capacity building of local CSOs and community members is one way to contribute to sustainability. Another way is to widen the donor base. Some organizations such as Africare, Plan International, AIDS Relief, Pediatrics Infectious Disease Clinic, Mildmay and Christian Aid were diversifying their donor sources by seeking non-USG funding. Uganda Program for Human and Holistic Development reported that the CSOs it was supporting carried out local fundraising drives to support their work on vulnerable children. TASO was receiving bursaries from schools to support the education of some of the vulnerable children it was supporting and also carrying out local fundraisings, at some TASO Centers, which have supported the education of 309 vulnerable children.

Some efforts were beginning to show outcomes. For example Plan International began indentifying dominant religious groups in the community it works in and has handed over to them some of the leadership in activities to support vulnerable children. Plan International was beginning to notice increased commitment of time and effort by these groups into these activities.

Comprehensiveness of services. The different needs of a vulnerable child are interlinked. For this reason the MGLSD has defined the 10 CPAs that encompass the comprehensive approach to programming for vulnerable children. For a given vulnerable child addressing one CPA, such as nutrition, can affect the effectiveness of another CPA, such as education. For this reason a comprehensive package in service delivery to vulnerable children should include as many of the 10 CPAs as possible. Many of the PEPFAR supported organizations have tried to provide as many of the CPAs as possible but, as Table 16 shows, none is able to do so.

However, a promising practice observed among the organizations was that where one supports vulnerable children in a particular program area they tended to provide the service comprehensively. For example those providing health care (Joint Clinical Research Centre, TASO, Mildmay, Makerere and Mbarara Universities Joint AIDS Program, PIDC and Reachout) did provide a whole range including HIV testing and counseling, HIV palliative care, antiretroviral treatment and child immunizations. In addition they added other related clinic-based services such as psychotherapy and nutritional support, especially the ready-touse foods, as well as hosting of child-clubs or youth clubs. They also distributed safe water vessels and mosquito nets. Further, they also tended to provide care for the mother of the child at the same clinic visit. 
This holistic approach has a tremendous advantage in that it makes it easier for the parent or guardian of the vulnerable child to make one journey to obtain a variety of services and hence improves the health care seeking for the vulnerable child as well as adherence to follow-up. Often these organizations add a component of community follow-up, home visits, as well as school visits, which further enhance outcomes for the vulnerable child. The health care organizations also try to provide additional services such as education support or food supply and where these are not provided by the health care organization firm referral links exist with the relevant organizations that provide these services such as the World Food Programme (WFP) for food.

Similarly, holistic approach models are emerging for organizations providing education support which also tend to be comprehensive in ensuring that the vulnerable child receives all she needs to stay in school. These include the provision of the usual educational support such as school fees, scholastic materials, school uniforms and goes beyond to include mattresses and feeding as well as helping households to grow food. It is however, widely recognized that no single organization can provide comprehensive services for vulnerable children. For this reason partnership, networking, linkages and referrals comprise a strategy that is reported by many organizations.

Collaboration, networking linkages and partnerships. Almost all PEPFAR-supported prime partners providing services for vulnerable children reported sharing of information with similar organizations and having a two-way referral of vulnerable children for services available at other organizations but not available at the organization that is providing the main support to the vulnerable child. Almost all organizations reviewed acknowledged the fact that none of them could provide all the services needed by a vulnerable child. The following words in the AFRICARE report serve to illustrate this point: "Given the current budget levels, the project will find it difficult to provide more than three services to OVC already identified.”

The reports show that networking involves not only referrals but regular meetings and often involves a coordination element when it is linked to meetings with government or LC officials. Some prime partner organizations, such as Africare and AVSI reported that the partnerships also involve a sub-grantee relationship where the prime partners ensure that the CSOs they are supporting network with each other. In some districts, such as Gulu and Bushenyi, the networking has evolved into a formal NGO coordination committee in which local government participates. Indeed, according to the Christian Aid report, networking was considered a vital element of their support for vulnerable children in conflict-affected areas where it was crucial to ensure that the services were well targeted and not duplicated.

Data from interviews in the Situation Analysis revealed innovative examples of strategic partnerships. For example in Lira, Child Protection Networks were developed that included: police, CSOs, probation officers and army personnel since this involved protecting children from abduction as child soldiers. AVSI reported a strategic partnership which involved not only working out local referral linkages but seeking out international partners to fill gaps that were lacking among the partners present on the ground. 
During the CORE Initiative workshop in August 09 in Kampala, partnership was a major topic of discussion. It was reported that in Gulu the partnerships are said to be working because the elected District leadership takes keen interest in the issues of vulnerable children. It was also reported that due to the successful partnership in Mubende the number of known service providers in the district increased from 20 in 2007 to over 120 to date, and there was an increase from 4 percent to over 20 percent of vulnerable children accessing services through the county and sub-county coalition of service providers.

Ideally such networking and partnerships should allow partners to detect gaps in geographical or program area coverage and do appropriate reallocation of resources to ensure a more comprehensive coverage. In the reports reviewed such an outcome was not reported. It is probable that the sheer lack of resources does not allow increased coverage. Another possible reason is the lack of concrete knowledge of the number of vulnerable children in a given district and what proportion was being reached.

These experiences suggest that partnerships and linkages work if they are strategic and have brought in all interested and resourceful people or agencies. Also, the presentation of good up-to-date monitoring and evaluation data in partnership meetings can help motivate partners, avoid duplication, identify gaps and encourage more data collection. It is also important that these partnerships are led by an agency or person interested in ensuring coordination and one who has a mandate such as a prominent NGO, an elected leader, or a governmental officer responsible for vulnerable children.

Coordination. Coordination refers to the practice of monitoring activities and sharing information among implementers and government to ensure that services for vulnerable child in a given geographical setting, such as a district, are delivered in ways that limit overlaps and gaps. PEPPAR funded organizations have demonstrated a promising practice especially through the CORE Initiative and the Technical Services Organizations (TSO) collaborating with the MGLSD and local government to coordinate the providers of support to vulnerable children. A number of PEPFAR supported organizations have reported they have participated in this coordination by attending monthly meetings at the districts and that they are ensuring that their activities are coordinated through the probation and social welfare officers. These organizations, which include UPHOLD, Reachout, State-IRC and State-IMC, have also reported holding regular coordination meetings with LC officials at lower levels. This is an emerging model of government and civil society partnering which can have advantages in terms of targeting resources and monitoring their use and should be encouraged. This model would work even better if the probation and welfare officers, who are the MGLSD staff in the field, are facilitated with transport and a budget to take lead in this effort. As reported in the earlier sections of this report, the inadequate personnel and resources of the MGLSD at the district are a major hindrance to effective coordination. But also as noted previously the whole area of coordination, collaboration and networking is greatly enhanced by the availability and sharing of high quality timely service delivery data.

Monitoring and evaluation. Monitoring and reporting of number of vulnerable children served by PEPFAR-funded organizations has been very well achieved through the MEEPP project. Table 16 shows the number of vulnerable children served in the reporting period by each of the 22 prime partners supporting services to vulnerable children. Each of the 
organizations has a good data collection component and they use this data to monitor the achievement of their set targets for the reporting period. The data collected is disaggregated to the sub-county level and by gender. This success in monitoring would have had a bigger impact on program planning if estimates were available of the total populations of vulnerable children in each district and sub-county. A good example is in Ntungamo where the MGLSD estimated the number of vulnerable children for Ntungamo district as at end of 2007 to be 102,679 COPE-AFRICARE had served 20,123 from April 2005 to March 31, 2008 which is 20 percent of the target population. And for a few other organizations such as Christian Aid and CRD/IRC the reports showed that they have data on the overall population of vulnerable children in the sub-counties they work in and as such are able to monitor what proportion they are reaching. However, for the majority of organizations their reports did not have any data on the general population of vulnerable children in the communities they are working in.

Service delivery organizations should also be able to demonstrate their effectiveness in terms of tangible measurable impacts on the targeted children. For example nutrition support should result in improved nutritional status as measured by mid-upper arm circumference of the targeted children. Education support should result in completion of school and obtaining of a degree or diploma. And socioeconomic support should result in the household moving to a higher wealth quintile. To be accurate, these measurements should be made in well designed household surveys such as the DHS. None of the organizations reviewed during this study could provide such outcome data from their services.

The discussion of effectiveness is incomplete without an element of quality of services being examined. Unfortunately, the scope of this study did not allow a systematic assessment of quality of services. However, a quality assessment was carried out by TSOs in 2007 as part of the mapping exercise and it was reported that the quality of services was generally poor with more than half of the organizations not meeting the quality of service as set by the MGLSD. Thus, the promising practices highlighted in this report do not necessarily imply high quality services.

\section{What are the challenges to the efforts to provide support to vulnerable children in Uganda by USG and other partners?}

This section discusses challenges to the provision of support to vulnerable children by all partners including GOU, USG, CSOs and other partners. The underlying factor behind these challenges is the sad reality of the sheer inadequacy of resources. As mentioned before, there is limited coverage of vulnerable children, including the critically vulnerable. Further, even for the vulnerable children who are reached not all the CPAs are provided. And because of the desire to reach as many vulnerable children with a given service, resources tend to be spread thin and quality may be compromised.

Throughout the interviews it was apparent that the very entity that is supposed to protect the vulnerable children, the household, can become a serious source of abuse of children and misuse donated resources or inherited properties of the children. These issues are supposed to be addressed by two CPAs, Child Protection and Legal Aid, yet these are the CPAs currently receiving the least attention. 
Another major threat to addressing child abuse cases is the lack of accommodation for victims of abuse after they have reported the case to police but before the matter has been resolved. They cannot return to the homes where they have been abused, yet the police have no accommodations except for juvenile offenders, which is where these victims are being sent at the moment.

Ensuring that high quality services are delivered in a coordinated manner that meets national standards remains a challenge. An assessment of capacity carried out by COPE in Ntungamo identified three major weaknesses at the community level: poor coordination, lack of monitoring and evaluation, and poor knowledge of national guidelines and standards. Similar issues were raised throughout interviews conducted during this situation analysis.

Another weakness is the lack of careful planning and good management skills for IGAs. It appears logical that empowering households though IGAs is the long term sustainable solution to poverty which is a major cause of child vulnerability. However, the report on SES by CORE and MGLSD (Makerere Institute of Social Research 2008) clearly shows that there are some households which are too poor to be helped by IGAs but rather would need initial cash transfers as an emergency measure. Indeed, those households in need of urgent cash transfers have ended up either selling the investment (e.g., seeds or piglets) to meet their immediate needs rather than supporting the investment to grow.

It is also reported that some of the agricultural and animal husbandry projects failed because of lack of technical knowledge, among household members. It is therefore important to include more intensive technical support in agriculture and animal husbandry through regular supervision by technical experts. Several organizations are reporting training in business skills prior to issuance of IGAs but it is not clear whether the training is based on a needs assessment. However, World Vision did report conducting assessments of community resources and challenges to socioeconomic progress as a first step to selecting communities for their services. After completing an assessment, World Vision staff plan and design programs to address community needs.

\subsubsection{Cost of delivering comprehensive care and support for vulnerable children}

The three NGOs selected for the cost analysis, UWESO, TASO and World Vision Uganda (WVU), cover 9 out of 10 of the CPAs identified in the NSPPI. Legal support is one CPA that none of the three NGOs covered and thus the analysis was unable to estimate the costs of providing such services to vulnerable children. When beneficiaries required legal support, these NGOs referred them to the public legal and social assistance systems (e.g., district probation and social welfare officers, child and family protection units) and the law enforcement agencies. Table 17 provides a brief overview of these organizations, including their coverage, service delivery approach, organizational background, and major sources of funds.

\section{Presentation of estimated costs}

The analysis shows the estimated costs by key interventions and by resource type (i.e., personnel, materials and services, equipment and furniture, building and land, transportation, 
utilities, and other administrative costs). For the key interventions implemented by each organization under the various CPAs, the total costs as well as the unit (i.e., per beneficiary) costs were estimated. However, for certain interventions, such as advocacy activities, these services are not directly delivered to vulnerable children or to households and do not support a specific group of beneficiaries and thus were excluded from the per unit cost estimates.

Table 17 Summary of the three selected vulnerable children programs

\begin{tabular}{|c|c|c|c|}
\hline & UWESO & TASO & World Vision Uganda \\
\hline $\begin{array}{l}\text { Number of } \\
\text { beneficiaries }\end{array}$ & $\begin{array}{l}\text { Served } 2,900 \text { vulnerable } \\
\text { children directly and more } \\
\text { than } 13,000 \text { households } \\
\text { in } 2008\end{array}$ & $\begin{array}{l}\text { Served } 30,000 \text { vulnerable } \\
\text { children directly and 9,300 } \\
\text { households in } 2008\end{array}$ & $\begin{array}{l}\text { More than } 124,000 \text { child } \\
\text { beneficiaries in } 2008^{(1)}\end{array}$ \\
\hline $\begin{array}{l}\text { Number of core } \\
\text { program areas } \\
\text { served }\end{array}$ & 5 & 7 & 8 \\
\hline $\begin{array}{l}\text { Service delivery } \\
\text { approach }\end{array}$ & Family-targeted approach & Clinic-based approach & $\begin{array}{l}\text { Community-based } \\
\text { approach }\end{array}$ \\
\hline $\begin{array}{l}\text { Geographic } \\
\text { coverage }\end{array}$ & $\begin{array}{l}\text { Served } 25 \text { of the country's } \\
80 \text { districts in } 2008\end{array}$ & $\begin{array}{l}\text { Present in all four } \\
\text { administrative regions }^{(2)}\end{array}$ & $\begin{array}{l}\text { Operated in } 40 \text { of the } \\
\text { country's } 80 \text { districts in } \\
2008\end{array}$ \\
\hline Type of organization & $\begin{array}{l}\text { Local NGO, some USG } \\
\text { funding }\end{array}$ & $\begin{array}{l}\text { Local NGO, some USG } \\
\text { funding }\end{array}$ & $\begin{array}{l}\text { International NGO, mostly } \\
\text { non-USG funding }\end{array}$ \\
\hline $\begin{array}{l}\text { Major sources of } \\
\text { funds }^{(3)}\end{array}$ & $\begin{array}{l}\text { USAID, IFAD, DANIDA, } \\
\text { FAO, UNDP, individual } \\
\text { donors }\end{array}$ & $\begin{array}{l}\text { USAID, Civil Society Fund, } \\
\text { and SIDA, DANIDA, DFID, } \\
\text { and Irish Aid }\end{array}$ & $\begin{array}{l}\text { World Vision sister } \\
\text { organizations in developed } \\
\text { countries }\end{array}$ \\
\hline \multicolumn{4}{|c|}{$\begin{array}{l}\text { Note: } \\
\text { 1. Number of beneficiaries reported in WVU's } 2008 \text { Annual Report. } \\
\text { 2. The majority of TASO services are clinic-based. Since the catchment area for a TASO clinic can spread over multiple } \\
\text { districts, we do not specify the number of districts TASO served here. } \\
\text { 3. USG = United States Government, NGO = Nongovernment organization, IFAD = International Fund for Agricultural } \\
\text { Development, DANIDA = Danish International Development Agency, FAO = Food and Agricultural Organization, UNDP = } \\
\text { United Nations Development Program, SIDA = Swedish International Development Agency, and DFID = UK Department for } \\
\text { International Development. }\end{array}$} \\
\hline
\end{tabular}

\section{Uganda women's effort to save orphaned children}

UWESO was founded in 1986 to provide relief aid to needy children left parentless by AIDS and violence in the country's northern region. Over the years UWESO shifted its focus from relief services to delivering services to improve the wellbeing of vulnerable children. The organization partners with the government, donor agencies, civil society organizations, and the communities where they operate.

UWESO provides services to beneficiaries by targeting households with vulnerable children. While interventions in the education area and some health related services target vulnerable children directly, all other services are provided at the household-level. UWESO also supported the implementation of the UPE policy nationwide. In 2008, UWESO directly served more than 13,000 households and 2,900 vulnerable children directly. The age of children supported by the organization range from 1 year to 18 years old. 
Community-based trainers (CBTs) work with local authorities, community leaders, and civil society organizations to identify the households and vulnerable children that need support. The CBTs then divide the selected households into clusters, each of which consists of approximately 30 households. One CBT typically coordinates services for one cluster. Services are delivered either to a group of beneficiaries or at the beneficiaries' home.

In 2008, UWESO served 25 of the country's 80 districts. Staff at the national and six regional offices managed operations in the districts. Each regional office is staffed with a regional manager, project officers, a project accountant, community based trainers, and other support staff. CBTs, who are volunteers receiving allowances and transportation support from UWESO, deliver most direct services. Based on the feedback from the executive committees and program staff, the regional offices manage resources for effective delivery of services.

UWESO provided six CPAs to vulnerable children in 2008, but not all of the six to each beneficiary or household. Socioeconomic security is provided as financial services through Village Savings and Loan Associations. Food security is addressed through farmer field schools and seed distribution, kitchen gardens, food processing and preservation, use of energysaving stoves, and distribution of goats and 'payback' ${ }^{4}$. Educational support is provided as school fee sponsorship, monitoring of UPE, vocational training and through the Masulita Children's Village. Health activities include water and sanitation including pit latrine construction, and growth monitoring of children under age five. UWESO also conducts psychosocial training and support and advocacy against child abuse.

In 2008 UWESO's total expenditure on these activities was \$1.1 million with the highest proportion (47 percent) being spent on education, followed by 27 percent on food and security (Table 18). The estimated costs of strengthening capacity do not include UWESO's role of providing technical assistance to local NGOs on planning and implementing programs for vulnerable children. Since capacity strengthening services do not directly target a specific group of beneficiaries, a unit cost for these services was not calculated.

Table 18 Total costs of vulnerable children services at UWESO by core program areas

\begin{tabular}{lccc}
\hline Core program area & $\begin{array}{c}\text { Total cost } \\
\text { (Ush) }\end{array}$ & $\begin{array}{c}\text { Total cost } \\
\text { (US \$) }\end{array}$ & $\begin{array}{c}\text { Share of total } \\
\text { cost (\%) }\end{array}$ \\
\hline Socioeconomic security & $399,202,451$ & $\$ 232,040$ & 21 \\
Food security and nutrition & $541,687,060$ & $\$ 314,861$ & 29 \\
Education & $882,611,907$ & $\$ 513,027$ & 47 \\
Health & $67,672,155$ & $\$ 39,335$ & 4 \\
Strengthening capacity \& resource mobilization & $5,682,406$ & $\$ 3,303$ & 0.3 \\
Grand total & $1,896,855,979$ & $\$ 1,102,567$ & 100 \\
\hline
\end{tabular}

Note: $\quad 1$ US $\$=1720.4$ USh (Bank of Uganda 2009)

\footnotetext{
${ }^{4}$ When one person is given a goat, once it delivers a baby the person "pays back" to the system by giving the baby goat to the next person in the queue waiting to benefit.
} 
The largest number of beneficiaries was reached by the socioeconomic security program with 5,959 households, followed by the farmer school fields and seed distribution reaching 4,500 households (Table 19). The Children’s Village only supports 27 children.

The following tables break these costs down per household (Table 19) or per vulnerable child supported (Table 20) and illustrate that the highest per capita costs were for the Children's Village (\$1,418 per child) and artisan training (\$1,311 per child) compared to growth monitoring at \$2 per child and goat distribution at \$4 per household. The activities reaching the most beneficiaries cost \$39 and \$37 per household, respectively. At an average household size of 5.3 (in this survey) this computes to a cost of only $\$ 7.8$ and $\$ 7.4$ per person, respectively.

Table 19 Cost per household for certain CPAs

\begin{tabular}{|c|c|c|c|}
\hline Core program area & $\begin{array}{l}\text { Total cost } \\
\text { (US \$) }\end{array}$ & $\begin{array}{l}\text { Number of } \\
\text { beneficiary } \\
\text { households }\end{array}$ & $\begin{array}{l}\text { Cost per } \\
\text { household } \\
\text { (US \$) }\end{array}$ \\
\hline \multicolumn{4}{|l|}{ Socio-economic security } \\
\hline Financial services through VSLA & $\$ 232,040$ & 5,959 & $\$ 39$ \\
\hline \multicolumn{4}{|l|}{ Food security and nutrition } \\
\hline Farmer field schools and seed distribution & $\$ 167,231$ & 4,500 & $\$ 37$ \\
\hline $\begin{array}{l}\text { Kitchen garden, food processing and preservation, and } \\
\text { use of energy saving stoves }\end{array}$ & $\$ 125,914$ & 1,606 & $\$ 78$ \\
\hline Goat distribution and payback & $\$ 21,716$ & 574 & $\$ 38$ \\
\hline \multicolumn{4}{|l|}{ Health } \\
\hline Water \& sanitation & $\$ 18,895$ & 20 & $\$ 945$ \\
\hline Pit latrine construction & $\$ 12,503$ & 640 & $\$ 20$ \\
\hline Psychosocial training and support & $\$ 2,903$ & 300 & $\$ 10$ \\
\hline
\end{tabular}

Table 20 Cost per vulnerable child for certain CPAs

\begin{tabular}{lrrr}
\hline Core program area & $\begin{array}{c}\text { Total cost } \\
\text { (US \$) }\end{array}$ & $\begin{array}{c}\text { Number of } \\
\text { beneficiary } \\
\text { children }\end{array}$ & $\begin{array}{c}\text { Cost per child } \\
\text { (US\$) }\end{array}$ \\
\hline Education & & & \\
$\quad$ Primary education sponsorship & $\$ 7,840$ & 14 & $\$ 560$ \\
$\quad$ Secondary education \& vocational training & $\$ 158,338$ & 323 & $\$ 490$ \\
$\quad$ Masulita Children's Village & $\$ 37,997$ & 27 & $\$ 1,407$ \\
$\quad$ Artisan training & $\$ 155,039$ & 400 & $\$ 388$ \\
Health & & & $\$ 2,134$ \\
$\quad$ Growth monitoring for children under 5 & $\$ 5,035$ & 2,30 \\
\hline
\end{tabular}

\section{Supporting Universal Primary Education requires substantial amount of resources}

UWESO coordinated efforts by students, parents, teachers, and other community members to support the implementation of the UPE policy. The total cost of the intervention was $\$ 153,813$ in 2008. UWESO suggested that it would be most appropriate to estimate the unit cost of this intervention per school, instead of per child. The intervention supported 48 
schools at an average cost of \$3,204 per school. About 2,500 students enrolled in these schools benefited from the services. Since this was a school level intervention, it was not targeted only for vulnerable children, and instead helped all students who were enrolled in these schools.

\section{Costs of services for vulnerable children by resource type}

When looking at how these amounts were spent overall, the largest share of expenses was personnel at 46 percent followed by materials and services at 23 percent (Figure 7). Materials and services provided to the beneficiaries take the largest share of costs: advocacy (63 percent), training and demonstration on pit latrine construction (62 percent), psychosocial support (62 percent), goat distribution and payback (59 percent), and secondary education and vocational training (57 percent).

Figure 7 UWESO share of expenditure 2008

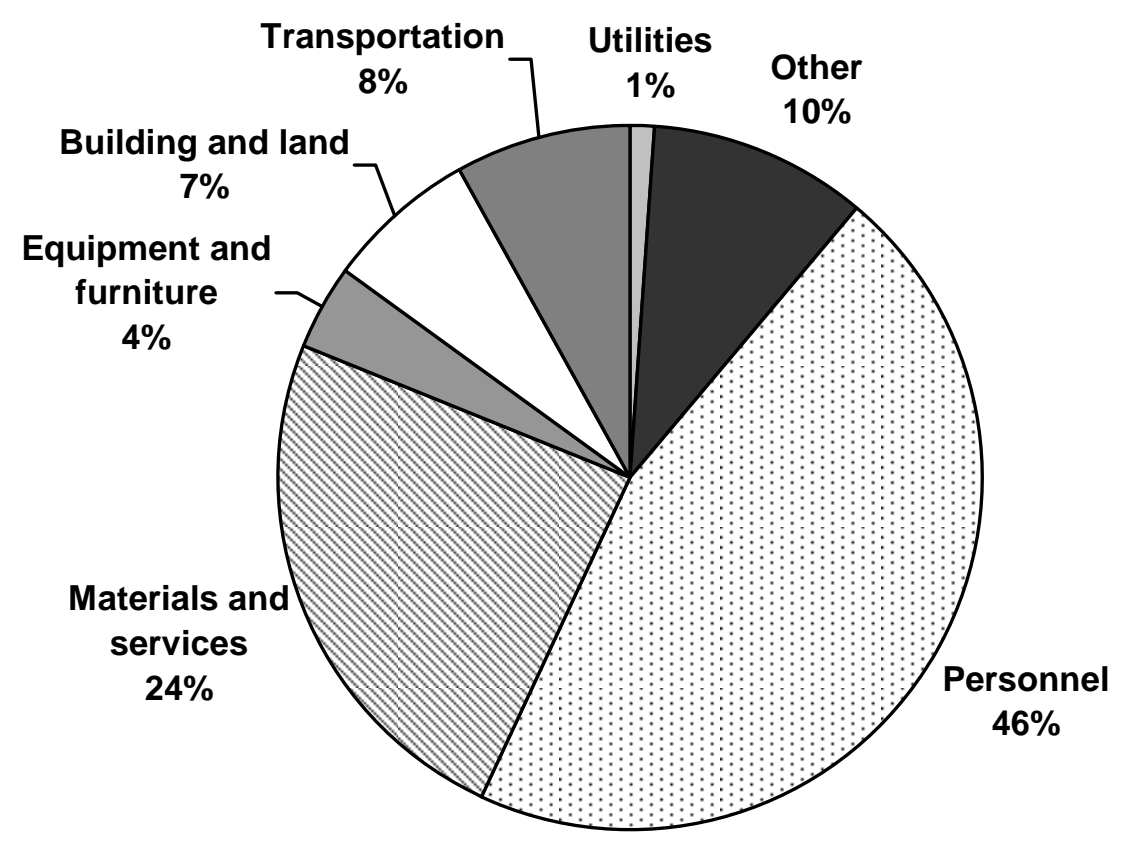

\section{The AIDS Support Organization (TASO)}

TASO was established in 1987 to provide counseling, treatment and social support to people living with and affected by HIV/AIDS in Uganda. The organization serves children of its adult beneficiaries as well as HIV-positive children who registered for services. The organization partners with the government, local and international donors, civil society organizations, and the communities it serves.

TASO's service delivery model is organized around a clinic-based facility. TASO staff deliver services at a clinic, called a "TASO Center," as well as in the community. Individuals who needed services registered voluntarily at a TASO Center. In addition, center level staff identified beneficiaries through outreach efforts. All adults and children registered at a TASO 
Center received health-related services consisting of medical care, antiretroviral therapy (ART), and HIV counseling on an as needed basis. In addition, children of adult beneficiaries received other services, including socioeconomic, nutritional, educational and psychosocial support. TASO staff delivered the health-related services at the center, and some of the other services at the household or the community level.

In 2008, TASO served about 30,000 vulnerable children directly and an additional 9,300 households. TASO staff delivered services through 11 Centers or operational branches. The Centers are located in public health facilities, and each Center had a catchment radius of 75 kilometers. Out of a total of 1,030 Center-level staff at TASO in 2008, 685 were involved in services for vulnerable children. Center-level staff involved in vulnerable children related services included project officers, medical officers, counseling coordinators, counselors, clinicians, pharmacists, nurses, laboratory technicians, field officers, and other support staff.

TASO provided six CPAs to vulnerable children in 2008. These included socioeconomic support through vocational training and apprenticeship, food security through agricultural production and nutrition, education through fee sponsorship and life skills training. TASO also provides psychosocial support through youth clubs and a child care center, health including medical care, antiretroviral therapy and HIV counseling and strengthens capacity through advocacy.

The estimated costs of services for vulnerable children at TASO should be interpreted in the context that these services were delivered as a package of comprehensive services delivered to adults and children, possibly leading to some efficiency gains in the delivery-cost for these services. Therefore, the estimated costs are likely to be lower than the costs of delivering each type of service by itself.

In 2008 TASO's total expenditure for these activities was \$3.4 million with the largest amount being spent on the health program which took 39 percent of the budget (Table 21). This was followed by education which accounted for 23 percent of the total costs.

Table 21 Total costs of vulnerable children services at TASO by core program areas

\begin{tabular}{lrrr}
\hline Core program area & $\begin{array}{c}\text { Total cost } \\
\text { (USh) }\end{array}$ & $\begin{array}{c}\text { Total cost } \\
\text { (US \$) }\end{array}$ & $\begin{array}{c}\text { Share of total } \\
\text { cost (\%) }\end{array}$ \\
\hline Socio-economic security & $533,202,803$ & $\$ 309,930$ & 9 \\
Food security and nutrition & $119,563,782$ & $\$ 69,498$ & 2 \\
Mitigation of impact of conflict & $64,616,108$ & $\$ 37,559$ & 1 \\
Education & $1,315,201,603$ & $\$ 764,474$ & 23 \\
Psychosocial support & $843,487,132$ & $\$ 490,285$ & 14 \\
Health & $2,291,230,344$ & $\$ 1,331,801$ & 39 \\
Strengthening capacity \& resource mobilization & $657,822,922$ & $\$ 382,366$ & 11 \\
Grand total & $5,825,124,693$ & $\$ 3,385,913$ & 100 \\
\hline
\end{tabular}

Note: $\quad 1$ US\$ $=1720.4$ USh (Bank of Uganda 2009) 
In 2008 TASO reached the most beneficiaries through its nutritional support program which reached 8,334 households possible with an average of 5 members each computing to 41,670 beneficiaries. The following tables break the total costs down per household or per child with the highest cost being the vocational training at $\$ 1,351$ per child and the lowest cost being the nutritional support at $\$ 4$ per household. The latter were purely distribution costs for food from the World Food Program and other organizations.

Table 22 TASO costs per household in 2008

\begin{tabular}{lcrr}
\hline Core program area & $\begin{array}{c}\text { Total cost } \\
\text { (US \$) }\end{array}$ & $\begin{array}{c}\text { Number of } \\
\text { beneficiary } \\
\text { households }\end{array}$ & $\begin{array}{c}\text { Cost per } \\
\text { household } \\
\text { (US \$) }\end{array}$ \\
\hline Food security and nutrition & & & \\
$\quad$ Sustainable livelihood (agricultural production) & $\$ 34,749$ & 1,000 & $\$ 35$ \\
$\quad$ Nutritional support & $\$ 34,749$ & 8,334 & $\$ 4$ \\
\hline
\end{tabular}

Table 23 TASO costs per vulnerable child in 2008

\begin{tabular}{|c|c|c|c|}
\hline Core program area & $\begin{array}{l}\text { Total cost } \\
\text { (US \$) }\end{array}$ & $\begin{array}{c}\text { Number of } \\
\text { beneficiary } \\
\text { children }\end{array}$ & $\begin{array}{c}\text { Cost per } \\
\text { child } \\
\text { (US\$) }\end{array}$ \\
\hline \multicolumn{4}{|l|}{ Socio-economic security } \\
\hline Vocational training and apprenticeship & $\$ 309,930$ & 221 & $\$ 1,402$ \\
\hline \multicolumn{4}{|l|}{ Mitigation of impact of conflict } \\
\hline Vocational training in Northern Uganda & $\$ 37,559$ & $\mathrm{n} / \mathrm{a}$ & $\mathrm{n} / \mathrm{a}$ \\
\hline \multicolumn{4}{|l|}{ Education } \\
\hline Basic education & $\$ 535,132$ & 3,015 & $\$ 177$ \\
\hline Life skills training & $\$ 229,342$ & 3,015 & $\$ 76$ \\
\hline \multicolumn{4}{|l|}{ Psychosocial support } \\
\hline Youth clubs & $\$ 208,493$ & 4,488 & $\$ 46$ \\
\hline Child care center & $\$ 97,174$ & 5,648 & $\$ 17$ \\
\hline HIVIAIDS counseling & $\$ 184,618$ & 5,259 & $\$ 35$ \\
\hline \multicolumn{4}{|l|}{ Health } \\
\hline Medical care & $\$ 460,708$ & 11,228 & $\$ 41$ \\
\hline ART & $\$ 871,093$ & 1,242 & $\$ 701$ \\
\hline \multicolumn{4}{|c|}{ Strengthening capacity and resource mobilization } \\
\hline Advocacy & $\$ 382,366$ & - & - \\
\hline
\end{tabular}

Note: n/a = not available; "-" = not applicable

\section{Costs of services for vulnerable children by resource type}

When looking at the total expenditure for 2008, TASO spent the largest proportion on personnel (57 percent) followed by materials and services (36 percent, Figure 8 ). The relative share of personnel cost is particularly high for HIV counseling (72 percent) and medical care (54 percent). This may be driven by the need for high skilled staff to deliver services at a clinic-based facility. 
Figure 8 TASO share of expenditure 2008

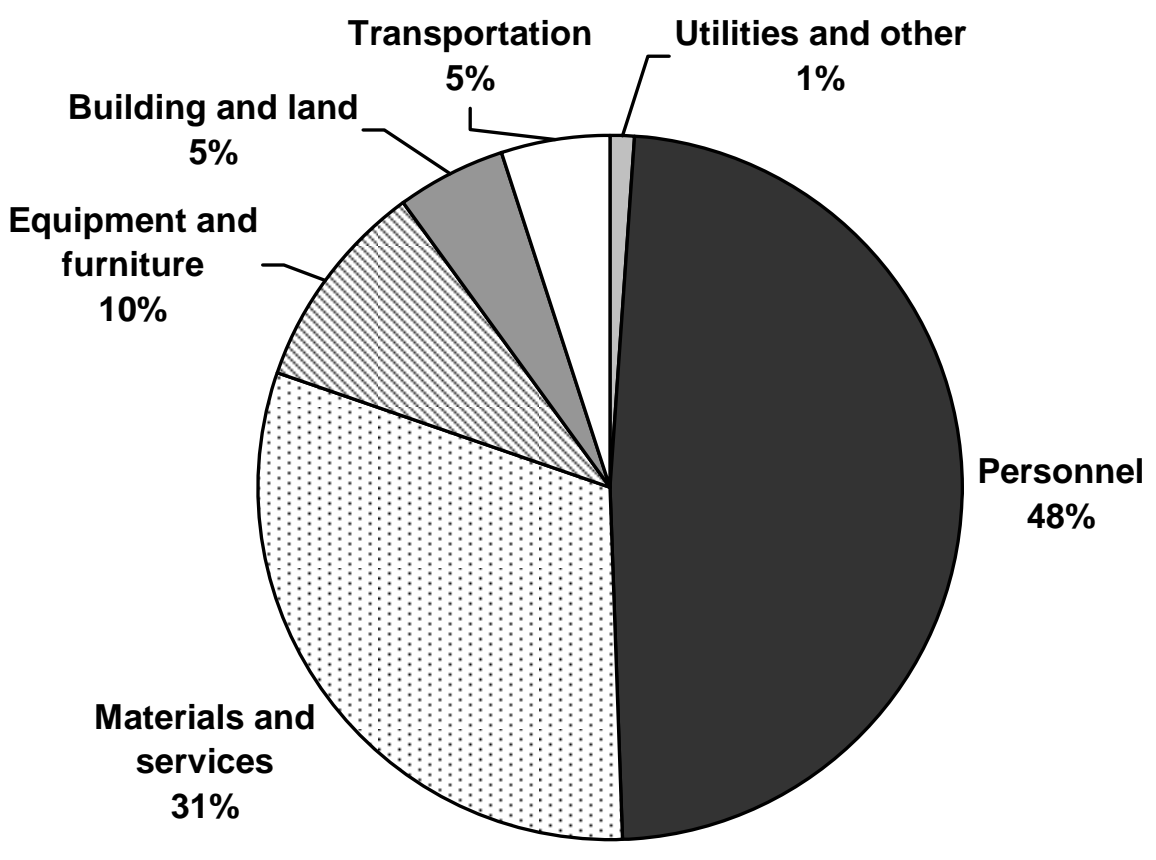

\section{World Vision Uganda}

WVU is the Uganda chapter of World Vision International, a Christian relief, development, and advocacy organization. WVU started its operations in 1986 to provide humanitarian assistance in central Uganda. Since then WVU expanded its programs to support people affected by the HIV pandemic. WVU also assists persons affected by the conflict in northern Uganda and impoverished people in western Uganda.

WVU delivers services to its beneficiaries using a community development approach. The organization focuses on selecting needy communities and then works to mobilize communities to advocate for child rights and HIV prevention, to improve agricultural practices, and to build peace and foster tolerance. WVU worked with communities to build educational infrastructure, increase capacity of local NGOs, and mobilize resources. The organization delivers services such as microfinance services, food and nutrition support, health care, and water and sanitation services, to families in the selected communities. WVU also provides services directly to vulnerable children, including provision of school fees and supplies, but most of its remaining interventions are centered on communities and families. In 2008, WVU served more than 124,000 children in communities across Uganda (WVU 2008).

In 2008, WVU worked in 40 of the country's 80 districts. Its operations were managed by a national office and five regional offices. Each region is divided into several clusters, and each cluster into multiple area development program (ADP) offices. There were a total of 17 clusters and 53 ADPs operating in 2008. A program manager at the cluster office oversaw operations at the ADP offices. Each ADP office covered one or two sub-counties, and approximately 50,000 people. 
Staff at the cluster level identified communities that would receive support from WVU. Once a target community was identified, community development facilitators worked with the leaders and members of the community to select the vulnerable and needy families to receive WVU services. WVU also collaborates with local CSOs to deliver services. In 2008, it partnered with about 300 local CSOs to deliver services to the community in which they were based.

Unlike most of the NGOs operating in Uganda, WVU receives most of its funding from World Vision sister organizations in developed countries, such as World Vision USA, Canada, Australia, as well as from individuals, families, churches, and other groups from developed countries. The majority of WVU's programs are funded through sponsorship from these donors who are linked to specific children or community projects. WVU also receives substantial amount of gifts in-kind from its donors. These included textbooks, reading materials, school supplies, clothing, medicine, hygiene kits, and medical supplies. The organization also receives some funding from international aid agencies, such as USAID and World Food Programme.

In 2008 WVU addressed eight CPAS. These included:

1. Socio-economic security

2. Food security and nutrition

3. Care and support

4. Mitigation of impact of conflict

5. Education

6. Health

7. Child protection, and

8. Strengthening capacity and resource mobilization.

\section{Financial cost of services for vulnerable children at WVU}

The cost of providing the services described above were estimated using data from WVU's financial records for the financial year 2008 (October 2007 to September 2008). It is important to note that the estimated total cost from the analysis is different from the total expenditures shown in WVU's annual financial report.

First, for the cost analysis, the financial expenses from reports compiled at the ADP level were aggregated. After aggregating all reported costs and capital costs, the estimated total cost of services in 2008 is about $\$ 38$ million. However, the total expenditure shown in the WVU's annual financial report is about $\$ 60$ million, which includes project expenditure of about \$36.4 million, gifts in-kind expenditure of \$21.3 million, and strategic management costs of $\$ 2.3$ million.

The difference between the estimated total cost from the cost analysis and the total expenditure in WVU's annual financial report is about \$22 million. Most of this discrepancy is caused by the exclusion from the analysis of gifts in-kind worth $\$ 21.3$ million that WVU received and distributed in 2008. Gifts in-kind were not included in the current analyses because the organization did not incur any financial costs for these items. The remaining difference is due to the fact that the cost analysis includes only the portion of 2008- 
expenditures on assets that can be assigned as usage cost for 2008. As mentioned earlier (see methodology section), the usage cost consists of the annual depreciation cost and the foregone interest earnings. For example, if WVU purchased a vehicle for \$10,000 in 2008, only the annual depreciation cost for the vehicle was included and the foregone interest earnings for 2008 in purchasing the vehicle.

Second, because WVU has a community development approach to service delivery and does not target individual beneficiaries, the organization does not distinguish between direct and indirect beneficiaries. ${ }^{5}$ As a result, the data on number of beneficiaries provided by WVU staff often included both direct and indirect beneficiaries. Estimating unit costs based on beneficiary numbers that include indirect beneficiaries would not be meaningful. Hence, for several interventions a unit cost estimate is not calculated.

Third, even when data on number of beneficiaries included only direct beneficiaries, it included both children and adults. In addition, WVU is unable to distinguish between vulnerable children and other children among their beneficiaries. As a result, a unit cost per person, not per vulnerable child is presented.

WVU spent approximately \$38 million in providing services for vulnerable children in 2008, with education taking the largest share of the total costs at almost \$20 million (52 percent), followed by health taking \$11 million (29 percent, Table 24). While "mitigation of the impact of conflict" only accounted for 5 percent of the total costs, given the size of the overall costs, this still amounted to over $\$ 2$ million in one year.

Table 24 Total costs of services for vulnerable children at World Vision Uganda

\begin{tabular}{lrrr}
\hline Core program area & \multicolumn{1}{c}{$\begin{array}{c}\text { Total cost } \\
\text { (USh) }\end{array}$} & $\begin{array}{c}\text { Total cost } \\
\text { (US \$) }\end{array}$ & $\begin{array}{c}\text { Share of total } \\
\text { cost (\%) }\end{array}$ \\
\hline Socio-economic security & $1,309,542,545$ & 761,185 & 2 \\
Food security and nutrition & $2,433,535,482$ & $1,414,517$ & 4 \\
Care and support & $1,609,092,552$ & 935,301 & 2 \\
Mitigation of impact of conflict & $3,464,872,505$ & $2,013,992$ & 5 \\
Education & $34,139,995,309$ & $19,844,220$ & 52 \\
Health & $18,987,544,909$ & $11,036,704$ & 29 \\
Child protection & $316,756,578$ & 184,118 & 0.5 \\
Strengthening capacity and resource mobilization & $3,040,438,086$ & $1,767,286$ & 5 \\
Grand total & $65,301,777,965$ & $37,957,323$ & 100 \\
\hline
\end{tabular}

Note: $\quad 1$ US\$ $=1,720.4$ USh (Bank of Uganda 2009)

WVU uses several approaches to providing educational support including providing school fees, uniforms, and school supplies through a sponsorship program; working with communities to construct classrooms, laboratories, offices, latrines and housing facilities for teachers; and an in-school feeding program.

\footnotetext{
${ }^{5}$ For example, a child receiving a uniform and other school supplies from an NGO is a direct beneficiary while a child living with a parent receiving agricultural training would be an indirect beneficiary.
} 
The health program operates through coalitions with community groups and health care providers to provide care for vulnerable children and families affected by HIV/AIDS. WVU trained faith leaders to respond to the HIV/AIDS pandemic and partnered with faith-based organizations to provide life-skills training to children to prevent HIV/AIDS. The organization provided care, support, and treatment services to individuals living with HIV/AIDS and extended immunization service, and support for reducing malaria prevalence among pregnant mothers and children under five. This cost also included water and sanitation services in which WVU protected water sources, built shallow wells and pit latrines. The NGO also trained teachers, students, and community members in basic hygiene and sanitation.

Table 25 Costs of services for vulnerable children at World Vision Uganda

\begin{tabular}{|c|c|c|c|}
\hline Core program area & $\begin{array}{l}\text { Total cost } \\
\text { (US \$) }\end{array}$ & $\begin{array}{c}\text { Number of } \\
\text { individual } \\
\text { beneficiaries }\end{array}$ & $\begin{array}{c}\text { Cost per } \\
\text { person } \\
\text { (US \$) }\end{array}$ \\
\hline \multicolumn{4}{|l|}{ Socio-economic security } \\
\hline Economic development (microfinance services) & $\$ 761,185$ & $\mathrm{n} / \mathrm{a}$ & $\mathrm{n} / \mathrm{a}$ \\
\hline \multicolumn{4}{|l|}{ Food security and nutrition } \\
\hline Agricultural services & $\$ 870,539$ & $\mathrm{n} / \mathrm{a}$ & $\mathrm{n} / \mathrm{a}$ \\
\hline Emergency food support & $\$ 534,418$ & 419,868 & 1 \\
\hline Nutrition support & $\$ 9,560$ & 2,200 & 4 \\
\hline \multicolumn{4}{|l|}{ Care and support } \\
\hline Support for individuals with disabilities & $\$ 70,045$ & 1,110 & 63 \\
\hline Relief in mine affected areas & $\$ 865,256$ & 9,103 & 95 \\
\hline \multicolumn{4}{|l|}{ Mitigation of impact of conflict } \\
\hline Psychosocial support and support to children of war & $\$ 928,427$ & $\mathrm{n} / \mathrm{a}$ & $\mathrm{n} / \mathrm{a}$ \\
\hline Peace building and conflict management & $\$ 1,085,565$ & 4,500 & 241 \\
\hline \multicolumn{4}{|l|}{ Education } \\
\hline Education support and sponsorship management & $\$ 13,939,409$ & $\mathrm{n} / \mathrm{a}$ & $\mathrm{n} / \mathrm{a}$ \\
\hline Relief in education & $\$ 5,904,810$ & $\mathrm{n} / \mathrm{a}$ & $\mathrm{n} / \mathrm{a}$ \\
\hline \multicolumn{4}{|l|}{ Health } \\
\hline HIVIAIDS prevention and health services & $\$ 8,991,692$ & 114,207 & 79 \\
\hline Water and sanitation services & $\$ 2,045,012$ & $\mathrm{n} / \mathrm{a}$ & $\mathrm{n} / \mathrm{a}$ \\
\hline \multicolumn{4}{|l|}{ Child protection } \\
\hline Advocacy & $\$ 169,830$ & 1,200 & 142 \\
\hline Protection from child labor & $\$ 14,288$ & 6,000 & 2 \\
\hline \multicolumn{4}{|l|}{ Strengthening capacity and resource mobilization } \\
\hline Assessment and program design & $\$ 1,213,765$ & - & - \\
\hline Collaboration with local CSOs & $\$ 85,814$ & - & - \\
\hline Leadership development & $\$ 467,707$ & - & - \\
\hline
\end{tabular}

Note: $\mathrm{n} / \mathrm{a}=$ not available; “-” = not applicable.

\section{Costs of vulnerable children services by resource type}

The largest share of expenses went to cover personnel costs which accounted for 47 percent of the total costs, followed by materials and services as illustrated in Figure 9 which shows 
the total costs by resource type for all services delivered by WVU in 2008. Detailed distribution of costs by resource type for each set of services.

Figure 9 Share of total costs at World Vision Uganda by resource type

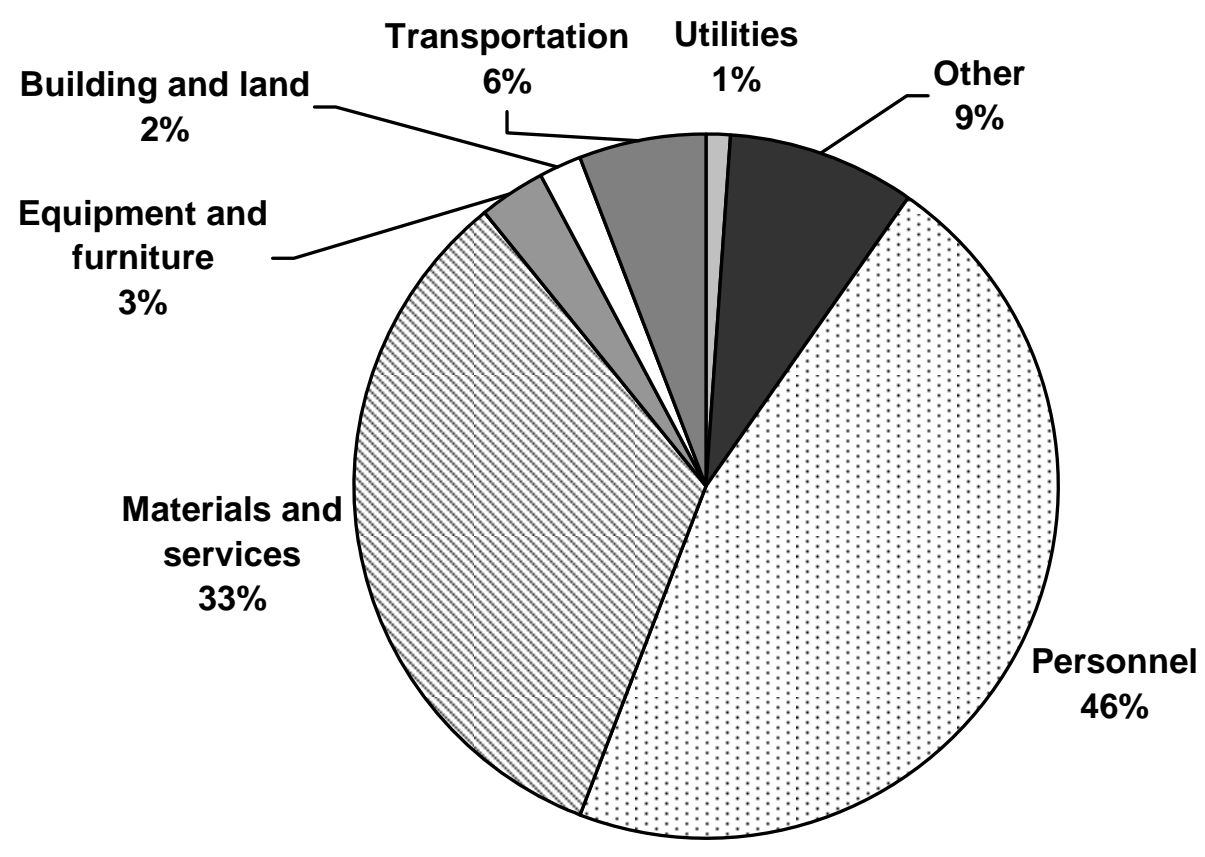




\section{Discussion}

This Situation Analysis brings together multiple data sources to explore the complex circumstances of children in Uganda who have been orphaned and rendered vulnerable through a variety of different factors.

When interpreting the results of this analysis, it is important to bear in mind some of the key limitations of the methodology as follows. By virtue of the fact that a household survey was employed, numerical data about children living on the streets and children living in institutions were not captured. Therefore, the situation analysis relied on qualitative interviews to get some insight into these two groups of vulnerable children. The vulnerability score used to estimate the number of vulnerable children is a tool still in its infancy and will require further statistical work and stakeholder validation before wider application. Further, since the vulnerability score included factors such as school attendance and orphanhood, it was not possible to analyze vulnerability by these factors. Child participation was through Child Forums which were conducted by school teachers, and the teacher-child relationship resulted in short responses by children without in-depth exploration of issues. In examining promising practices of service provision and cost of services to vulnerable children, data on outcomes of interventions was not available and as such the effectiveness of interventions was beyond the scope of this exercise.

However, despite acknowledging these methodological limitations, it remains important to recognize that this exercise-the first of its kind in Uganda-has broken pioneering new ground in furthering the in-depth understanding of the circumstances of vulnerable children. In this section, key findings are highlighted to clarify how the original aims and objectives of the exercise have been met. Specific recommendations for action based upon these findings are derived in the following section.

\section{Objective 1: Definition of Vulnerable Children}

Initial exploration revealed a need for an operational definition of vulnerable children specific to the Ugandan context, with which to analyze data from the household survey. The vulnerability score developed in this report, based upon the input of Ugandan experts, represents an initial effort to conduct a rapid analysis that combines multiple factors of children's vulnerability into a single vulnerability score. This score can be used to assess and identify degrees of children's vulnerability from household survey data; differentiating between children who are critically, moderately or generally vulnerable, and those not to be considered vulnerable at all. The vulnerability score contributes to the overall goal of this Situation Analysis by providing an easily accessible tool to prioritize the circumstances of the most vulnerable children and to facilitate planning a response by policy makers and program implementers. Factors included in the definition include orphanhood, child marriage, being affected by HIV or other diseases, living in an area under conflict, living in a child-headed household, and lacking in access to basic services such as schooling. A notable limitation of the vulnerability score is that some of the criteria used such as school attendance, engagement in sexual activity, and alcohol and drug use were age-dependant and as such could not be 
applied to young children. For this reason the scores cannot be compared across all age groups.

The team acknowledges that there are a variety of technical statistical approaches to scoring and index development (e.g., WHO's Quality of Life tool [WHO 2004], Depression Index [Beck et al. 1979]). There are also several existing efforts to categorize vulnerability, including a Vulnerability Index (Forsyth 1996) and PEPFAR's Child Status Index (Nyangara et al. 2008). The current effort to develop vulnerability scores is based on a motivation to derive a Uganda-specific approach suitable for rapid analysis of household survey data. Further development and exploration of this scoring methodology are beyond the scope of the current Situation Analysis, but next steps for action necessary before further use of the vulnerability score include refining indicators, assigning weights and rankings to score components, research linking vulnerability factors to outcomes, participatory review by stakeholders (including children themselves), and statistical analysis (such as principal components analysis, scale development and validation techniques).

\section{Objective 2: Estimate of the Magnitude and Characteristics of Vulnerable Children}

According to the analysis of survey data presented in this Situation Analysis, vulnerability is widespread among children in Uganda. According to the Uganda-specific definition and indicators developed by this exercise, nationally, up to 96 percent of children have some level of vulnerability. Within this broad grouping of vulnerable children, degrees of vulnerability can be distinguished for the prioritization of support services: nationally, 51 percent of children in Uganda are considered moderately or critically vulnerable, equivalent to a national total of approximately 8 million vulnerable children in Uganda.

The use of the Uganda-specific vulnerability score permits patterns of regional vulnerability to be described: vulnerability tends to be highest in the conflict-affected Northern region, and lower in the more affluent Central region. Vulnerability tends to be higher in rural areas. The percentage of children defined as critically vulnerable remains fairly constant throughout the regions, at approximately 8-9 percent.

The distribution of vulnerable children in Uganda is different from the distribution of children who have been orphaned. While children in the Central region have the lowest vulnerability scores, more of them are orphaned compared to the Northern and Eastern regions. These trends reflect regional differences and could be explained in terms of higher HIV prevalence in the Central region compared to the Eastern region, resulting in more orphaned children. Further, the Northern region, which has the highest vulnerability scores, is in the lower wealth quintiles and has had a long period of conflict, which has increased poverty and lack of basic services. These issues should be considered when determining whether to target children with higher vulnerability with services as opposed to children who are orphaned. The data on targeting of external support to vulnerable children or their households suggests that while the provision of external support targets orphaned children to a reasonable extent, it is not adequately targeting other vulnerable children. Orphaned children constitute about 14 percent of the general population of children but in six services 
(start-up capital, agricultural inputs, modern farming, school support, school meals and medical care) they comprised more than 14 percent of recipients of the service (Figure 5). In contrast, moderately and critically vulnerable who constitute about 51 percent of the general population of children comprised more than 51 percent of recipients in only two services (school support and school meals) (Figure 6).

Nevertheless, the widespread levels of children's vulnerability remain a cause of great concern, raising questions about the ability of existing services to address such high levels of need, and the efficiency of setting targeting criteria to guide service delivery. Stakeholders concur that they are overwhelmed by the task of providing services to such high levels of vulnerable children in increasingly dire circumstances.

While most vulnerable children do remain in the extended family, communities are extremely poor and are struggling with the impacts of HIV and AIDS. More and more families are turning to CSOs to support their children. In addition, caregivers in families, community members and leaders are also reported to be misusing and diverting to personal use the resources provided for vulnerable children by these CSOs. Thus a sad reality is that a culture of dependency and exploitation is emerging from the extended family and community which are meant to be the safety net for vulnerable children. The dependency is sometimes reflected in expressions that vulnerable children are children of a particular CSO that is supporting them and that the family and community do not do anything to support those children. Throughout interviews the community involvement that was cited was in terms of community members facilitating CSO work with very little or no comment on community members using their own resources to provide support to vulnerable children. If this trend continues, it implies that when donor aid comes to an end the children will have no support.

\section{Objective 3: Approaches Currently Used to Address the Needs of Vulnerable Children}

\section{Government response}

It is the police family units and probation officers who are the frontline actors to assist street children. These structures were created as part of the government response to vulnerable children (NSPPI) and are some of the few components that are functioning well. In many parts of the country these family units are respected by the communities they serve. They are involved with both prevention of the problem through community sensitization regarding the rights of children, and with trying to resolve instances of the abuse of child rights. However, in much of the country these units are hampered by their lack of resources, both financial and human, to be able to conduct their activities properly.

Individual police are digging into their own pockets to support vulnerable children and in some cases, street children are being taken off the street but are sleeping in the police stations due to the lack of any transitional homes. There is an urgent need to build more transitional homes in which children can receive shelter, security, counseling, love, care and basic needs as their families are traced or alternative foster homes are found. 


\section{Civil society response}

Although the MGLSD reports that about 4,000 organizations are said to be providing support to vulnerable children, respondents from the 124 organizations assessed felt that their organizations were leaving out many who are in need of their assistance. This is in spite of the fact that most organizations are trying to reach as many children as possible with a few services rather than providing full comprehensive care. The only organizations who approach comprehensive care provision are the children's residential "Homes" which reach very few children each, usually at a high cost per child. The assessment of free external support received by children in the survey illustrated how few are actually being reached. The best case scenario was medical support reaching only 15 percent of the children in the households surveyed.

\section{Education best addressed CPA}

Education is only one of the ten core program areas which the government of Uganda stipulates as services that vulnerable children should be provided with in the NSPPI. In fact, according to most respondents in the FGDs, interviews and organizational assessments, education was the best addressed of the CPAs with 70 percent of organizations reporting they deal with it in some way. Most organizations addressed education through school fees but others also support supplies and uniforms. Some respondents mentioned inadequate funding and delays in receiving school and UPE budgets from the government which drove teachers to find resources from families, many of whom could not afford them (and consequently the children dropped out of school). Indeed, the household survey showed that orphaned children had a higher rate of school drop-out than non-orphaned children. This issue should be explored further to identify the cause and efforts made to improve the situation.

One approach to assisting vulnerable children which has been implemented by World Vision and UWESO is to use the schools to provide free meals. UWESO has assisted schools to develop gardens to grow vegetables to be able to do this. This not only ensures one good meal each day for the children but also encourages them to attend and the parents/guardians to send children to school. A more extensive model is the 'Schools as Centers of Care and Support' program funded by the Swiss Agency for Cooperation and Development, the Embassy of the Kingdom of the Netherlands, the Rockefeller Brothers Foundation, UNESCO and UNICEF and coordinated by the Media in Education Trust, Africa (MiETA). This program is proving to be successful across several countries in southern Africa. In this model, School Support Teams comprising teachers, volunteer community members and students follow up on suspected vulnerable children to investigate the home situation, identify needs, provide support directly or refer the family for appropriate support. The schools have gardens which are worked on by community members, teachers and students, the produce of which is used to enrich the school meals and those for vulnerable households. The program does not only provide nutritional support but also will provide psychosocial support in school, link children to the police for suspected abuse cases, invite the local police to give talks on Child Rights and abuse and refer children for medical care. Vulnerable households are also linked to organizations providing socioeconomic support. The program is an integrated, multisectoral approach involving several government ministries, donors, CSOs and 
communities with the aim of “improving children's lives”. Applying this model in Uganda may well be a good way forward.

\section{Least addressed CPAs}

The least-addressed CPAs were legal support, mitigation of the impact of conflict, and shelter, based on the low numbers of organizations addressing these needs and comments from respondents. One organization, FIDA-Uganda, has a very comprehensive legal support program which needs to be replicated or expanded to reach more of the vulnerable children. The program comprises legal representation in court, training paralegals to assist with settling conflicts in communities precluding the need for travel to court and costly legal fees, community and stakeholder education on civil law and production of educational materials to assist with this work.

Socioeconomic support was also one of the least addressed CPAs but is critical to reducing household poverty and the vulnerability of children. A recent study funded by the CORE Initiative (2008) on the status of interventions for socioeconomic strengthening showed that there are four main categories: skills training and vocational training; Agricultural income generating projects; Animal Husbandry Projects; and Village Savings and Loans Associations (VSLA). The study showed that these projects were usually more helpful for less poor families but that for the very poor families the projects would fail. The study recommended that for the very poor there is no viable alternative but direct cash transfer as an emergency rescue measure until the family is able to help itself. Nonetheless, during the current situation analysis stakeholders suggested that households with vulnerable children be empowered through income generating projects.

\section{Coordination and networking}

One of the major areas that is deficient in the effort to help vulnerable children is coordination and networking. Although the government has included a mechanism in the NSPPI and established a committee at national level to coordinate the response (the National Implementation Unit) it was the opinion of respondents that this has been fairly ineffective on the ground. According to respondents, the coordination structures have been put in place and staff has been trained in much of the country, but salaries and resources to conduct their activities are not being received. In the North, good coordination of services for vulnerable children was credited to UNICEF and other UN organizations in response to the war. Elsewhere in the country, any coordination at district, county and sub-county level was reported to be due to the efforts of groups of organizations networking with each other as opposed to being coordinated by the government.

\section{Surveillance, monitoring, and evaluation}

Continuous monitoring of the situation of vulnerable children is of paramount importance. To this end, process and output indicators need to be incorporated into regular household 
surveys. External support needs to be monitored at a national, local and organizational level to assess the coverage and effectiveness of support programs. Efforts have been undertaken by the MGLSD to develop a number of tools including the quality standards and the Management Information System (MIS) tool which has been field tested and is about to be implemented. A key issue which needs to be addressed is the lack of resources and sufficient staffing for the offices of the probation and social welfare officers to implement the surveillance, monitoring and evaluation of service delivery to vulnerable children.

\section{Objective 4: Successful Strategies and Challenges, Focusing on the USG funded partners}

USG partners have applied a number of successful strategies in providing support for vulnerable children. For example to address the fact that no single partner is able to meet all the needs of a vulnerable child a number of partners managed to achieve comprehensiveness of service delivery through partnerships and linkages. To avoid stigmatization of vulnerable children and because there is wide spread poverty some partners adopted the strategy of targeting entire communities to receive services as opposed to singling out a few vulnerable children or their households. Further, in an attempt to curb on misuse of resources some partners work with community members to monitor the use of resources donated for vulnerable children by the extended family. Sharing of accurate M\&E data at a local level enabled collaboration and coordination to increase coverage and avoid overlaps.

However, there are a number of challenges, and these are not restricted to the USG partners. Regarding M\&E this situation analysis has shown that the best that can be achieved at the moment is output data as opposed to outcome data. A major challenge hindering all organizations and government structures is the inadequacy of funding reaching them and the children themselves. This was compounded by a very common complaint that funds are going missing before reaching the children they were originally designated for. This was reported to permeate from the top levels of the government officials through international NGO officials, local officials and down to the immediate caregiver of the vulnerable children. Many are reported to be diverting funds away for their own use or directing support to their own family and friends who are not vulnerable.

\section{Objective 5: Determine the Costs of Delivering Support Services to Vulnerable Children}

Based on the costs per child for school support (UWESO \$65/child), the number of primary school age children in Uganda (7.3 million, UBOS), the proportion who are critically vulnerable (9.4 percent) and the proportion of these who are currently out of school (30 percent) the amount needed to support all of the critically vulnerable, primary school children to return to school for one year would be approximately \$13million. For 12 to 14 year-old children this is likely to be $\$ 42.7$ million given that UWESO report spending \$485 per child for secondary school support. Providing vocational training was even more expensive at $\$ 1,300$ per child, which would cost a total of $\$ 127$ million to support all of the 15 to 17 yearold, critically vulnerable children who are currently out of school. 
The most expensive intervention per child was found to be institutionalized care and the least expensive was food security and nutritional support. This corresponds to findings of the World Bank (Subbarao 2004) and Desmond and Gow (2001) who were able to conduct a cost-effectiveness analysis of programs, albeit with limitations. 


\section{Recommendations}

This section highlights evidence-based recommendations for action, based upon the findings of this Situation Analysis. Recommendations are presented according to their intended audience, starting off with recommendations for actions to be taken in the strategy and policy arena, and moving through the domain of program managers and implementers.

\section{Strategy and Policy Makers}

- Build district-level Government structures-The government of Uganda should strengthen its structures at the district level by filling vacancies at the field level as well as providing transport to its staffs in order to provide leadership to the existing partnerships to enable monitoring and coordination of VC services.

- Increase funding and collaboration for child protection-To enhance legal support and child protection services, the USG and other donors should consider funding the Police Family Support Unit, especially to assist with transport and salaries and the expansion of FIDA programs. The GOU should increase child protection efforts especially through child protection committees comprising the police, NGOs, probation officers and legal protection agencies.

- Review universal education systems - The UPE and USE systems need reviewing and funding mechanisms must be improved to ensure that moderately and critically vulnerable children do not continue to drop out and/or be excluded.

- Strengthen monitoring and evaluation-Process and output indicators need to be incorporated into regular household surveys to enable the continuous monitoring of the situation of vulnerable children and the effectiveness of support programs. The current study can be used to initiate the discussion of these indicators.

- Consider the role of institutional care and transition homes-Although institutional care is considered resource-intensive and controversial for many reasons, perhaps the time has come to reconsider its role in Uganda. There may still be a role for establishing some form of transition homes to shelter and protect children who are taken off the streets or who have escaped from abusive homes, following the model of Tigers Club/RETRACK.

- Address corruption at all levels-Strategies to address the misuse of funds and widespread corruption include the implementation of MoGLSD resource tracking tools to determine what resources allocated for vulnerable children actually reach the intended beneficiaries. It is recommended that this tool be operationalized together with the MIS system.

\section{Program Managers and Implementers}

- Review targeting criteria for interventions -The selection criteria of all service providers in the country urgently need reviewing since the majority of services are not reaching the most critically vulnerable children.

- Conduct household assessments before delivering IGAs - It is recommended that before offering IGAs to families, implementing partners should conduct household assessments 
regarding the financial and technical abilities of the households. This is important to determine if an emergency cash transfer is a better option and if not, to determine the type of technical support needed.

- Strengthen networking and coordination-Since no single organization is able to provide all of the CPAs to each beneficiary, the best way to provide services is through strongly networked and coordinated organizations, each providing a few of the CPAs so that each individual vulnerable child receives a comprehensive package. Referral directories that are regularly updated by all the stakeholders are critical. Referral reporting slips should also be established to help monitor the referrals to ensure the vulnerable children receive the services they need.

- Increase community involvement in intervention design and delivery-Implementing partners should increase community involvement in the identification of beneficiaries, service planning, delivery and monitoring. Taking into account community perceptions of vulnerability is vital for identifying the actual needs of vulnerable children/populations and their households and suggesting possible interventions to address identified gaps. Greater involvement of communities and vulnerable children will also increase the level of transparency and reduce the opportunities for abuse of resources directed towards vulnerable children.

- Where vulnerability and poverty are widespread, consider the role of block grants and community coverage of interventions rather than targeted interventions-Where there is abject poverty it is difficult to ensure that the identified vulnerable children benefit from the support provided without the resources being shared out by the rest of the children in the extended family. Also if the infrastructure such as schools and health facilities is poor it is difficult to reach the identified vulnerable children with services unless these structures are improved for the entire community.

- Address older vulnerable children-With the current age cut-off used by donors and implementing organizations many children are being dropped from programs once they reach the age of 18 years old. It is likely that large numbers of children and youth missed out on education entirely due to the war and insecurity in the north and this leaves them more vulnerable. It is recommended that new programs are initiated that target the 15 to 24 year olds who have never attended school to give them some basic education as well as vocational skills.

\section{Community-level Organizations}

- Empower existing village level structures-GOU should empower existing village level structures such as village health teams to participate in the monitoring of resources provided to households for the care of vulnerable children and in identifying gaps to be addressed. GOU should strengthen and entrench the local structures and volunteerism in service delivery to vulnerable children by developing policy guides.

- Build capacity of family members to care for and protect vulnerable childrenImplementing partners should enhance training of household members in care and support. While it is obvious that the best caregivers for vulnerable children are in the household there is no evidence that substantial investment has been made in training of household heads or designated caregivers in psychosocial care of vulnerable children. In 
the organizational assessments a number of organizations reported providing training in IGAs (World Vision) and on child rights and avoidance of abuse (Caritas). However, little or no training was reported on the topic of parenting skills. This is a worthwhile investment as it will help to address not only the immediate psychosocial needs of vulnerable children, but will also help to improve the attitudes of household heads and caregivers toward child rights, avoidance of abuse and enabling vulnerable children to benefit from the support the household receives for vulnerable children.

- Expand support networks for community-run programs-The most sustainable and cost effective programs are often those run by community groups and targeted at economic empowerment of households with vulnerable children. This calls for the expansion of umbrella networks of well-coordinated, community-based organizations implementing interventions to support the whole household as well as vulnerable children. The focus will need to be placed on building the capacity of a large number of CBOs throughout the country.

- Address the emerging culture of dependency-There is need to shift from large NGOs and donors providing direct handout services and move towards facilitating smaller community based organizations (CBO) to support their own vulnerable children using appropriate means. While direct service delivery is easier to manage and account for it may have high staff costs and it ceases once the funding for the NGO stops. Facilitation of local CBOs may not show tangible results in a short time but it will help the communities to identify and use their own resources to support their children.

\section{Researchers}

- Provide more detailed mapping of OVC-The current study grouped the data by the four major geographical zones of the country but further analysis of future datasets by district would allow for more detailed mapping of vulnerable children. Further analyses are also recommended to explore correlations such as geographic location and school attendance.

- Measure outcomes over time-Further studies are needed to evaluate the impacts associated with OVC programs over time and to assess program effectiveness.

- Develop vulnerability scores - The current study is only the start of the development of this vulnerability score, which will require more investment to assess it statistically and validate it for local adaptation.

- Investigate street children further-More effort is needed to understand the factors causing children to go to the streets as well as the different types of street kids and how best they can be reached. While exploring the circumstances of and quantifying the number of street children was beyond the scope of this exercise, they remain among the most vulnerable of children. 


\section{References}

Beck, A. T. et al. 1979. Cognitive Therapy of Depression. New York: Guilford Press.

Bank of Uganda. 2009. Periodic Rates and Statistics: Monthly Exchange Rate Averages. Bank of Uganda. Downloaded on 24 July 2009 from

http://www.bou.or.ug/bouwebsite/opencms/bou/rates_statistics/statistics/monthly_exchange_ rates.html

Desmond, C., and J. Gow. 2001. "The cost-effectiveness of 6 models of care for orphans and other vulnerable children.” Durban, South Africa: Health Economics and HIV/AIDS Research (HEARD), University of Natal and UNICEF.

Dunn, A. et al. 1992. The Social Consequences of HIV/AIDS in Uganda. London: Save the Children.

Family Health International. 2005. Conducting a Participatory Situation Analysis of Orphans and Vulnerable Children Affected by HIV/AIDS: Guidelines and Tools. Arlington, VA: Family Health International.

Forsyth, Brian W. C. et al. 1996. "The child vulnerability scale: An instrument to measure parental perceptions of child vulnerability," Yale University School of Medicine Journal of Pediatric Psychology 21(1): 89-101.

Hunter, S. S. 1990. "Orphans as a window on the AIDS epidemic in Sub-Saharan Africa: initial results and implications of a study in Uganda,” Social Science \& Medicine 31(6): 681690.

Hunter, S. S. and J. Williamson. 2000. Children on the Brink Executive Summary: Updated Estimates \& Recommendations for Intervention. Washington, DC: USAID. The Synergy Project.

Makerere Institute of Psychology. 2008. Assessment of Psychosocial Support Programs for Orphans and Other Vulnerable Children. Kampala, Uganda: Makerere Institute of Psychology.

Makerere Institute of Social Research. 2008. An Assessment of Socio-Economic Strengthening Interventions for Orphans and Other Vulnerable Children in Uganda. Kampala, Uganda: Makerere Institute of Social Research.

Ministry of Gender, Labour and Social Development (MGLSD). 2009a. A Tool Kit for Assessing and Improving Quality of Interventions for Orphans and Other Vulnerable Children (OVC). Kampala, Uganda: MGLSD.

- 2009b. Guidelines for Training of Trainers Working with Orphans and Other Vulnerable Children. Kampala, Uganda: MGLSD. 

MGLSD.

2009c. Technical Services Organizations Capacity Assessment. Kampala, Uganda:

- 2009d. Supporting Orphans and Other Vulnerable Children through Communication and Basic Counseling: A Reference Guide for Service Providers. Kampala, Uganda: MGLSD.

- 2009e. Support Supervision Guide for Orphans and Other Vulnerable Children (OVC) Service Delivery. Kampala, Uganda: MGLSD.

. 2009f. National Orphans and Other Vulnerable Children Program Coordination Programs. Kampala, Uganda: MGLSD.

_ 2009g. The OVC-MIS: A Brief Overview. Kampala, Uganda: MGLSD.

- 2009h. Understanding and Applying Quality Standards for OVCs: Facilitators Guide. Kampala, Uganda: MGLSD.

- 2008a. Community Mapping to Strengthen Programming for Orphans and Other Vulnerable Children. Kampala, Uganda: MGLSD.

- 2008b. The Situation of Orphans and Other Vulnerable Children in Uganda A Report on: Meta-Analysis of National Data on Orphans and Other Vulnerable Children (OVC) and Primary Analysis of District Data on OVC Service Delivery and Gaps. Kampala, Uganda: MGLSD.

_. 2008c. A Toolkit for Community Service Providers. Kampala, Uganda: MGLSD.

- 2007. Applying National Quality Standards for the Protection, Care and Support of Orphans and Other Vulnerable Children in Uganda. Kampala, Uganda: MGLSD.

- 2006a. National Policy and Strategy for Orphans and Other Vulnerable Children. Popular Version. Kampala, Uganda: MGLSD.

- 2006b. Guidelines for Disseminating the National Policy and Strategy for Orphans and Other Vulnerable Children. Kampala, Uganda: MGLSD.

- June 2005. Integrated Care for Orphans and Other Vulnerable Children: A Training Manual for Community Service Providers. Kampala, Uganda: MGLSD.

MGLSD.

. 2004a. National Orphans and Other Vulnerable Children Policy. Kampala, Uganda:

- 2004b. National Strategic Programme Plan of Interventions for Orphans and Other Vulnerable Children, Kampala, Uganda: MGLSD. 
2002. Situation Analysis of Orphans in Uganda Orphans and their Households:

Caring for their Future -Today. Kampala, Uganda: MGLSD.

Ministry of Sport, Youth, and Child Development [Zambia]. 2004. Orphans and Vulnerable Children in Zambia: 2004 Situation Analysis. Lusaka, Zambia: Ministry of Sport, Youth, and Child Development.

Müller, O., and N. Abbas. 1990. "The impact of AIDS mortality on children's education in Kampala (Uganda),” AIDS Care 2(1): 77-80.

Nyangara, F. et al. 2008. Child Status Index Made Easy. Chapel Hill, North Carolina: MEASURE Evaluation.

Schenk, K. and J. Williamson. 2005. Ethical Approaches to Gathering Information from Children and Adolescents in International Settings: Guidelines and Resources. Washington, DC: Population Council.

Subbarao, K. and D. Coury. 2004. "Reaching out to Africa's orphans: a framework for public action.” Washington, DC: World Bank.

Uganda Bureau of Statistics (UBOS) and Marco International, Inc. 2007. Uganda Demographic and Health Survey 2006. Calverton, Maryland: UBOS and Marco International, Inc.

Urassa, M. et al. 1997. "Orphanhood, child fostering and the AIDS epidemic in rural Tanzania." Health Transition Review 7(Supplement 2).

World Health Organization. 2004. The World Health Organization Quality of Life (WHOQOL)-BREF. .1993. WHOQoL Study Protocol. WHO (MNH7PSF/93.9). 


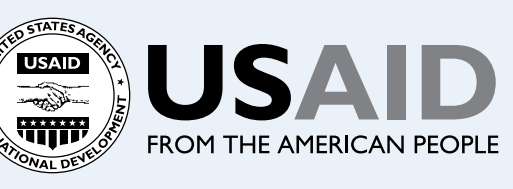

